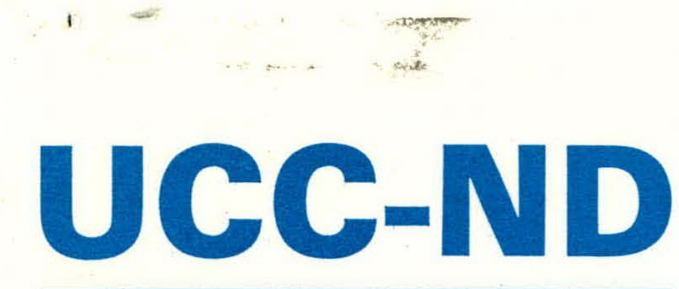

NUCLEAR DIVISION
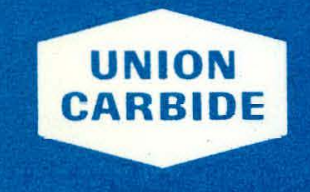

NUREG/CR-1499

ORNL/NUREG/CSD/TM-14

\section{Two Finite Element Techniques for Computing Mode I Stress Intensity Factors in Two- or Three-Dimensional Problems}

\author{
S. K. Iskander
}

Prepared for the U.S. Nuclear Regulatory Commission Office of Nuclear Regulatory Research

Under Interagency Agreements DOE 40-551-75 and 40-552-75
OPERATED BY

UNION CARBIDE CORPORATION FOR THE UNITED STATES DEPARTMENT OF ENERGY 


\section{DISCLAIMER}

This report was prepared as an account of work sponsored by an agency of the United States Government. Neither the United States Government nor any agency Thereof, nor any of their employees, makes any warranty, express or implied, or assumes any legal liability or responsibility for the accuracy, completeness, or usefulness of any information, apparatus, product, or process disclosed, or represents that its use would not infringe privately owned rights. Reference herein to any specific commercial product, process, or service by trade name, trademark, manufacturer, or otherwise does not necessarily constitute or imply its endorsement, recommendation, or favoring by the United States Government or any agency thereof. The views and opinions of authors expressed herein do not necessarily state or reflect those of the United States Government or any agency thereof. 


\section{DISCLAIMER}

Portions of this document may be illegible in electronic image products. Images are produced from the best available original document. 


\section{The following pages are an exact representation of what is in the original document folder.}


Printed in the United States of America. Available from

National Technical Information Service

U.S. Department of Commerce

5285 Port Royal Road, Springfield, Virginia 22161

\section{Available from \\ GPO Sales Program}

Division of Technical Information and Document Control

U.S. Nuclear Regulatory Commission

Washington, D.C. 20555

This report was prepared as an account of work sponsored by an agency of the United States Government. Neither the United States Government nor any agency thereof, nor any of their employees, makes any warranty, express or implied, or assumes any legal liability or responsibility for the accuracy, completeness, or usefulness of any information, apparatus, product, or process disclosed, or represents that its use would not infringe privately owned rights. Reference herein to any specific commercial product, process, or service by trade name, trademark, manufacturer, or otherwise, does not necessarily constitute or imply its endorsement, recommendation, or favoring by the United States Government or any agency thereof. The views and opinions of authors expressed herein do not necessarily state or reflect those of the United States Government or any agency thereof. 
NUREG/CR-1499

ORNL/NUREG/CSD/TM-14

Distribution Category RF

TWO FINITE ELEMENT TECHNIQUES FOR COMPUTING MODE I

STRESS INTENSITY FACTORS IN TWO- OR

THREE-DIMENSIONAL PROBLEMS

S. K. Iskander

NUREG/CR--1499

TI85 015917

Sponsor: R. D. Cheverton

Manuscript Completed: November 1979

Date Published: February 1981

Prepared for the

Office of Nuclear Regulatory Research

U. S. Nuclear Regulatory Commission

Washington, DC 20555

Under Interagency Agreements DOE 40-551-75 and 40-552-75

NRC FIN No, B0119

COMPUTER SCIENCES DIVISION

at

Onk Ridgc Gnocnun Diffucion Plant

Post Office Box $P$

Oak Ridǵe, Tennessee 37830

Union Carbide Corporation, Nuclear Division operating the

Oak Ridge Gaseous Diffusion Plant - Oak Ridge National Laboratory

Dak Ridge Y-12 Plant . Paducah Gaseous Diffusion Plant

under Contract No. W-7405-eng-26

for the

Department of Energy 


\section{THIS PAGE \\ WAS INTENTIONALLY \\ LEFT BLANK}




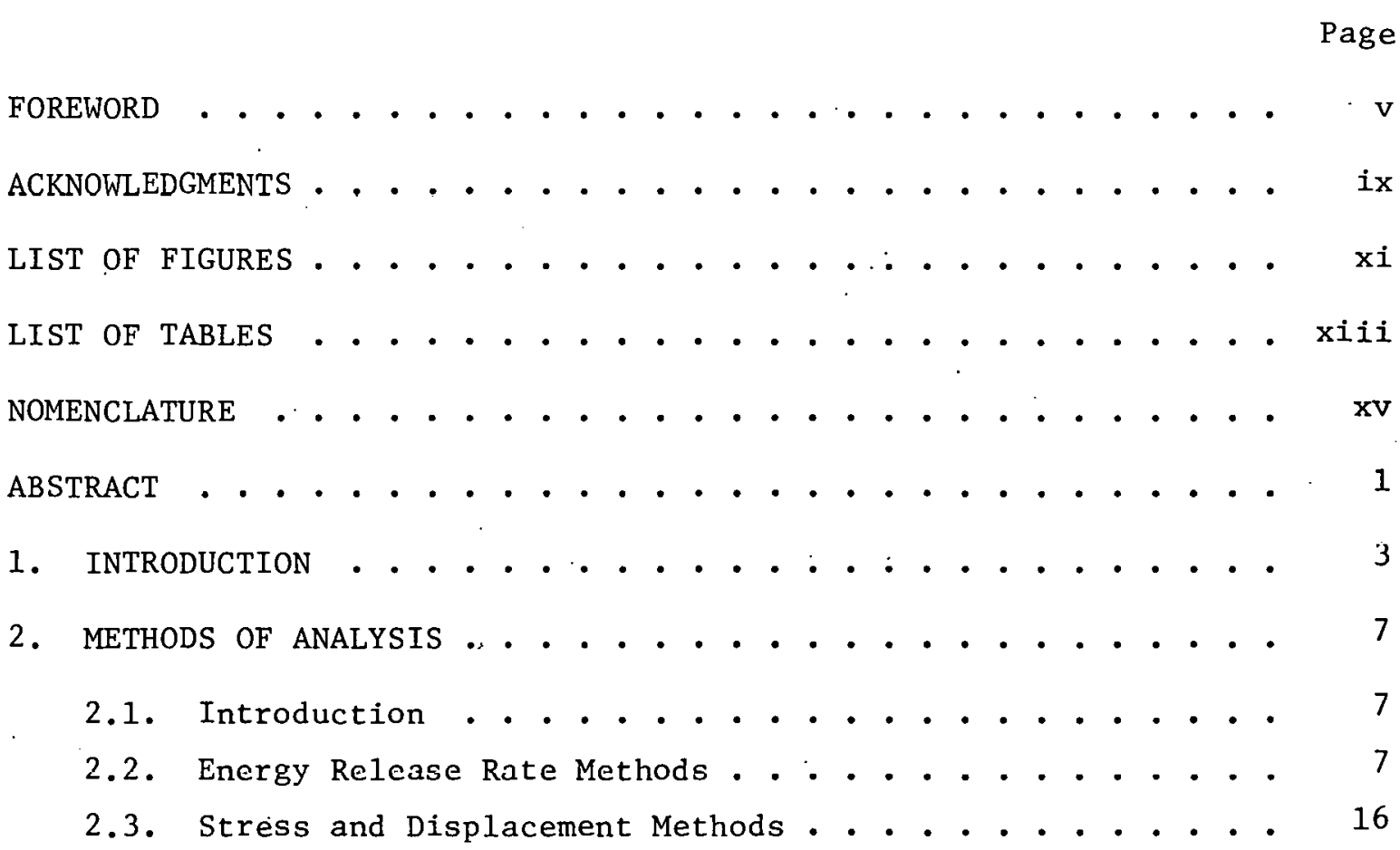

3. EXAMPLES OF ANALYSIS . . . . . . . . . . . . . 21

3.1. Introduction .................. 21

3.2. Two-Dimensional Examples . . . . . . . . . . 21

3.2.1. Finite Length Strip With a Central Crack . . . . 21

3.2.2. Long Axial Flaw in a Cylinder Under
Thermal Shock. . . . . . . . . . 23

3.3. Three-Dimensional Examples . . . . . . . . . 29

3.3.1. Plane Circular Crack Located Centrally

in a Cylindcr.............. $3 n$

3.3.2. Variation of $\mathrm{K}_{\mathrm{I}}$ in an Axially Cracked Cylinder Subjected to Therma1 Shock . . . . 37

3.3.3. Analysis of the V-8 Cylinder . . . . . . . 47

4. DISCUSSIONS AND CONCLUSIONS . . . . . . . . . . . . 59

REFERENCES .................................. 61 
TABLE OF CONTENTS (Contd.)

APPENDICES . . . . . . . . . . . . . . . . . ${ }^{6}{ }^{6}$

APPENDIX A. FINITE ELEMENT MESH GENERATION AND PROFILE REDUCTION ................ 67

APPENDIX B. DETAILS OF THE FE MODELING AND ANALYSIS . • • • 75

CONVERSION FACTORS FOR UNITS USED IN THIS REPORT . . . . . . . . 79 


\section{FOREWORD}

The work reported here was performed at Oak Ridge National Laboratory (ORNL) under sponsorship of the U.S. Nuclear Regulatory Commission's (NRC's) Heavy-Section Steel Technology Program, which is directed by ORNL. The program is conducted as part of the ORNL Pressure Vessel Technology Program, of which G. D. Whitman is manager. The manager for the NRC is Milton Vagins.

This report is designated Heavy-Section Steel Technology Program Technical Report 58. Prior reports in this series are listed below:

1. S. Yukawa, Evaluation of Periodic Proof Testing and Warm Prestressing Procedures for Nuclear Reactor Vessels, HSSTP-TR-1, General Electric Company, Schenectady, N.Y. (July 1, 1969).

2. L. W. Loechel, The Effect of Section Size on the Transition Temperature in Steel, MCR-69-189, Martin Marietta Corporation, Denver, Colo. (Nov. 20, 1969).

3. P. N. Randall, Gross Strain Measure of Fracture Toughness of Steels, HSSTP-TR-3, TRW Systems Group, Redondo Beach, Calif. (Nov. 1, 1969).

4. C. Visser, S. E. Gabrielse, and W. VanBuren, A Two-Dimensional Elastic-Plastic Analysis of Fracture Test Specimens, WCAP-7368, Westinghouse Electric Corporation, PWR Systems Division, Pittsburgh, Pa. (October 1969).

5. T. R. Mager, F. O. Thomas, and W. S. Hazelton, Evaluation by Linear Elastic Fracture Mechanics of Radiation Damage to Pressure Vessel Steels, WCAP-7328 (Rev.), Westinghouse Electric Corporation, PWR Systems Division, Pittsburgh, Pa. (October 1969).

6. W. O. Shabbits, W. H. Pryle, and E. T. Wessel, Heavy Section Fracture Toughness Properties of A533 Grade B Class 1 Steel Plate and Submerged Arc Weldment, WCAP-7414, Westinghouse Electric Corporation, PW.R Systems Division, Pittsburgh, Pa. (December 1969).

7. F. J. Loss, Dynamic Tear Test Investigations of the Fracture Toughness of Thick-Section Steel, NRL-7056, U.S. Naval Rescarch Laboratory, Washington, D.C. (May 14, 1970).

8. P. B. Crosley and E. J. Ripling, Crack Arrest Fracture Toughness of A533 Grade B Class 1 Pressure Vessel Steel, HSSTP-TR-8, Materials Research Laboratory, Inc., Glenwood, Ill. (March 1970).

9. T. R. Mager, Post-Irradiation Testing of $2 T$ Compact Tension Specimens, WCAP-7561, Westinghouse Electric Corporation, PWR Systems Division, Pittsburgh, Pa. (August 1970).

10. T. R. Mager, Fracture Toughness Characterization Study of A533, Grade B, Class I Steel, WCAP-7578, Westinghouse F.lectric Corporation, PWK Systems Division, Pitusburgh, Pd. (Octoher 1970).

11. T. R. Mager, Notch Preparation in Compact Tension Specimens, WCAP-7579, Westinghouse Electric Corporation, PW.R Systems Division, Pittsburgh, Pa. (November 1970).

12. N. Levy and P. V. Marcal, Three-Dimensional Elasiic-Plastic Stress and Strain Analysis for Fracture Mechanics, Phase I: Simple Flawed Specimens, HSSTP-TR-12, Brown University, Providence, R.I. (December 1970).

13. W. O. Shabbits, Dynamic Fracture Toughness Properties of Heavy Section A533 Grade B, Class 1 Steel Plate, WCAP-7623, Westinghouse Electric Corporation, PWR Systems Division, Pittsburgh, Pa. (December 1970).

14. P. N. Randall, Gross Strain Crack Tolerance of A533-B Steel, HSSTP-TR-14, TRW Systems Group, Redondo Beach, Calif. (May 1, 1971). 
15. H. T. Corten and R. H. Sailors, Relationship Between Material Fracture Toughness Using Fracture Mechanics and Transition Temperature Tests, T\&AM Report 346, University of Illinois, Urbana, Ill. (Aug. 1, 1971).

16. T. R. Mager and V. J. McLoughlin, The Effect of an Environment of High Temperature Primary Grade Nuclear Reactor Water on the Fatigue Crack Growth Characteristics of A533 Grade B Class 1 Plate and Weldment Material, WCAP-7776, Westinghouse Electric Corporation, PWR Systems Division, Pittsburgh, Pa. (October 1971).

17. N. Levy and P. V. Marcal, Three-Dimensional Elastic-Plastic Stress and Strain Analysis for Fracture Mechanics, Phase II: Improved Modeling, HSSTP-TR-17, Brown University, Providence, R.I. (November 1971).

18. S. C. Grigory, Six-inch-thick Flawed Tensile Tests, First Technical Summary Report, Longitudinal Specimens I through 7, HSSTP-TR-18, Southwest Research Institute, San Antonio, Tex. (June 1972).

19. P. N. Randall, Effects of Strain Gradients on the Gross Strain Crack Tolerance of A533-B Steel, HSSTP-TR-19, TRW Systems Group, Redondo Beach, Calif. (May 1, 1972).

20. S. C. Grigory, Tests of Six-inch-thick Flawed Tensile Specimens, Second Technical Summary Report, Transverse Specimens Numbers 8 through 10, Welded Specimens Numbers 11 through 13, HSSTP-TR-20, Southwest Research Institute, San Antonio, Tex. (June 1972).

21. L. A. James and J. A. Williams, Heavy-Section Steel Technology Program Technical Report No. 21, The Effect of Temperature and Neutron Irradiation upon the Fatigue-Crack Propagation Behavior of ASTM A533, Grade B, Class 1 Steel, HEDL-TME-72-132, Hanford Engineering. Development Laboratory, Richland, Wash. (September 1972).

22. S. C. Grigory, Tests of Six-inch-thick Flawed Tensile Specimens, Third Technical Summary Report, Longitudinal Specimens Numbers 14 through 16, Unflawed Specimen Number 17, HSSTP-TR-22, Southwest Research Institute, San Antonio, Tex. (October 1972).

23. S. C. Grigory, Tests of Six-inch-thick Flawed.Tensile Specimens, Fourth Technical Summary Report, Tests of One-inch-thick Flawed Tensile Specimens for Size Effect Evaluation, HSSTPTR-23, Southwest Research Institutc, San Antonio, Tex. (June 1973).

24. S. P. Ying and S. C. Grigory, Tests of Six-inch-thick Tensile Specimens, Fifth Technical Summary Report, Acoustic Emission Monitoring of One-inch and Six-inch-thick Tensile Specimens, HSSTP-TR-24, Southwest Research Institute, San Antonio, Tex. (November 1972).

25. R. W. Derby et al., Test of 6-inch-thick Pressure Vessels. Series 1: Intermediate Test Vessels V-I and V-2, ORNL-4895 (February 1974).

26. W. J. Stelzman and R. G. Berggren, Radiation Strengthening and Embrittlement in Heavy Section Plates and Welds, ORNL-487I (June 1973).

27. P. B. Crosley and E. J. Ripling, Crack Arrest in an Increasing K-Field, HSSTP-TR-27, Materials Research Laboratory, Glenwood, III. (January 1973).

28. P. V. Marcal, P. M. Stuart, and R. S. Bettes, Elastic-Plastic Behavior of a Longitudinal SemiElliptical Crack in a Thick Pressure Vessel, Brown University, Providence, R.I. (June 1973).

29. W. J. Stelzman, Characterization of HSST Plates 01, 02, and 03 (in preparation).

30. D. A. Canonico, Characterization of Heavy Section Weldments in Pressure Vessel Steels (in preparation).

31. J. A. Williams, The Irradiation and Temperature Dependence of Tensile and Fracture Properties of ASTM A533, Grade B, Class 1 Steel Plate and Weldment, HEDL-TME 73-75, Hanford Engineering Development Laboratory, Richland, Wash. (August 1973). 
32. J. M. Steichen and J. A. Williams, High Strain Rate Tensile Properties of Irradiated ASTM A533 Grade B Class 1 Pressure Vessel Steel, HEDL-TME 73-74, Hanford Engineering Development Laboratory, Richland, Wash. (July 1973).

33. P. C. Riccardella and J. L. Swedlow, A Combined Analytical-Experimental Fracture Study, WCAP-8224, Westinghouse Electric Corporation, PWR Systems Division, Pittsburgh, Pa. (October 1973).

34. R. J. Podlasek and R. J. Eiber, Final Report on Investigation of Mode III Crack Extension in Reactor Piping, Battelle Laboratories, Columbus, Ohio (May 1974).

35. T. R. Mager et al., Interim Report on the Effect of Low Frequencies on the Fatigue Crack Growth Characteristics of A533 Grade B Class 1 Plate in an Environment of High-Temperature Primary Grade Nuclear Reactor Water, WCAP-8256, Westinghouse Electric Corporation, Pittsburgh, Pa. (December 1973).

36. J. A. Williams, The Irradiated Fracture Toughness of ASTM A533, Grade B, Class I Steel Measured with a Four-inch-thick Compact Tension Specimen, HEDL-TME 75-10, Hanford Engineering Development Laboratory, Richland, Wash. (January 1975).

37. R. H. Bryan et al., Tests of 6-in.-thick Pressure Vessels, Series 2: Intermediate Test Vessels V-3, V-4, and V-6, ORNL-5059 (November 1975).

38. T. R. Mager, S. E. Yanichko, and L. R. Singer, Fracture Toughness Characterization of HSST Intermediate Pressure Vessel Material, WCAP-8456, Westinghouse Electric Corporation, Pittsburgh, Pa. (December 1.974).

39. J. G. Merkle, G. D. Whitman, and R. H. Bryan, An Evaluation of the HSST Program Intermediate Pressure Vessel Tests in Terms of Light-Water Reactor Pressure Vessel Safety, ORNL/TM-5090 (November 1975).

40. J. G. Merkle et al., Test of 6-in.-thick Pressure Vessels, Series 3: Intermediate Test Vessel V-7, ORNL/NUREG-1 (August 1976).

41. J. A. Davidson et al., The Irradiated Dynamic Fracture Toughness of ASTM A533, Grade B, Class 1 Steel Plate and Submerged-Arc Weldment, WCAP-8775, Westinghouse Electric Corporation, Pittsburgh, Pa. (October 1976).

42. R. D. Cheverton, Pressure Vessel Fracture. Studies Pertaining to a PWR LOCA-ECC Thermal Shock: Experiments TSE-1 and TSE-2, ORNL/NUREG/TM-31 (September 1976).

43. .J. G. Merkle et al., Test of 6-inch-thick Pressure Vessels. Series 4: Intermediate Test Vessels V-5 and V-9, ORNL/NUREG-7 (August 1977).

44. J. A. Williams, The Ductile Fracture Toughness of Heavy Section Steel Plate, Hanford Engineering Development Laboratory, Richland, Wash. (September 1979),

45. R. H. Bryan et al., Test of 6-in.-thick Pressure Vessels. Series 3: Intermediate Test Vessel V-7A under Sustained Loading, ORNL/NUREG-9 (February 1978).

46. R. D. Cheverton and S. E. Bolt, Pressure Vessel Fracture Studies Pertaining to a PWR LOCAECC Thermal Shock: Experiments TSE-3 and TSE-4, and UPdate of TSE-1 and TSE-2 Analysis, ORNL/NUREG-22 (December 1977).

47. D. A. Canonico, Significance of Reheat Cracks to the Integrity of Pressure Vessels for Light-Water Reactors, ORNL/NUREG-15 (July 1977).

48. G. C. Smith and P. P. Holz, Repair Weld Induced Residual Stresses in Thick-Walled Steel Pressure Vessels, NUREG/CR-0093 (ORNL/NUREG/TM-153) (June 1978).

49. P. P. Holz and S. W. Wismer, Half-Bead (Temper) Repair Welding for Heavy-Section Steel Technology Vessels, NUREG/CR-0113 (ORNL/NUREG/TM-177) (June 1978). 
50. G. C. Smith, P. P. Holz, and W. J. Stelzman, Crack Extension and Arrest Tests of Axially Flawed Steel Model Pressure Vessels. NUREG/CR-0126 (OR NI/NUREG/TM-196) (October 1978).

51. R. H. Bryan et al., Test of 6-in.-Thick Pressure Vessels, Series 3: Intermediate Test Vessel V-7B, NUREG/CR-0309 (ORNL/NUREG-38) (October 1978).

52. R. D. Cheverton, S. K. Iskander, and S. E. Bolt, Applicability of LEFM to the Analysis of PWR Vessels Under LOCA-ECC Thermal Shock Conditions, NUREG/CR-0107 (OR NL/NUREG-40) (October 1978).

53. R. H. Bryan et al., Test of 6-in.-Thick Pressure Vessels. Series 3: Intermediate Test Vessel V-8, NUREG/CR-0675 (ORNL/NUREG-58)(December 19\%9).

54. R. D. Cheverton, S. K. Iskander, Application of Static and Dynamic Crack Arrest Theory to TSE-4, NUREG/CR-0767 (ORNL/NUREG-57) (June 1979).

55. J. A. Williams, Tensile Properties of Irradiated and Unirradiated Welds of A533 Steel Plate and A508 Forgings, NUREG/CR-1 158 (ORNL/ Sub-79-50917/2), Hanford Engineering Development Laboratory, Richland, Wash. (July 1979).

56. K. W. Carlson and J. A. Williams, The Effect of Crack Length and Side Groove on the Ductile Fracture Toughness Properties of ASTM A533 Steel, NUREG/CR-1171 (ORNL/Sub-79/50917/3) Hanford Engineering Development Laboratory, Richland, Wash. (October 1979).

57. P. P. Holz, Flaw Preparations for HSST Program Vessel Fracture Mechanics Testing: Mechanical-Cyclic Pumping and Electron-Beam Weld-Hydrogen-Charge Crack Schemes, NURËG/CR-1274 (ORNL/NUREG/TM-369) (May 1980). 
The work described in this report was performed with funds provided by the Heavy-Section Steel Technology (HSST) program under sponsorship of the U. S. Nuclear Regulatory Commission (NRC). The author gratefully acknowledges the encouragement provided by many individuals: R. D. Cheverton, G. D. Whitman, R. H. Bryan, and J. G. Merkle. The author gratefully acknowledges the help and support that W. G. Dodge has provided in connection with the ADINA code. Acknowledgment is also due R. S. Wallace for his assistance with many of the computations and P. G. Fowler for generating the 3-D plots. 


\section{LIST OF FIGURES}

1 . The three basic modes of deformation associated with cracks . . . . . . . . . . . . . . . . .

2 The two coordinate systems of axes used. The orientation of the axes is determined by the tangent (t) to the crack root edge and the normal (n) to the crack edge, with both $(t)$ and $(n)$ in the plane of the crack. The z-axis is then normal to both tand $n$-axes. The polar system $(r-\theta)$ is in the

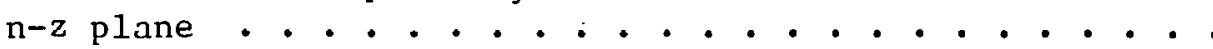

3 Quarter point singularity element. Number adjacent to the nodes refer to the FE displacements at these nodes in Table 7 . . . ..................

4 Finite element idealization for a centrally cracked strip . . . . . . . . . . . . . . . . . . .

5 Estimates of $\mathrm{K}_{\mathrm{I}}$ as calculated from nodal displacements . .

A typical FE mesh used with energy release methods . . .

7 A typical model for use with displacement or stress methods .. . . . . . . . . . . . . . . . .

8 Two-dimensional mesh used to generate the 3-D FE mesh by propagating it normal to the plane of the paper. The resulting 3-D mesh, shown in Figure 9, was used for the analysis of the circular central crack . . . . . . . . . . . . . . . . . . . . . .

9 Three-dimensional FE mesh used with the circular crack problcm . . . . . . . . . . . . . . . :

10 Flot of the $u_{z} i^{-1 / 2}$ results from the circilar crack problem . . . . . . . . . . . . . . . . . . .

11 Notation used in the end effects study: (a) geometry of the problem, (b) nomenclature . . . . . . . . . . .

12 Temperature distributions calculated by HEATING5 and uscd in the end cffects study . . . . . . . . . . . . .

1.3 Variation of $\mathrm{K}_{\mathrm{I}}$ with distance from mid-length for different times in the transient for the $914 \mathrm{~mm}$ (36 in.) cylinder 
14 Variation of $\mathrm{K}_{\mathrm{I}}$ with axial distance from mid-length for different cylinder lengths . . . . . . . . . .

15 Axial displacements at the free end of radial lines on the plane of symmetry ...............

16 Anomaly in crack opening displacements near the free end .....................

17 FE model used in the analysis of the V-8 cylinder: (a) quarter cylinder analyzed, (b) crack geometry ....

18 Two-dimensional generating plane for the V-8 cylinder analysis showing the "fine" and "coarse" mesh regions

19 Two-dimensional "fine" mesh portion of the generating plane (Mesh 1) for the V-8 cylinder ..........

20 Two-dimensional "fine" mesh portion of the generating plane (Mesh 2) for the V-8 cylinder with more nodes than Mesh 1 . . . . . . . . . . . . . . .

21 Three-dimensional mesh generated from that shown in Figure 18 for the V-8 cylinder analysis . . . . . . .

A.1 (a) Typical finite element mesh generated by the "GEN8" code. The singularity block (b) is then "merged" into a pair of elements, e.g., those shown shaded in (a) to produce a model with a "crack" located at $a / w=0.5$, a portion of which is shown in (c) . . . . . . . .

A.2 (a) Example of type of mesh produced by STRIP code, and the incorporation of the singularity block (b) by the MERGE code to produce the mesh (c) used in numerical experiments on the center cracked or edge notched bars. Note that the singularity block can be relocated at different positions giving in this case nine "specimens" with $a / w=0.1$ through $\mathrm{a} / \mathrm{w}=0.9$..................... 
Table

Page

1 Comparison of $\mathrm{K}_{\mathrm{I}}$ obtained by energy release rate methods to those obtained by the displacement method ....................

2 Dimensions and material properties used in the analysis of centrally cracked cylinder .........

3 Nodal displacements from FE analysis for a central circular crack in the cylindrical bar with $\nu=0.25$. : . 35

4 Input data for HEATING5 analysis, case designation 13C . 39

5 Data used in the free-end-effects study on cylinders . . . 42

6 Cases analyzed for V-8 test . . . . . . . . 55

$7 \quad$ Nodal displacements obtained from FE analysis of the V-8 cylinder for the four load cases... . . . . 56 $\mathrm{K}_{\mathrm{I}}$ in $\mathrm{MNm}^{-3 / 2}$ as a function of $\phi . . . . . . . .$.

A.1 Effect of node renumbering on the IBM 360/195 computer resources required by the ADINA computer code . . . .

A. 2 REDUCE code data . . . . . . . . . . . 74

B.1 Data used to propagate meshes from 2-D into 3-D . . . . 76

B.2 Miscellaneous data of interest related to the 3-D FE analysis using the ADINA 75 code ........... 
NOMENCLATURE

Latin

Characters

a

A

B

$\mathrm{d}_{\text {ii }}$

D

E

f

F

$\mathrm{F}_{\mathrm{B}}$

F e

$\mathrm{F}_{0}$

G

G

$K_{I}, K_{I 2 D}, K_{I 3 D}$

$\ell$

L

N

P

$Q$

r
Crack length or crack radius

Crack area

Strain-displacement transformation matrix

A term on the diagonal of the stress-strain transformation matrix

Diagonal matrix or stress-strain transformation matrix

Young's modulus of elasticity

Modified right-hand side of the upper triangularized matrix

Total force

Body force per unit volume

Nodal forces statically equivalent to the body forces plus the surface tractions

Nodal forces statically equivalent to the thermal plue initial etraine

Potential energy released per unit extension or crack area (the so-called energy release "rate")

Modulus of rigidity

Stress intensity factor, in $2-D$ and $3-D$, respectively

Length parameter

Lower triangular matrix

Field to nodal values transformation matrix (interpolating functions)

Potential energy of the structure

Thermal strain energy of the structure

Distance to crack root in polar coordinate system 


\section{NOMENCLATURE (Contd.)}

Lat in

Characters

(Contd.)

$\mathrm{T}$

u

$u_{n}, u_{z}$

$u^{\prime}$

$\mathrm{U}$

V

w

W

Greek

Characters

$\alpha$

$\varepsilon$

$\varepsilon_{0}$

$v$

$\sigma$

$\sigma_{\mathrm{nz}}$

$\tau_{\mathrm{nz}}$

$\theta$

$\phi$
Surface traction per unit area

Generalized nodal displacements

Nodal displacements in the $\mathrm{n}$ - and $\mathrm{z}$-directions, respectively

Generalized displacement field

Upper triangular matrix

Volume

Width parameter

Strain energy density function

Coefficient of linear expansion

Generalized strain matrix

Initial or thermal strain matrix

Poisson's ratio

Generalized stress matrix

Stresses in the $\mathrm{n}$ - and $z$-directions, respectively

Shear stress in the $n-z$ direction

Polar angle between $\mathrm{n}$ - and $\mathrm{r}$-directions

Angular location of a point on the crack front 


\section{NOMENCLATURE (Contd.)}

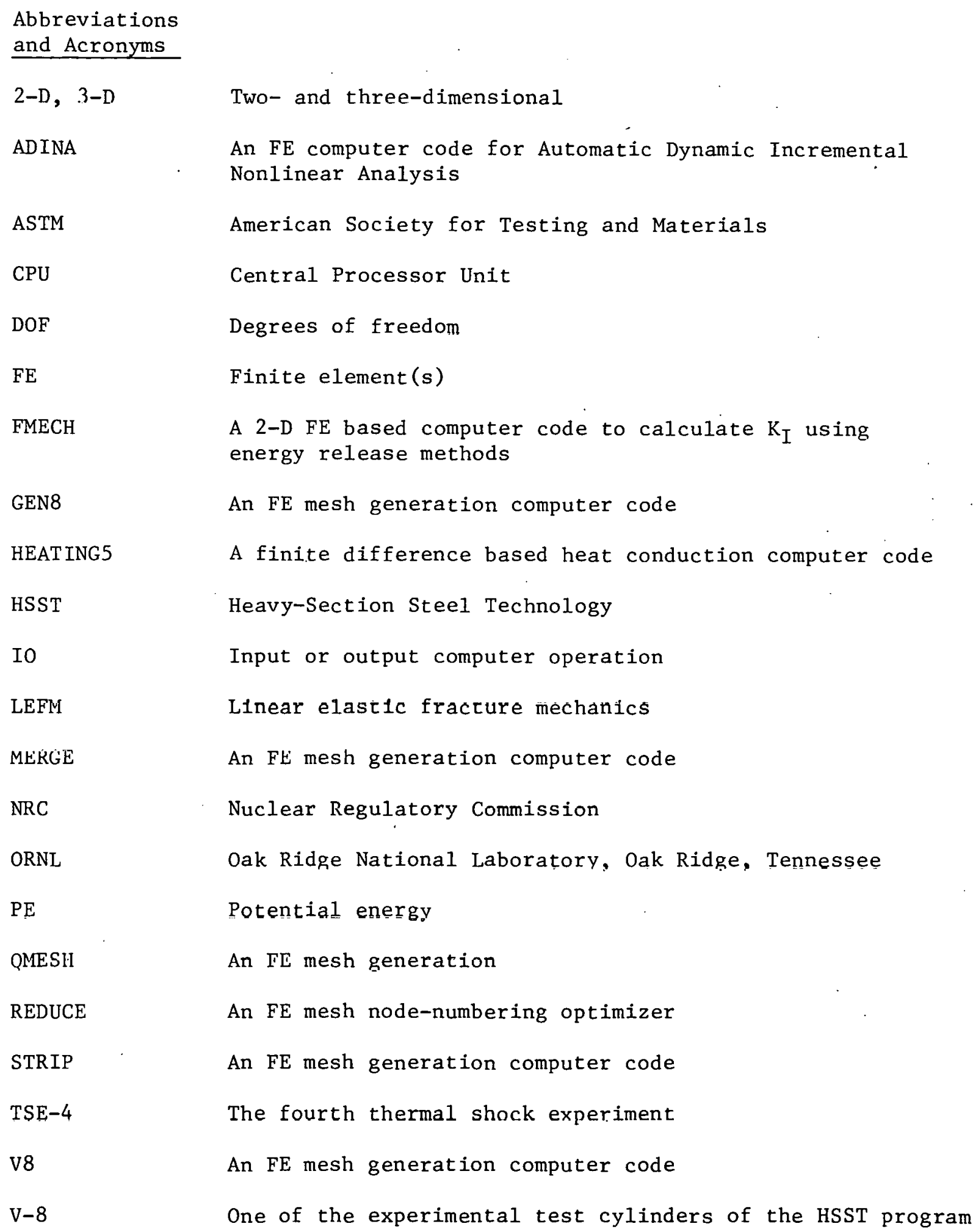


TWO FINITE ELEMENT TECHNIQUES FOR COMPUTING MODE I

STRESS INTENSITY FACTORS IN TWO- OR

THREE-DIMENSIONAL PROBLEMS

S. K. Iskander

ABSTRACT

Two finite element (FE) approaches were used to calculate opening mode $I$ stress intensity factors $\left(K_{I}\right)$ in two- and threedimensiona1 (2-D and 3-D) problems for the Heavy-Section Steel Technology (HSST) program. For problems that can be modeled in two dimensions, two techniques were used. One of these may be termed an "energy release rate" technique, and the other is based on the classical near-tip displacement and stress field equations. For three-dimensional problems, only the latter technique was used.

In the energy release technique, $\mathrm{K}_{\mathrm{I}}$ is calculated as the change in potential energy of the structure due to a small change in crack length. The potential energy is calculated by the FE method but without completely solving the system of linear equations for the displacements. Furthermore, the system of linear equations is nnly slightly perturbed by the change in crack length and, therefore, many computations need not be. repeated for the second structure with the slight change in crack length. Implementation of these last two items has resulted in considerable savings in the calculation of $\mathrm{K}_{\mathrm{I}}$ as compared to two complete FE analyses. These ideas are incorporated in the FMECH code.

The accuracy of the methods has been checked by comparing the results of the two approaches with each other and with closed form solutions. It is estimated that the accuracy of the results is about $\pm 5 \%$. 


\section{INTRODUCTION}

Flaws in structural components may occur during the fabrication processes or after the component has been put into service. Such flaws may escape detection in inspection. An important consideration in the design and analysis of such structural components is the stability of such flaws not only under normal operating conditions, but under hypothetical accident conditions.

Among the significant parameters in judging the propensity of flaws to propagate is the stress intensity factor, which depends upon the geometry and loading of the structure. These factors may be classified into three basic types, each associated with a local mode of deformation near the crack tip as shown in Figure 1 [1]. Conceptually, the methods described in this report can be used for the determination of the stress intensity factor associated with any of the three modes. This report, however, deals with the opening mode I type of deformation, which implies a loading symmetric with respect to the plane of the crack. A11 the methods described are based upon the basic assumptions of linear-elastic fracture mechanics (LEFM), viz., that all nonlinear effects are confined to a "small" region surrounding the crack tip and, consequently, may be neglected. A linear elastic analysis then approximates the essential features of such cases.

The number of "closed" form solutions in LEFM are 1imited. For the case of an arbitrarily shaped structure subjected to a general system of loads, numerical methods are used. There are many such methods, among which the influence function [2], the boundary integral [3], and the FE [4] approaches are noteworthy. Of these approaches, the ones based 
DWG. NO. K/G-80-2164

(u)

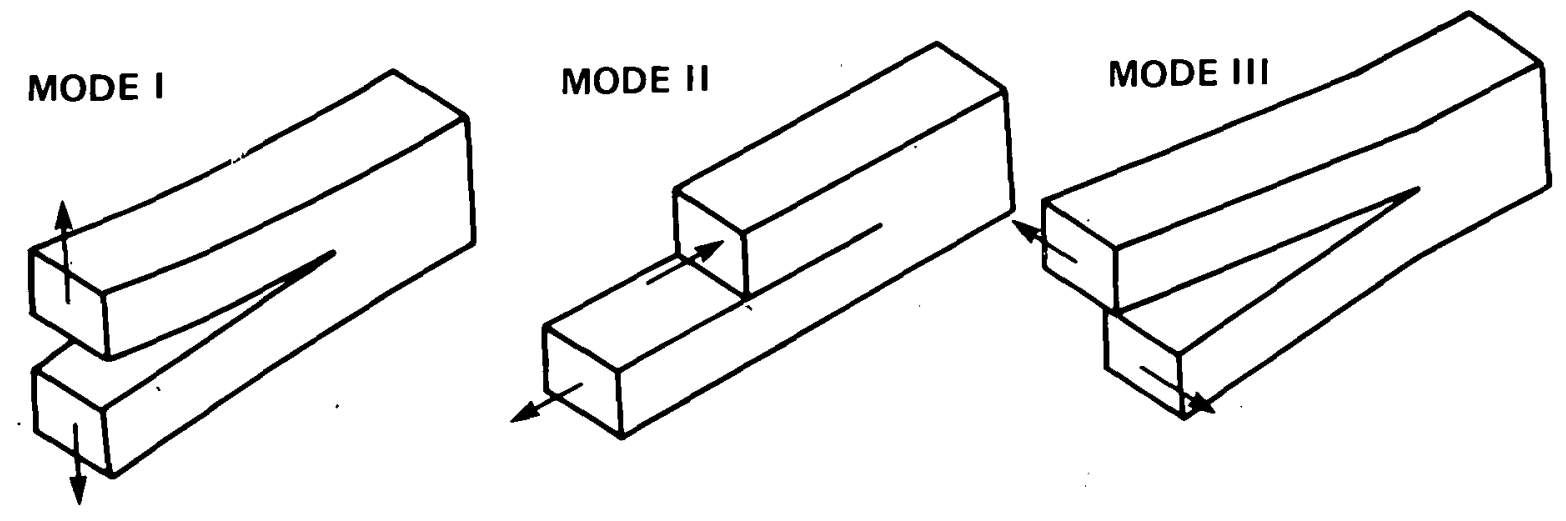

Figure 1. The three basic modes of deformation associated with cracks 
upon $\mathrm{FE}$ have been particularly popular due to the widespread availability of general-purpose computer codes, and this report discusses the implementation of two $\mathrm{FE}$ procedures used to calculate $\mathrm{K}_{\mathrm{I}}$. One of these is based upon the so-called energy release concept of LEFM and the other on the classical relationship between the near-tip stress (or displacement) fields and the stress intensity factor. $\mathrm{K}_{\mathrm{I}} \cdot{ }^{1}$ The energy release rate concept has been used with our 2-D models only, whereas the stress/displacement method has been used with both our 2-D and 3-D models. Verification of the methods has been carried out by comparison with closed form solutions and by comparing the results of the two different FE approaches for the 2-D problems.

The objective of this report is to document the energy release and stress/displacement methods as they have been implemented for the HSST program. Thus, in Chapter 2 two approaches based upon the energy release method are presented. The first approach is labeled the potential energy method, whereas the second one is termed the strain energy method. It is shown that, for special cases of either external loads only or thermal gradients only, both methods give the correct stress intensity factor. In cases where both types of loads are present, the strain energy approach will lead to erroneous results. Also presented is the complete derivation of a simple procedure to extract the potential energy from the upper triangularized system of equations arising in FE methods without solving explicitly for the displacements. The stress/displacement method is also documented.

\footnotetext{
${ }^{1}$ This method will be referred to as the stress/displacement method for brevity.
} 
In Chapter 3, results from several 2- and 3-D examples are presented. First, as partial verification of the methods given in Chapter 2, a problem for which a closed form solution exists was solved in both 2-D and 3-D cases. Second, in 2-D cases, both the potential energy and stress/displacement methods were used to solve the same problem. In all cases, the results were within a few percentage points of the closed form solution or each other. Also presented are the results of two 3-D analyses performed for the HSST program. The first analysis explores, for several different cylinder lengths, the variation of $\mathrm{K}_{\mathrm{I}}$ along the length of a uniform depth axial crack in a cylinder subjected to a thermal shock. The second deals with the variation of $\mathrm{K}_{\mathrm{I}}$ along the crack front for several different load cases of the $\mathrm{V}-8$ cylinder.

One important task in the FE modeling--that of mesh generation--is also one of the most time-consuming. Many codes have been developed by the author to facilitate this task and they will be mentioned briefly. The method used in optimizing the profile of the system of linear equations occurring in our 3-D FE analysis is also mentioned. Optimization is critical since, in many cases, analysis would not be possible due to limitations imposed by the computer environment: 


\section{METHODS OF ANALYSIS}

\subsection{Introduction}

In this chapter, both the energy release rate and the stress/displacement methods will be discussed.

\subsection{Energy Release Rate Methods}

This section presents the basis of the energy release rate method for calculation $\mathrm{K}_{\mathrm{I}}$ as it is implemented in the FMECH code. This method relies upon the calculation of the $\mathrm{PE}$ of the structure, and this is accomplished by means of the FE method. A brief derivation of the governing equations of the FE method based upon PE considerations is first given. These equations will be referred to in a discussion of the errors that arise if the strain energy is used in place of the potential energy in situations where both thermal and mechanical loads act on the structure (since some authors have used the strain energy release rate to calculate $\mathrm{K}_{\mathrm{T}}$ ). The governing equations of the $\mathrm{FE}$ method are also referred to in reviewing an economical computational method for calculating the PE. It is shown that the PE of the structure is available at the end of the forward elimination process and, hence, if the displacements or stresses are not required, the FE solution can be terminated at this point, thereby saving the cost of back substitution and the cost of computing the displacements and stresses.

One of the earliest papers in fracture mechanics was that of

Griffith [5]. It introduced the concept of energy release due to the propagation of cracks in brittle materials. Later, Irwin [6] and 
Orowan [7] extended Griffith's work to account for the "small" plastic zone ahead of the crack tip; so this concept may also be termed the Griffith-Irwin-Orowan theory.

Let $P$ be the total potential energy ( $P E$ ) of deformation of a structure, and $G$ dA be the total elastic energy made available when the crack extends by an amount $\mathrm{dA}$, where $\mathrm{A}$ is the crack surface area (one side of the (rack); then

$$
G=-\frac{\mathrm{dP}}{\mathrm{dA}}
$$

Furthermore, Irwin [8] showed that

$$
\begin{array}{rlr}
G=\frac{1}{E} K_{I}^{2} & \text { for plane stress } \\
\text { and } G=\frac{1-v^{2}}{E} K_{I}^{2} & \text { for plane strain }
\end{array}
$$

where

$$
\begin{aligned}
& \mathrm{K}_{\mathrm{I}}=\text { opening mode stress intensity factor, } \\
& \mathrm{E}=\text { modulus of elasticity, } \\
& \mathrm{V}=\text { Poisson's ratio. }
\end{aligned}
$$

Thus, it is possible to estimate $K_{I}$ by evaluating the change in the $P E$ of a structure $(\Delta P)$ due to a small extension of the crack surface $(\Delta A)$. There are various approaches to implementing energy methods using $\mathrm{FE}$ analysis. One approach would be to perform an $\mathrm{FE}$ analysis on the cracked structure, then extend the crack by a small amount and perform a second FE analysis, thus determining the PE corresponding to each crack length [9]. The disadvantage of this method is the necessity of having to perform two complete FE analyses. 
Rather than perform two complete and separate $\mathrm{FE}$ analyses to obtain $\mathrm{K}_{I}$, it is possible to optimize the process in a manner that reduces the costs to an amount equal to or less than that for a single complete FE analysis. In describing this optimization, many of the basic equations of the FE method will be referred to and, therefore, they will now be reviewed from a PE viewpoint although such a derivation is common in the FE 1iterature.

The total PE of a structure is given by [11, p. 384]

$$
P=\int_{\text {vol }} W d V-\int_{\text {vol }} u^{\prime} F_{B} d V-\int_{\text {area }} u^{\prime} T d A \text {, }
$$

where

$$
\begin{aligned}
& \mathrm{W}=\text { strain energy density, } \\
& \mathrm{u}^{\prime}=\text { displacement field, } \\
& \mathrm{F}_{\mathrm{B}}=\text { body forces per unit volume, } \\
& \mathrm{T}=\text { surface tractions per unit area. }
\end{aligned}
$$

The first term is the internal strain energy and the remaining two terms are the work done by the external forces.

Equation (3) will be rewritten in a form suitable for FE analysis.

The strain energy density can be expressed as?

$$
W=\frac{1}{2}\left(\varepsilon-\varepsilon_{0}\right)^{T} D\left(\varepsilon-\varepsilon_{0}\right),
$$

\footnotetext{
${ }^{2}$ Vectors and matrices will not be given any special symbol (e.g., $\left\{\varepsilon_{0}\right\}$ or [D]) since their definition and context of their use make their meaning unambiguous.
} 
where

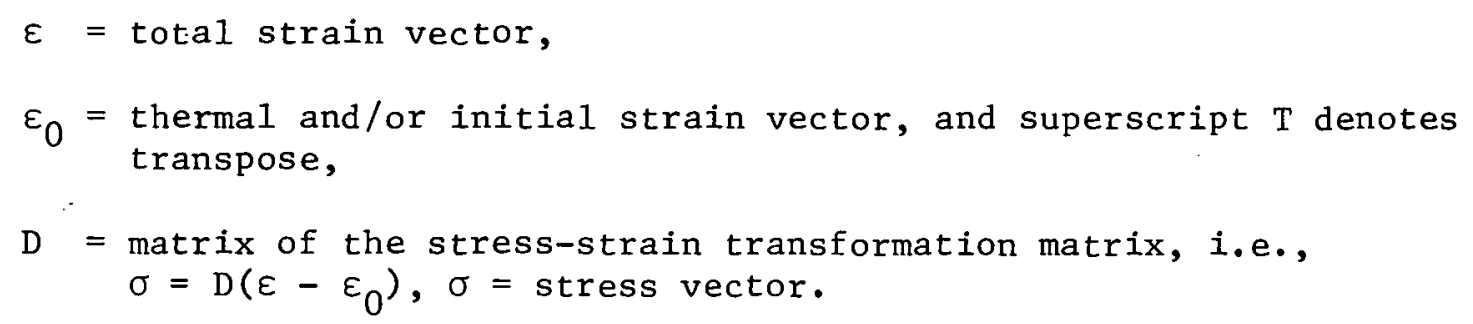

Let $\varepsilon=\mathrm{B} \mathrm{u}$, where

$$
\begin{aligned}
& \mathrm{u}=\text { nodal displacement vector } \\
& \mathrm{B}=\text { strain-displacement transformation matrix. }
\end{aligned}
$$

Then for the structure

$$
\begin{aligned}
\int W d V= & \frac{1}{2} u^{T} \int_{\text {vol }} B^{T} D B d V u-u^{T} \int_{\text {vol }} B D \varepsilon_{0} d V \\
& +\frac{1}{2} \int_{\text {vol }} \varepsilon_{0}^{T} D \varepsilon_{0} d V \\
= & \frac{1}{2} u^{T} K u-u^{T} F_{0}+Q
\end{aligned}
$$

where

$$
\begin{aligned}
\mathrm{K} & =\text { stiffness matrix for the structure } \\
& =\int_{\mathrm{vol}} \mathrm{B}^{\mathrm{T}} \mathrm{D} \mathrm{B} \mathrm{dV} \\
\mathrm{F}_{0} & =\underset{\text { nodal loads statically equivalent to the thermal or initial }}{\text { strains }} \\
& =\int_{\mathrm{vol}} \mathrm{B}^{\mathrm{T}} \mathrm{D} \varepsilon_{0} \mathrm{dV} \\
\mathrm{Q} & =\text { thermal energy }=\frac{1}{2} \int \varepsilon_{0}^{\mathrm{T}} \mathrm{D} \varepsilon_{0} \mathrm{dV} .
\end{aligned}
$$

Thus, the PE can be written as

$$
P=\frac{1}{2} u^{T} K u-u^{T} F_{0}-u^{T} F_{e}+Q \text {, }
$$


where $\mathrm{F}_{\mathrm{e}}$ are the nodal forces statically equivalent to the body forces and the surface tractions, i.e.,

$$
F_{e}=\int_{\text {area }} \mathrm{N}^{\mathrm{T}} \mathrm{T} \mathrm{dA}+\int_{\text {vol }} \mathrm{N}^{\mathrm{T}} \mathrm{F}_{\mathrm{B}} \mathrm{dV}
$$

where $\mathrm{N}=$ the interpolating functions relating the displacement field within an clement to its nodal displacements, viz., $\mathrm{u}^{\prime}=\mathrm{N}$ u.

Thus, the PE can be written in the form

$$
P=\frac{1}{2} u^{T} K u-u^{T} F+Q
$$

where $F=F_{e}+F_{0}$ (the sum of the external loads $F_{e}$ and the initial or thermal loads $\mathrm{F}_{0}$ ).

The use of the theorem of minimum potential energy, viz., the first variation on $P$ with respect to the displacement $\delta u[11, P .382]$

$$
\begin{aligned}
\text { viz., } \delta \mathrm{P} & =0 . \text { leads to } \\
\mathrm{Ku} & =\mathrm{F}
\end{aligned}
$$

Equation (5) forms the basis for the FE method. Substituting for $\mathrm{F}$ from Eq. (5) into Eq. (4)

$$
P=\frac{1}{2} u^{T} k u-u^{T} k u+?
$$

or

$$
P=-\frac{1}{2} u^{T} K u+Q
$$

Recall that the term $Q$ depends upon the thermal strains $\varepsilon_{0}$ and the material properties $D$. The $\varepsilon_{0}$ are functions of temperature and the coefficient of thermal expansion (which is not contained in D) only. The term $Q$ is therefore independent of the boundary conditions. Thus, the 
change in $\mathrm{PE}$ with respect to a change in crack area can be written as

$$
G=-\frac{d P}{d A}=\frac{d}{d A}\left(\frac{1}{2} u^{T} K u\right)
$$

In the absence of external mechanical loads, the PE of a structure, Eq. (3), is given by $\int W d V$, the internal strain energy of the structure. On the other hand, if there are no thermal stresses, the strain is equal to the work done by the external forces ${ }^{3}$ (Clapeyron's Theorem [11, p. 86]). In both these cases, the use of the strain energy in place of the $\mathrm{PE}$ in Eq. (1) is valid, except for the sign. This has lead many authors [1,12] to use the term "strain energy release rate" in place of the "potential energy release rate." Where both external and thermal loads act on a structure, the use of strain energy can lead to errors, since this does not account for the work done by thermal expansion on the external loads.

For example, consider a bar supported at one end in such a manner that a uniform temperature change only causes a stress-free thermal expansion. If the bar is subjected to external mecharical loads, a uniform temperature change will cause no change in the strain energy, but will alter the PE of the structure.

As mentioned above, one obvious and straightforward method of calculating $\mathrm{K}_{\mathrm{I}}$ by the energy release rate method would be to perform two complete and separate FE analyses. However, two simplifications are possible. First, the element stiffnesses calculated for the first FE analysis are saved and, since they are a function of the dimensions and material properties only, they may be utilized in the second FE analysis

$$
{ }^{3} \text { Mathematicaliy expressed as } \int_{\text {vol }} u^{\prime} F_{B} d V+\int_{\text {area }} u^{\prime} T d A=2 \int W d V .
$$


and only the boundary conditions are modified to account for the new crack root. Since the cost of the calculation of the element stiffness comprises a major portion of the cost of an FE analysis, the savings are significant.

The second simplification concerns the solution of Eq. (5) and the computation of the displacements and stresses. About half the cost associated with these operations can be saved by means of a scheme due to Hellen [10]. It is shown that the PE of the structure is available at the end of the forward elimination process and thus, if the displacements or the stresses are not required, their costs can be eliminated by terminating the FE computation at this point. Basically, this scheme enables the computation of the term $\left(u^{\mathrm{T}} \mathrm{K} u\right.$ ) or, equivalently, the work done by the total forces acting through their corresponding displacements $\left(\mathrm{F}^{\mathrm{T}} \mathrm{u}\right)$. The method relies upon the symmetry of the stiffness matrix $\mathrm{K}$ and upon the ability to decompose the matrix into the following form [13]

$$
\mathrm{K}=\mathrm{L} \mathrm{DU},
$$

where $\mathrm{L}$ and $\mathrm{U}$ are lower and upper triangular matrices with units along their principal diagonals, and $D$ is a diagonal matrix whose elements are the "pivots" of Gaussian elimination. Moreover, since $K$ is symmetric, $\dot{\mathrm{U}}=\mathrm{L}^{\mathrm{l}} \mathrm{l}$. . Then

$$
K=L \quad L^{T}
$$

The solution of Eq. (5) then proceeds as follows:

$$
\mathrm{K} u=\mathrm{F}
$$

or

$$
\text { L D } \mathrm{L}^{\mathrm{T}} \mathrm{u}=\mathrm{F}
$$


Forward elimination is symbolically represented as:

$$
\text { D } \mathrm{L}^{\mathrm{T}} \mathrm{u}=\mathrm{L}^{-1} \mathrm{~F}
$$

or, if the pivots are reduced to unity, then

$$
\mathrm{L}^{\mathrm{T}} \mathrm{u}=\mathrm{D}^{-1} \cdot \mathrm{L}^{-1} \mathrm{~F}
$$

For brevity, let

$$
\mathrm{F}^{\prime \prime}=\mathrm{L}^{-1} \mathrm{~F}
$$

and

$$
F^{\prime}=D^{-1} L^{-1} F
$$

then

$$
\mathrm{L}^{\mathrm{T}} \mathrm{u}=\mathrm{F}^{\prime}
$$

In other words, $F^{\prime}$ (or $F^{\prime \prime}$ ) is the state of the total force vector at the end of the forward elimination process. The remaining back substitution process is symbolized as

$$
\mathrm{u}=\mathrm{L}^{\mathrm{T}^{-1}} \mathrm{~F}^{\prime}
$$

then

$$
\begin{aligned}
& u^{T} k u=\left(F^{\prime T} L^{-1}\right)\left(L^{D} L^{T}\right)\left(L^{T^{-1}} F^{\prime}\right) \\
& =F^{T} D F^{\prime}
\end{aligned}
$$

or

$$
\mathrm{u}^{\mathrm{T}} \mathrm{Ku}=\mathrm{F}^{\prime \prime} \mathrm{D}^{-1} \mathrm{~F}^{\prime \prime}
$$


Here the form (12b) would be used if, at the end of the forward elimination, the pivots had been normalized; otherwise, (12a) would be used.

Thus,

$$
u^{T} k, u=\sum_{i=1}^{n}\left(f_{i}^{\prime}\right)^{2} d_{i i}
$$

In other words, the above sum can be accumulated during the forward elimination process and there is no need to carry out the back substitution stage or its attendant cost in $\mathrm{CPU}^{4}$ and $\mathrm{IO}^{5}$ nor is there a need to calculate either the displacements or the stresses.

There are many advantages to the energy method and these have been documented in detail in [9]. For a given mesh, energy methods give better accuracy than stress/displacement methods and they are insensitive to a large extent to the details of the mesh layout. This may be due to errors that cancel out since the meshes used in both analyses (the first with a crack length $A$ and the second with a crack length of $(A+\triangle A)$ are identical except for the boundary conditions on the crack front. A significant advantage is also the high degree of automation which energy methods lend themselves to, as contrasted with the stress or displacement methơds mentioned later.

\footnotetext{
${ }^{4} \mathrm{CPU}=$ Central Processor Unit--used synonomously for computations. ${ }^{5}$ IO $=$ Input or Output operations to disks or tapes.
} 


\subsection{Stress and Displacement Methods}

These methods rely upon the classical relationships between the near field solution and the stress intensity factor $\mathrm{K}_{I}$ [14] (see Figure 2 for coordinate system notation). The stresses are given by

$$
\begin{aligned}
& \sigma_{n}=\frac{K_{I}}{(2 \pi r)^{1 / 2}} \cos \frac{\theta}{2}\left[1-\sin \frac{\theta}{2} \sin \frac{3 \theta}{2}\right]+\ldots \\
& \sigma_{z}=\frac{K_{I}}{(2 \pi r)^{1 / 2}} \cos \frac{\theta}{2}\left[1+\sin \frac{\theta}{2} \sin \frac{3 \theta}{2}\right]+\ldots \\
& \tau_{n z}=\frac{K_{I}}{(2 \pi r)^{1 / 2}} \sin \frac{\theta}{2} \cos \frac{\theta}{2} \cos \frac{3 \theta}{2}+\ldots
\end{aligned}
$$

The displacements are (assuming plane strain conditions)

$$
\begin{aligned}
& u_{n}=\frac{K_{I}}{G}\left(\frac{r}{2 \pi}\right)^{1 / 2} \cos \frac{\theta}{2}\left(1-2 \nu+\sin ^{2} \frac{\theta}{2}\right)+\ldots \\
& u_{z}=\frac{K_{I}}{G}\left(\frac{r}{211}\right)^{1 / 2} \sin \frac{\theta}{2}\left(2-2 \nu-\cos ^{2} \frac{\theta}{2}\right)+\ldots
\end{aligned}
$$

where $\ldots$ represent terms of order $r$ and $r^{(2 n+1) / 2}(n=0,1, \ldots, \alpha)$ that are small with respect to the first term when $r$ becomes small,

$$
\begin{aligned}
& G=\text { modulus of rigidity }=E / 2(1+\nu) \text { for isotropic materials, } \\
& V=\text { Poisson's ratio, } \\
& E=\text { Young's modulus of elasticity. } \\
& \text { In the region close enough to the crack, } K_{I} \text { is calculated from }
\end{aligned}
$$

Eq. (14a) or (14b). If the displacements are used, by taking $\theta=\pi$, we get

$$
K_{I}=\frac{E \sqrt{2 \pi}}{4\left(1-v^{2}\right)}\left(\frac{u_{z}}{\sqrt{r}}\right)
$$




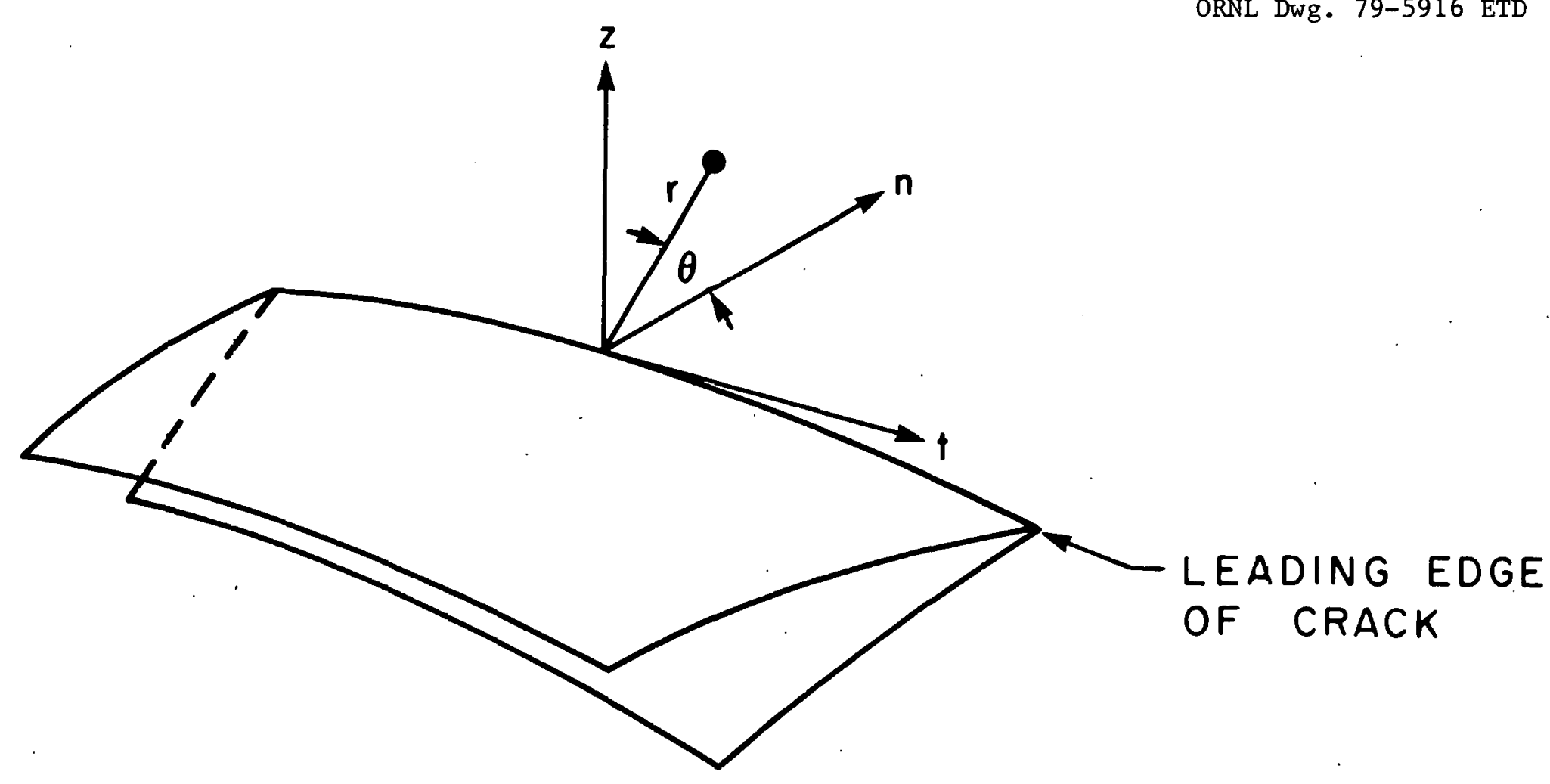

Figure 2. The two coordirate systems of axes used. The orientation of the axes is determined by the tangent ( $t$ ) to the crack root edge and the normal ( $n$ ) to the crack edge, with both $(t)$ and $(n)$ in the plane of the crack. The z-axis is then normal to both $t-$ and n-axes. The polar system $(r-\theta)$ is in the $\mathrm{n}-\mathrm{z}$ plane. 
Similarly, if the stresses are used, by taking $\theta=0$, we get

$$
\mathrm{K}_{\mathrm{I}}=(2 \pi)^{1 / 2}\left(\sigma_{\mathrm{z}} \sqrt{\mathrm{x}}\right)
$$

The displacements are the primary solution in most FE computer codes. The stresses are obtained by numerical differentiation with some loss in accuracy. In the interests of accuracy, the stresses are computed at the so-called gaussian integration points, which are interior to the element and not exactly at $\theta=0$. Thus, it may be preferable to use the displacements whenever possible. However, the stresses would be used to calculate $\mathrm{K}_{\mathrm{I}}$ where the displacements are not available, for example, in 3-D problems in which the crack front does not intersect the free surface at a right angle.

The procedure used to calculate $\mathrm{K}_{\mathrm{I}}$ is to plot either the term $\mathrm{ur}^{-1 / 2}$ or $\sigma \mathrm{r}^{1 / 2}$ as a function of $r$. The stresses or displacements are taken from the FE solution along a ray normal to the crack front. By extrapolating the curve back to $r=0$, an estimate of $\mathrm{K}_{\mathrm{I}}$ may be obtained. It has been found by solving problems with closed form solutions that a straight line extrapolation gives reasonably good results [31]. (Also see Sections 3.2.1. and 3.3.1. of this report.)

The total number of degrees of freedom (DOF) and, hence, the computational effort can be decreased considerably by the use of so-called "singularity elements" around the crack tip. These elements reproduce the $\frac{1}{\sqrt{\mathrm{r}}}$ singularity in the stresses, thereby allowing the use of relatively few elements in the crack tip region; otherwise, the high stress gradients in that region necessitate a highly refined mesh so that these gradients can be modeled with reasonable accuracy by either constant or linear 
stress elements. One type of singularity element can be produced from any element with mid-side nodes by locating the mid-side nodes adjacent to the crack front at the $\frac{1}{4}$ point (Figure 3 ). ${ }^{6}$ The stresses in the element will possess the correct singularity in the stresses as well as the correct stiffness, but the displacements at the $\frac{1}{4}$ nodes will be inaccurate [16]. Such an element is often referred to as the $\frac{1}{4}$ point element.

One advantage of the energy methods mentioned is the immediate computation of $\mathrm{K}_{I}$ as compared to stress or displacement methods which require a certain amount of manual plotting and computation, thereby lending themselves to a high degree of automation.

The energy methods described above have been implemented in the finite element code FMECH (Fracture Mechanics). This code is designed to compute $\mathrm{K}_{\mathrm{I}}$ for problems with any form of loading, mechanical or thermal. However, it is particularly useful and relatively efficient in LEFM problems with transient thermal loadings. In such cases, the aim is to calculate $\mathrm{K}_{\mathrm{I}}$ for a large number of different temperature distributions as well as different values of the crack depth.

\footnotetext{
${ }^{6}$ Such elements were introduced almost simultaneously by Barsoum [15] and Henshe11 [16].
} 


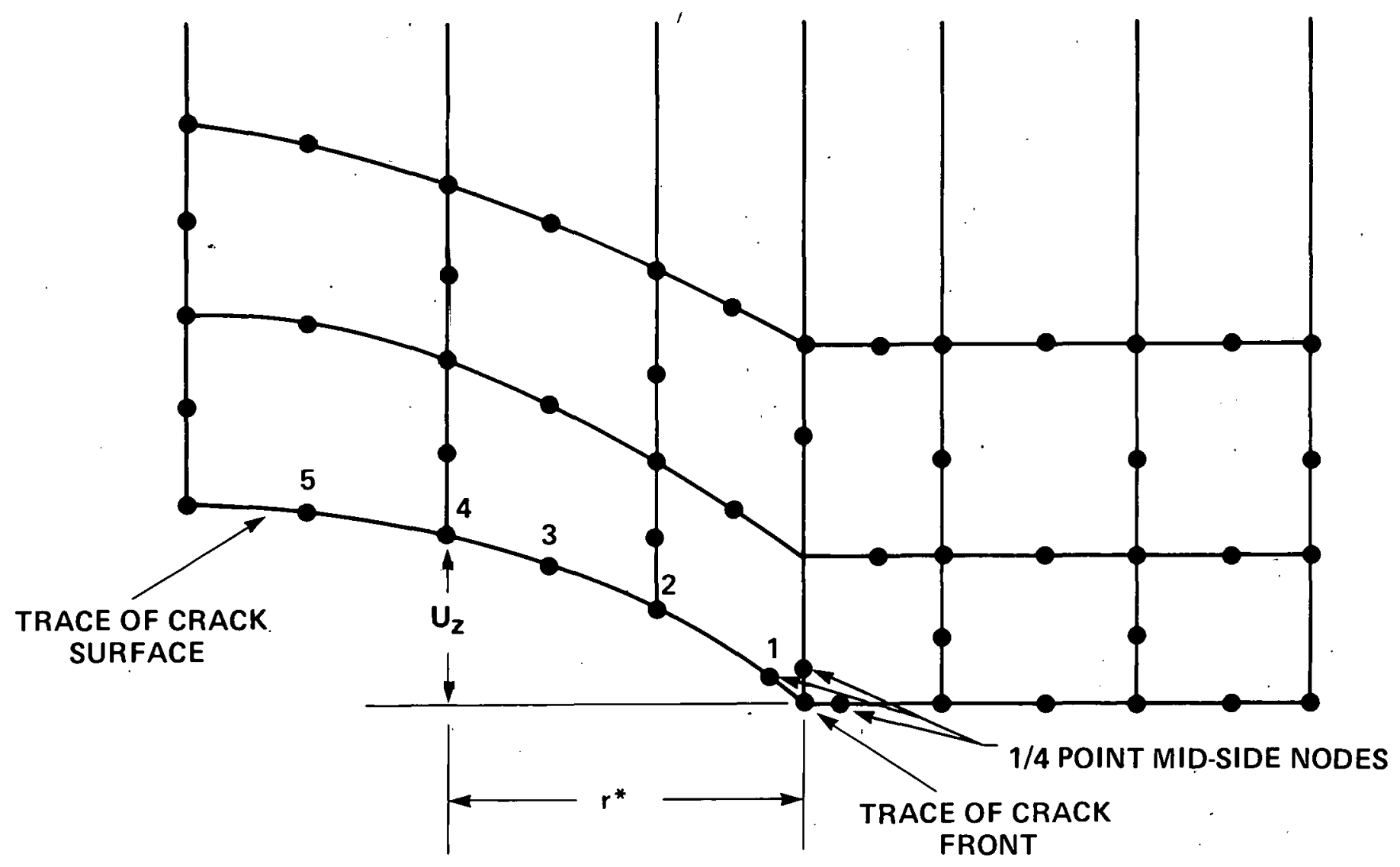

Figure 3. Quarter point singularity element. Number adjacent to the nodes refer to the FE displacements at these nodes in

Table ? 


\section{EXAMPLES OF ANALYSIS}

\subsection{Introduction}

This chapter presents some problems that have been solved using the techniques previously described in this report. The object of this is twofold. First, by solving problems that have either well-established or "closed form" solutions, a partial validation of the method and some assessment of the accuracy of the solution can be made. Second, it presents examples of the type of problems arising in the HSST program that have been solved with these techniques.

The first section deals with 2-D problems, the second one with 3-D problems. Both sections start with a problem for which a closed form solution exists then deal with the problems arising in the HSST program.

\subsection{Two-Dimensional Examples}

Twn prohlems will be discussed in this section. The first has a closed form solution and thus gives a rough assessment of the accuracy of the stress/displacement method. The second problem, one that arises in the HSST program, was solved using all the different approaches described in this report and the results have been compared.

\subsubsection{Finite Length Strip With a Central Crack}

The closed form solution of the centrally cracked strip has been given by Isida [17] and has been used extensively to verify numerical solutions. Such a strip with a crack-to-width ratio $(a / w)$ of 0.10 and a length-to-width $(\ell / w)$ of 3 has been modeled with 14 elements and is shown in Figure 4. The 
DWG. NO. K/G-80-2316

(U)
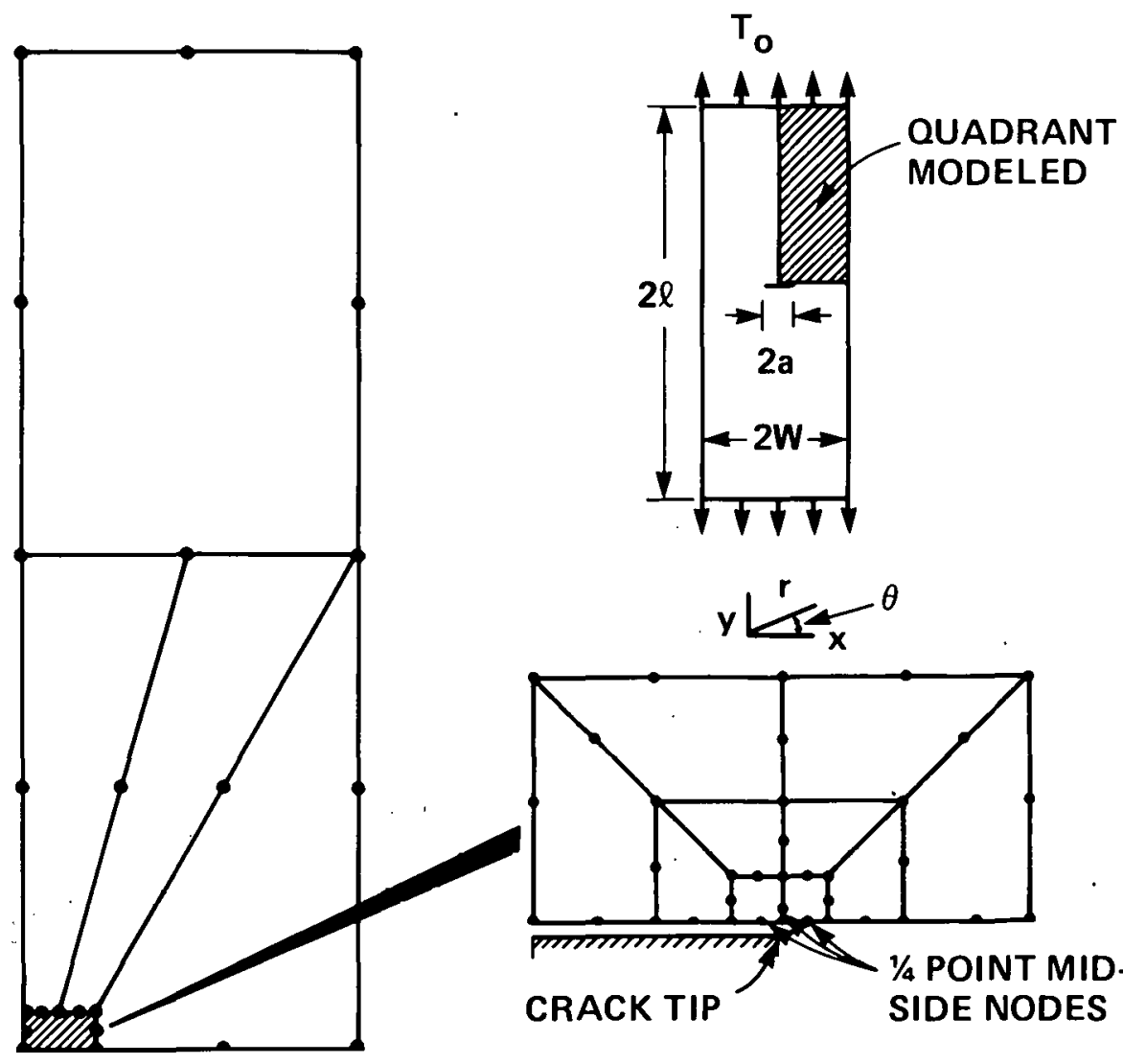

Figure 4. Finite element idealization for a centrally cracked strip 
displacement method was used. The stress intensity factor $\mathrm{K}_{\mathrm{I}}$ was normalized by dividing it by $\mathrm{T} \sqrt{\pi a},{ }^{7}$ where $\mathrm{T}$ is the externally applied traction and $2 \mathrm{a}$ is the crack length (Figure 4). The theoretical value given by Isida is 1.006. The normalized stress intensity factor calculated from the displacements ${ }^{8}$ is plotted against $r$, the distance from the crack tip, and is shown in Figure 5. The two straight-line fits give the values obtained when using either two or three integration points ${ }^{9}$ in the FE code. The results for the two integration points are better ( $2 \%$ higher than theoretical) than three integration points ( $7 \%$ lower). Hellen $[29,30]$ has reported results showing similar trends. Two integration points were used in all subsequent work of this type.

\subsubsection{Long Axial Flaw in a Cylinder Under Thermal Shock}

The cylinder analyzed is the one used in the TSE-4 experiment [19]. In this experiment, the test specimen was a cylinder of $0.533 \mathrm{~m}$ (21 in.) outside diameter, $0.241 \mathrm{~m}$ (9.5 in.) Inside diameter, and $0.914 \mathrm{~m}$ (36 in,) long. The material was A508, class 2 with a quench only heat treatment (from $871^{\circ} \mathrm{C}$ ). The long axial flaw was $11 \mathrm{~mm}$ (0.42 in.) deep. Initially, the whole cylinder was heated to $291^{\circ} \mathrm{C}\left(555^{\circ} \mathrm{F}\right)$ then the inside surface was suddenly cooled by a methyl alcohol/water mixture.

${ }^{7}$ The stress intensity factor for an infinite plate.

${ }^{8} \mathrm{All}$ the FE analyses with the stress and displacement method were performed using the ADINA Code [18].

${ }^{9}$ Implying a $2 \times 2$ or $3 \times 3$ integration order in 2-D and $2 \times 2 \times 2$ or $3 \times 3 \times 3$ in 3-D integration order in 3-D. 
ORNL Dwg. 77-11558

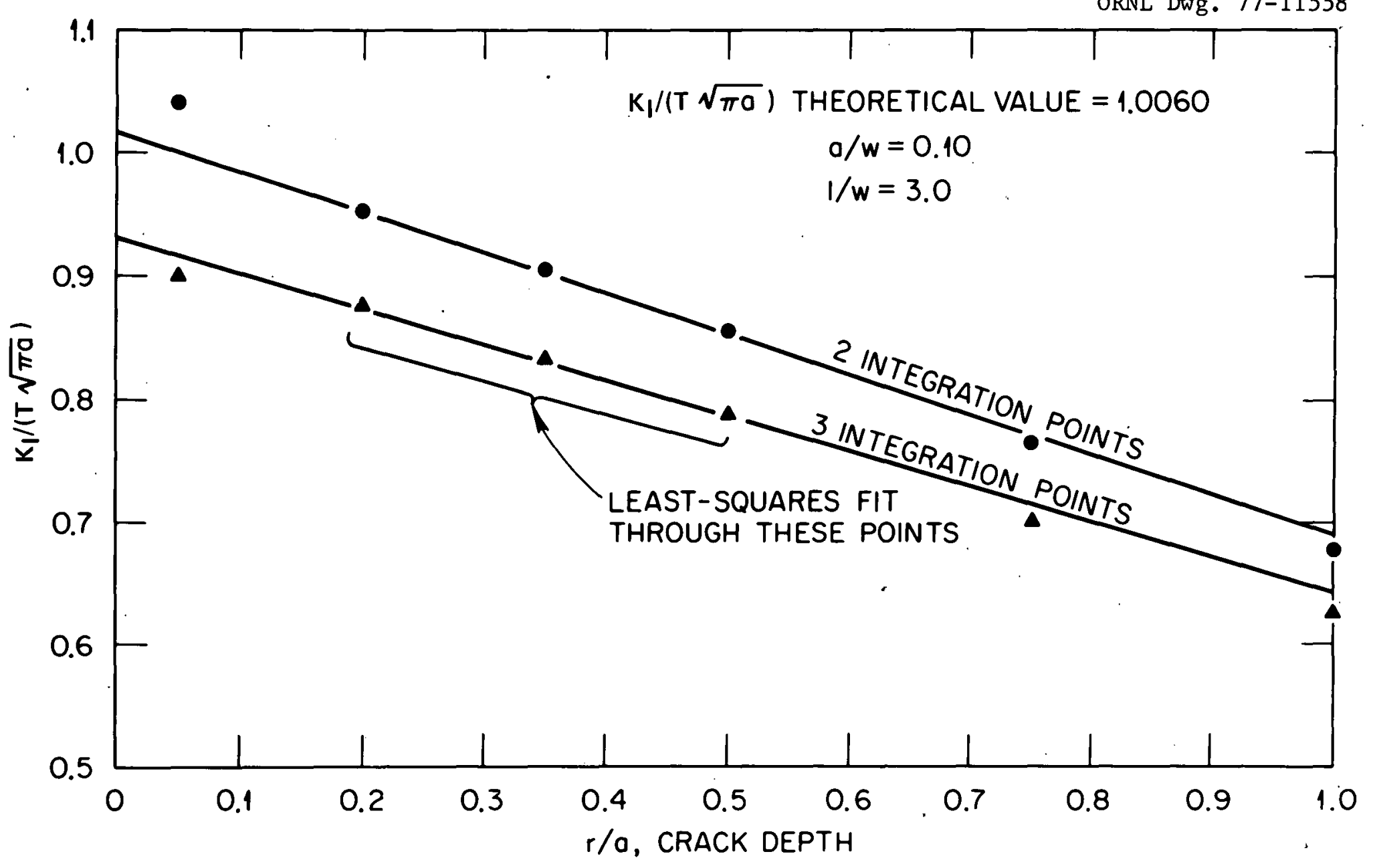

Figure 5. Estimates of $\mathrm{K}_{\mathrm{I}}$ as calculated from nodal displacements 
The coolant temperature was initial1y $-25^{\circ} \mathrm{C}\left(-13^{\circ} \mathrm{F}\right)$. The actual experimental temperatures obtained by the thermocouples on the cylinder during the transient were used in the calculation of $\mathrm{K}_{\mathrm{I}}$. The analysis was performed using two different codes, each with different techniques. The FMECH code utilizes energy-based techniques, but two slightly differing approaches were used.

The first approach with this code, which is documented in Reference [9], may be termed the "strain" energy approach and is based upon the fact that, in the absence of external forces, the $\mathrm{PE}$ and the internal strain energy are identical (see Eq. (3)). The displacements and stresses are first computed by the FMECH code and then the internal strain energy term is calculated from a quadratic expression in the stresses [9]. The other approach uses a more economical method described in section 2.2. of this report and has been termed the "potential energy" approach. A typiral mesh for both approaches is shown in Figure 6.

The mesh for the displacement method using the ADINA code is shown in Figure 7 . The results of the analysis using all of these different approaches are given in Table 1. The maximum difference between the $\mathrm{K}_{\mathrm{I}}$ values for any particular time interval is $7 \%$. The results calculated by the potential energy approach are more accurate than those obtained by the strain energy method since fewer computations are performed and, therefore, round-off . errors are less.

Considering the accuracy demonstrated by the stress/displacement method in Section 3.2., the close agreement between the 
DWG. NO. K/G-80-2160

(u)
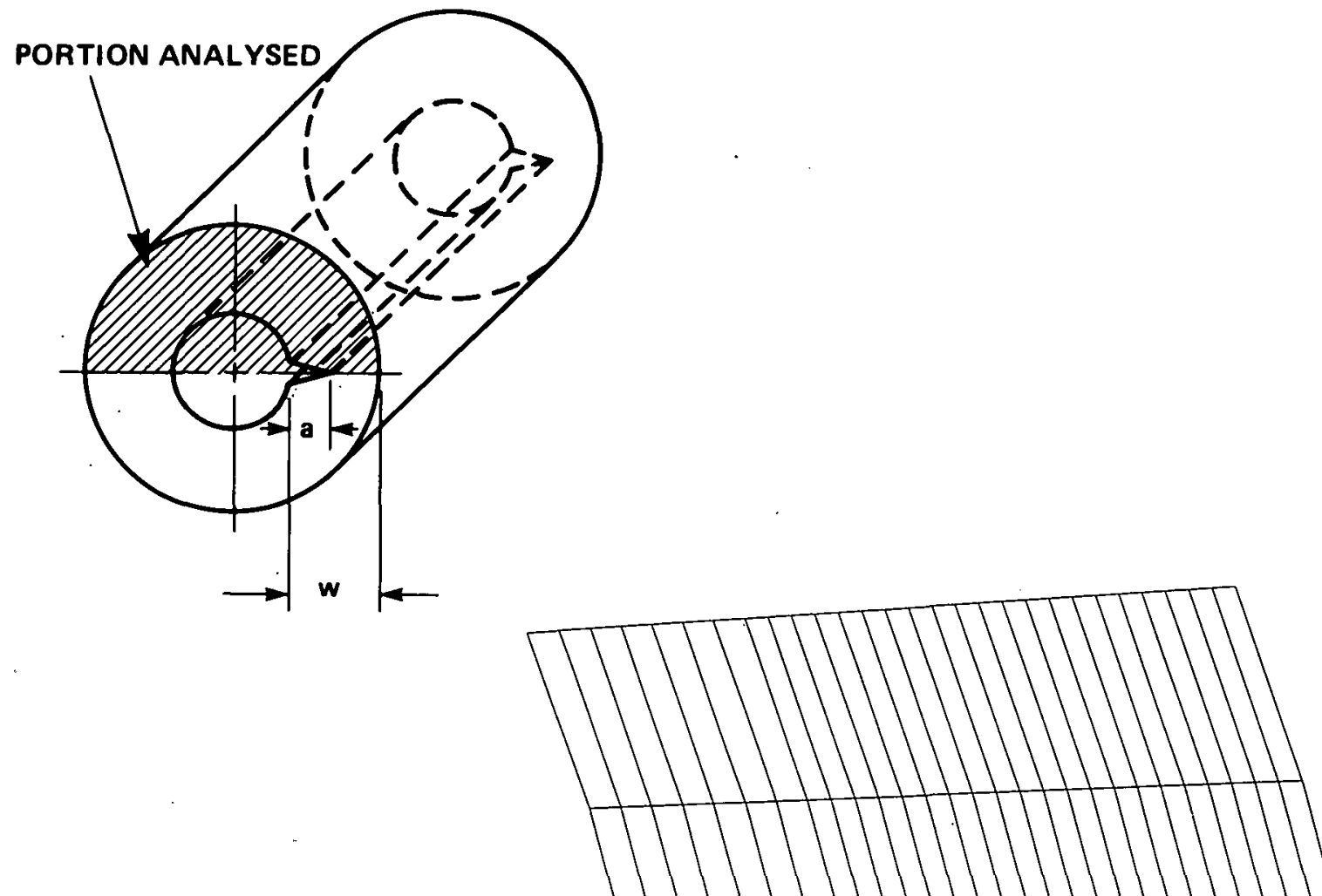

(a)

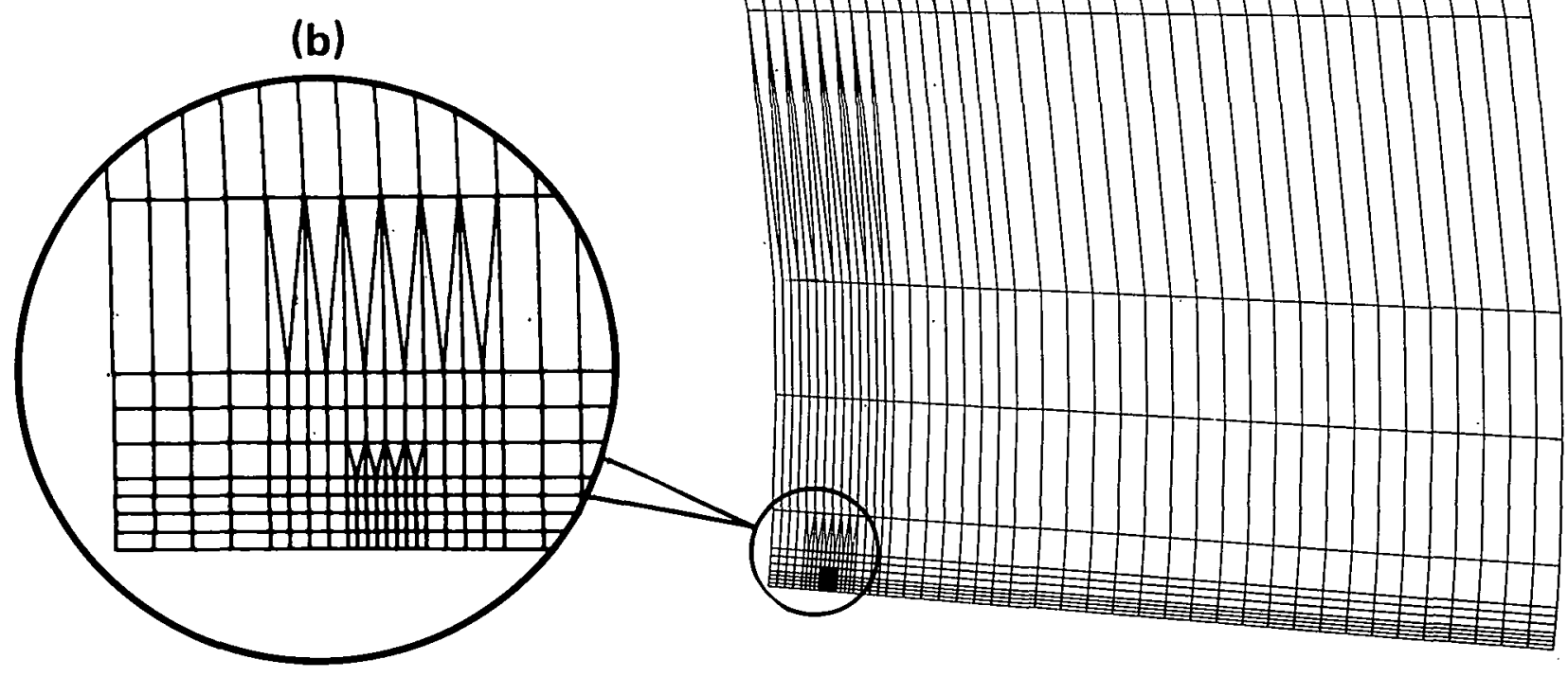

Figure 6. A typical $\mathrm{FE}$ mesh used with energy release methods 
DWG. NO. K/G-80-2159 (U).

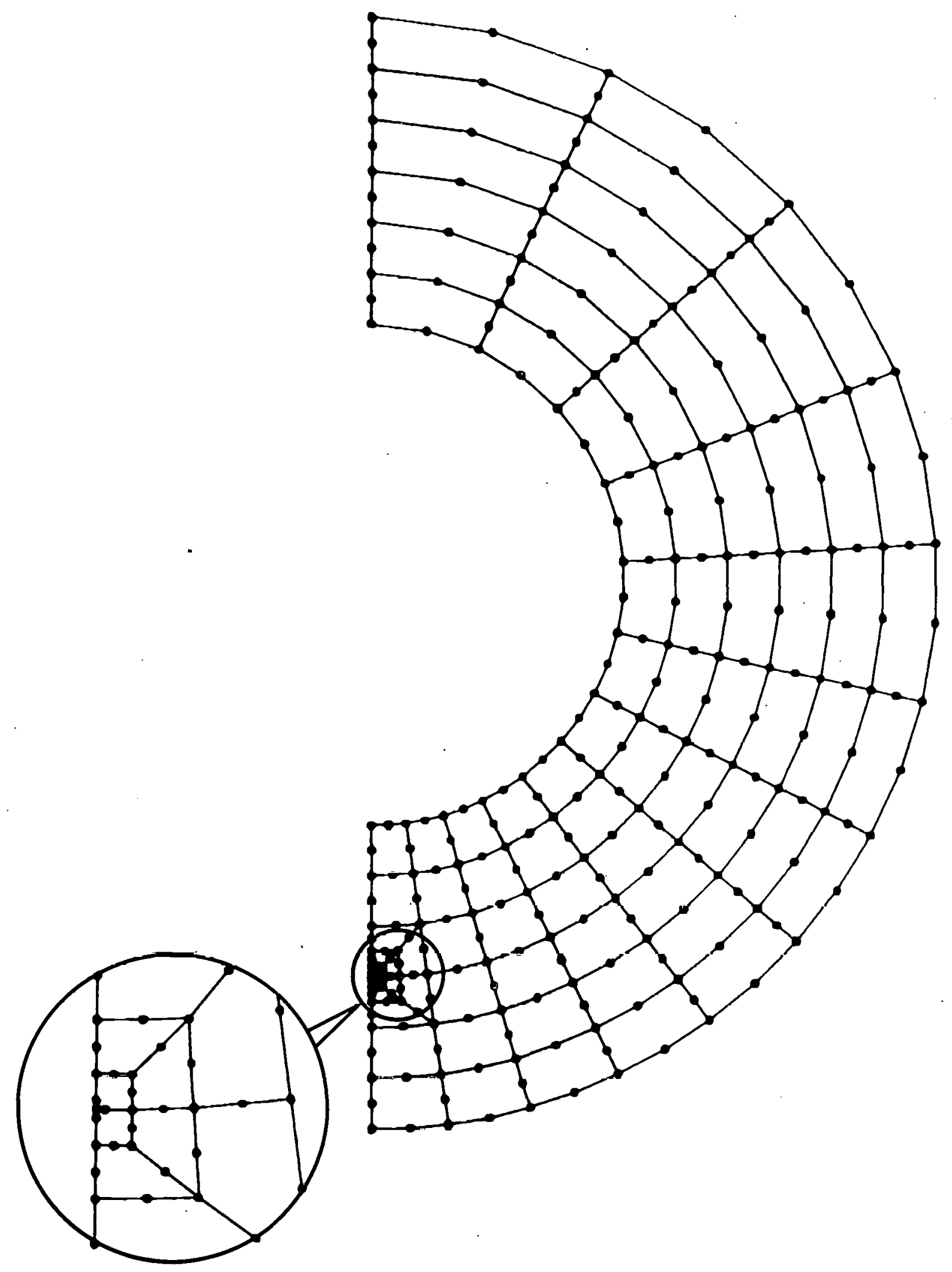

Figuie 7. A typical model for use with dioplacement or stress methods 
Table 1

Comparison of $\mathrm{K}_{\mathrm{I}}$ obtained by energy release rate methods to those obtained by the displacement method

$$
\mathrm{K}_{\mathrm{I}} \mathrm{MPa} \cdot \mathrm{m}^{1 / 2}\left(\mathrm{ksi} \cdot \mathrm{m}^{1 / 2}\right)
$$

Time in Transient (Minutes)

0.4

5.03

15.03

Energy Release Rate Methods (FMECH Code)

Strain Energy

Potential Energy

$\begin{array}{ccc}26.9 & 94.3 & 69.0 \\ (24.5) & (85.8) & (62.8) \\ & & \\ 27.8 & 97.1 & 71.1 \\ (25.3) & (88.4) & (64.7)\end{array}$

Displacement Method (ADINA Code)

251 Nodes

625 Nodes

$\begin{array}{ccc}25.1 & 90.7 & 66.5 \\ (22.8) & (82.5) & (60.5)\end{array}$

$\begin{array}{ccc}25.5 & 91.2 & 66.9 \\ (23.2) & (83.0) & (60.9)\end{array}$


stress/displacement and the energy methods also indicates that the energy method gives good accuracy.

The main advantage of the energy method over the stress/displacement method is the high degree of automation that the former one lends itself to. Stress/displacement methods as described in this report require some manual effort: extracting the stresses or displacements at the proper locations, calculating the $\mathrm{K}_{\mathrm{I}}$ values, plotting and extrapolating the values to $r=0$. Some of this effort may be eliminated by automating some of it. However, an element of judgment will always still be required in fitting the straight line through the data points. The energy method on the other hand yields $K_{I}$ values immediately.

\subsection{Three-Dimensional Examples}

In this section, analyses of some 3-D problems will be presented. Although the stress/displacement method is easily applied to 3-D problems, the usual difficulties of generating 3-D FE meshes become more acute in 3-D crack problems in which it is difficult to obtain the number of nodes necessary for a reasnnable degree of accuracy and still remain within the available computer caparity. Snme of the problems described here were close to the maximum size problems that could be handled with the software and hardware existing at the time.

A brief description of the mesh generation process is given in Appendix A, and the details of the FE modeling and analysis are given in Appendix B. 
The questions of validating the model and the mesh for 3-D problems are the same as for $2-D$ problems. Partial verification of the overall method was obtained by solving the 3-D problem of an imbedded plane circular crack located centrally in a cylinder which has a closed form solution. The other examples presented are problems arising in the HSST program.

One of these problems, that of the variation of $\mathrm{K}_{\mathrm{I}}$ axially along a longitudinal crack of uniform depth in cylinders of differing lengths, implicitly provides some verification of the results since, as the length increases, the stress intensity factors at mid-length should approach those of the corresponding 2-D plane strain problem.

Another problem presented arose during the pretest analysis of the V-8 cylinder. A part-through crack was to be produced on the outsidé surface of a cylinder in an HSST program test whose purpose was the determination of the influence of a residual stress field on the behavior of a flaw in a pressurized vessel.

\subsubsection{Plane Circular Crack Located Centrally in a Cylinder}

The closed form solution for the case of a long cylinder subjected to a uniform axial tensile load applied at the ends and stress-free cylindrical sides and a centrally located plane circular crack was obtained by Sneddon and Welch [20]. Values of $\mathrm{K}_{\mathrm{I}}$ from that solution for Poisson's ratio of 0.25 have been reproduced in a graphical form by Rooke [21]. A particular case of such a cylinder was modeled and analyzed. Table 2 gives the dimensions, material properties, and loading used in the analysis. The axisymmetry of the problem allows a sector of any angular 
Table 2

Dimensions and material properties used in the analysis of centrally cracked cylinder

Dimensions

Radius of cylinder

Cracked radius

$254 \mathrm{~mm}$ (10 in.)

Distance from crack plane to ends

$127 \mathrm{~mm}$ (5 in.)

$812.8 \mathrm{~mm}$ (32 in.)

Material Properties

Young's modulus E

Poisson's ratio $v$

$200 \mathrm{GPa}\left(29 \times 10^{6} \mathrm{psi}\right)$

0.25

Loading

End traction

$68.9 \mathrm{MPa}$ (10 ksi) 
dimension to be analyzed, but the restrictions imposed by the $\operatorname{code}^{10}$ lead to the choice of a quarter of the cylinder to be modeled. Figure 8 shows the 2-D mesh used to generate the 3-D model shown in Figure 9. Details of the FE modeling and analysis are given in Appendix $B$.

The nodal displacements from the FE analysis are given in Table 3. As an illustration of the process of estimating $K_{I}$ from these displacements, the term $u_{z} r^{-1 / 2}$ has been plotted in Figure 10. A best fit straight line extrapolated to $r=0$ gives a value of

$$
\left.u_{z} r^{-1 / 2}\right|_{r=0, \theta=\pi}=7.14 \times 10^{-3} \mathrm{~mm}^{1 / 2} 1.42 \times 10^{-3} \mathrm{in}^{1 / 2},
$$

and the use of expression (15) yields a value of

$$
\mathrm{K}_{\mathrm{I}}=30.2 \mathrm{MPa} \cdot \mathrm{m}^{1 / 2}\left(27.5 \mathrm{ksi} \cdot \mathrm{in}^{1 / 2}\right)
$$

When this value is normalized by dividing by $2 \mathrm{~T} \sqrt{\mathrm{a} / \pi}$, the stress intensity factor for a plane circular crack of radius a in an infinite medium subjected to a uniform stress of $\mathrm{T}$ gives a value of 1.088. Rooke [19] gives a corresponding value of 1.074. Thus, the method gives values within $1.5 \%$ of the closed form solution. No convergence studies with differing mesh sizes were performed to insure that this result is not fortuitous. However, in the V-8 analysis described later in this report, convergence studies with a mesh similar to this one and a mesh with $50 \%$ more nodes

${ }^{10}$ In the ADINA code, boundary conditions at the planes of symmetry can only be applied in directions. parallel to the $x-y-z$ coordinate axes. 


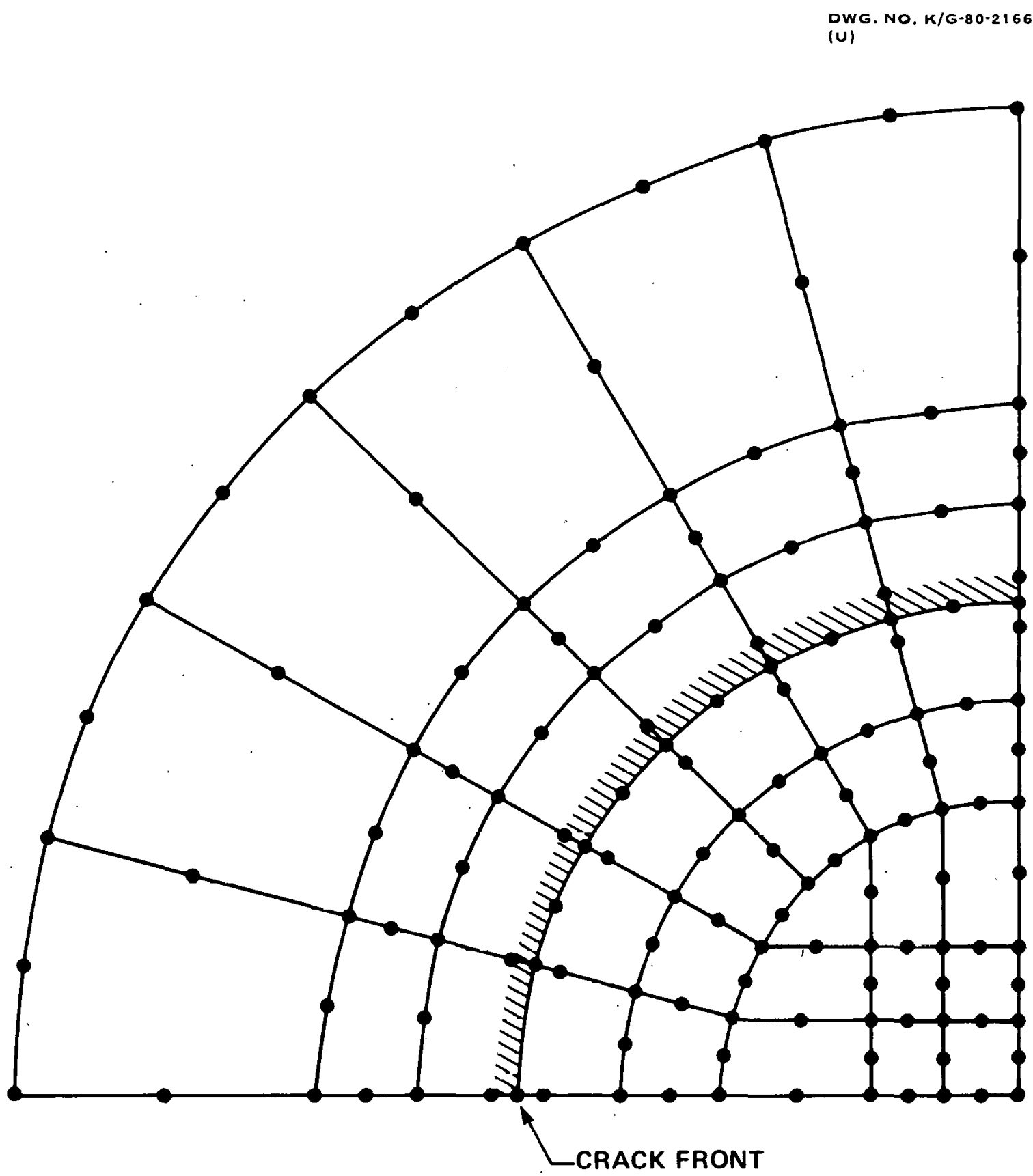

Figure 8. Two-dimensional mesh used to generate the 3-D FE mesh by propagating it normal to the plane of the paper. The resulting 3-D mesh, shown in Figure 9, was used for the analysis of the circular central crack 
(u)

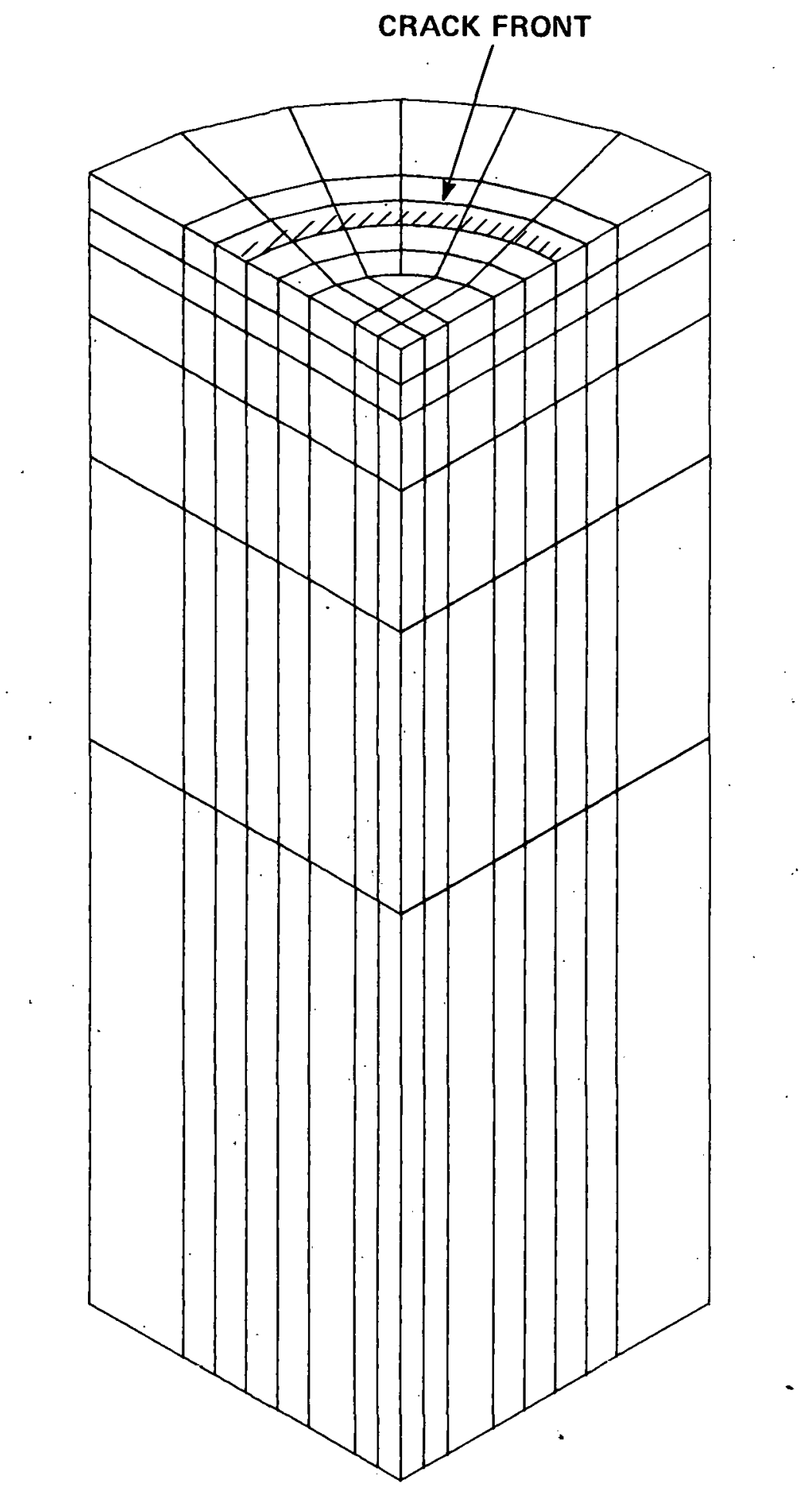

Figure 9. Three-dimensional FE mesh used with the circular crack problem 


\section{Table 3}

Nodal displacements from FE analysis for a central circular crack in the cylindrical bar with $\nu=0.25$ (Ratio of crack-to-cylinder $\operatorname{radii}=0.5$ )

\begin{tabular}{clll}
\hline $\begin{array}{l}\text { Distance } \begin{array}{r}\text { r from } \\
\text { Crack Tip }\end{array} \\
\text { mm }\end{array}$ & in. & \multicolumn{1}{l}{ Nodal Displacements } \\
\hline 6.35 & 0.25 & $\mu \mathrm{m}$ & in. \\
25.4 & 1 & 18.4 & $.724 \times 10^{-3}$ \\
38.1 & 1.5 & 33.3 & 1.310 \\
50.8 & 2 & 40.1 & 1.583 \\
69.9 & 2.75 & 45.0 & 1.773 \\
88.9 & 3.5 & 50.2 & 1.977 \\
98.4 & 3.875 & 53.6 & 2.112 \\
108 & 4.25 & 54.8 & 2.157 \\
117.5 & 4.625 & 55.6 & 2.189 \\
127 & 5 & 56.1 & 2.208 \\
\hline
\end{tabular}


DWG. NO. K/G-79-296

(U)

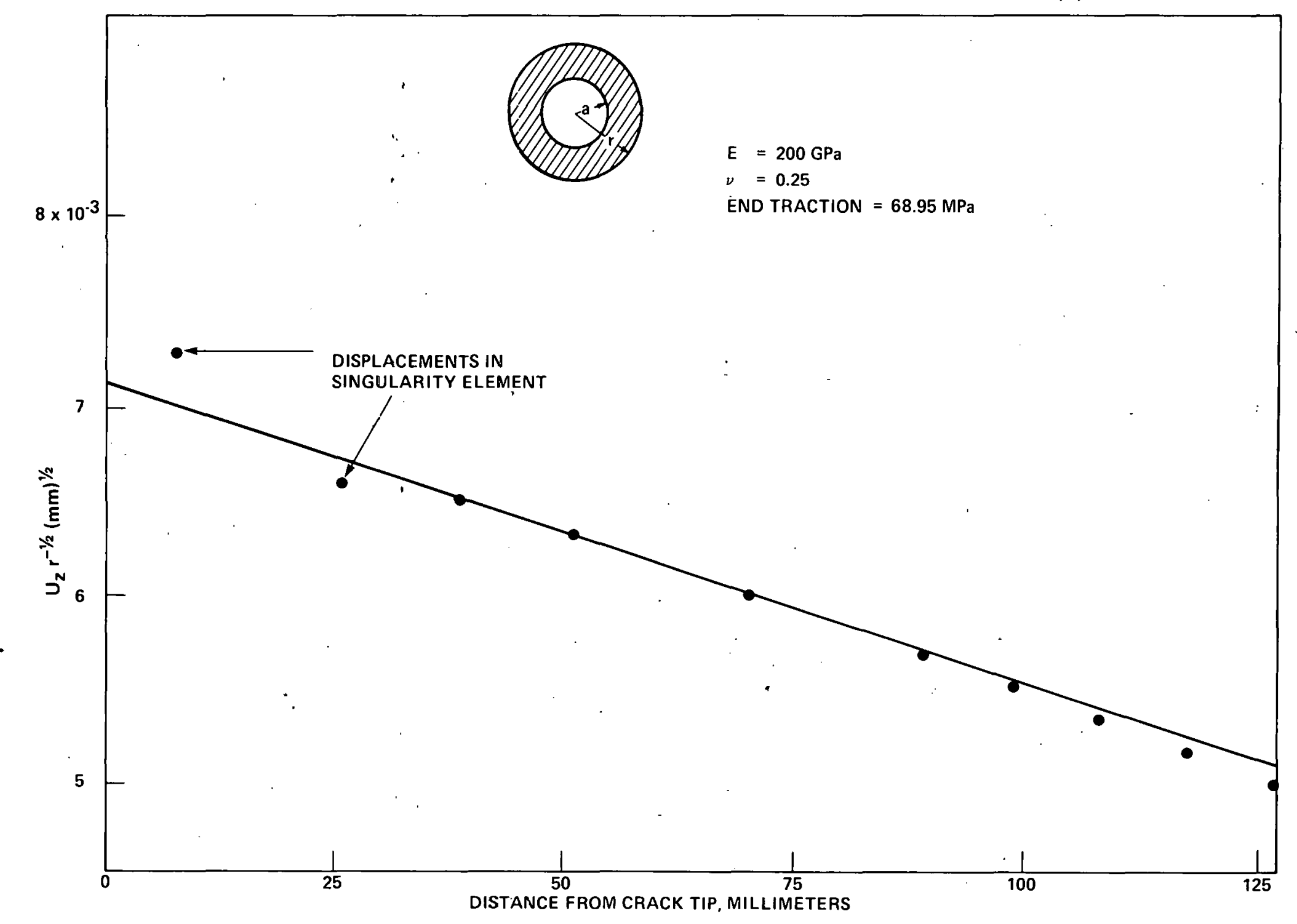

Figure 10. Plot of the $u_{z} r^{-1 / 2}$ results from the circular crack problem 
were performed. The results of the finer mesh were almost

identical to those from the coarser one.

3.3.2. Variation of $\mathrm{K}_{\mathrm{I}}$ in an Axially Cracked Cylinder Subjected to Thermal Shock (the End Effect Problem) ${ }^{11}$

The object of this series of analyses was the determination of the effect of the free ends on the values of $K_{I}$ for a specific thermal shock problem. The problem is that of a thick cylinder with an axial crack extending along the whole length, Figure 11(a). As the length of the cylinder increases, the $\mathrm{K}_{\mathrm{I}}$ values along a central portion of the crack will approach the 2-D plane strain value. The problem of concern is to determine the minimum lengths that will satisfy a required relationship between the 2-D and 3-D $\mathrm{K}_{\mathrm{I}}$ values over a specified central portion of the cylinder. The cylinder analyzed has an inner radius of $343 \mathrm{~mm}$ and a wall thickness of $152 \mathrm{~mm}$. It is initially at a uniform temperature of $129^{\circ} \mathrm{C}$. The inside surface is quenched with coolant at $-196^{\circ} \mathrm{C}$. The thermal analysis was performed on a one-dimensional axisymmetric model using the HEATING5 [23] code with the data shown in Table 4 and some of the resulting temperature distributions through the wall thickness is glven in Figure 12. The radial temperature distributions were used in the FE analysis of the cracked cylinder. Figure $11(\mathrm{~b})$ shows the models ${ }^{12}$ analyzed while Table 5 gives the cylinder lengths, times in the transient,

${ }^{11}$ If the ratio cylinder-length-to-outside-radius is of the same order of magnitude as unity, neither the plane strain nor the plane stress assumptions are useful and complete 3-D theory must be employed [22, p. 289].

${ }^{12}$ Details of the method of mesh generation and profile reduction are given in Appendix A. The 2-D mesh used to generate the 3-D meshes is similar to that shown in Figure 7. 


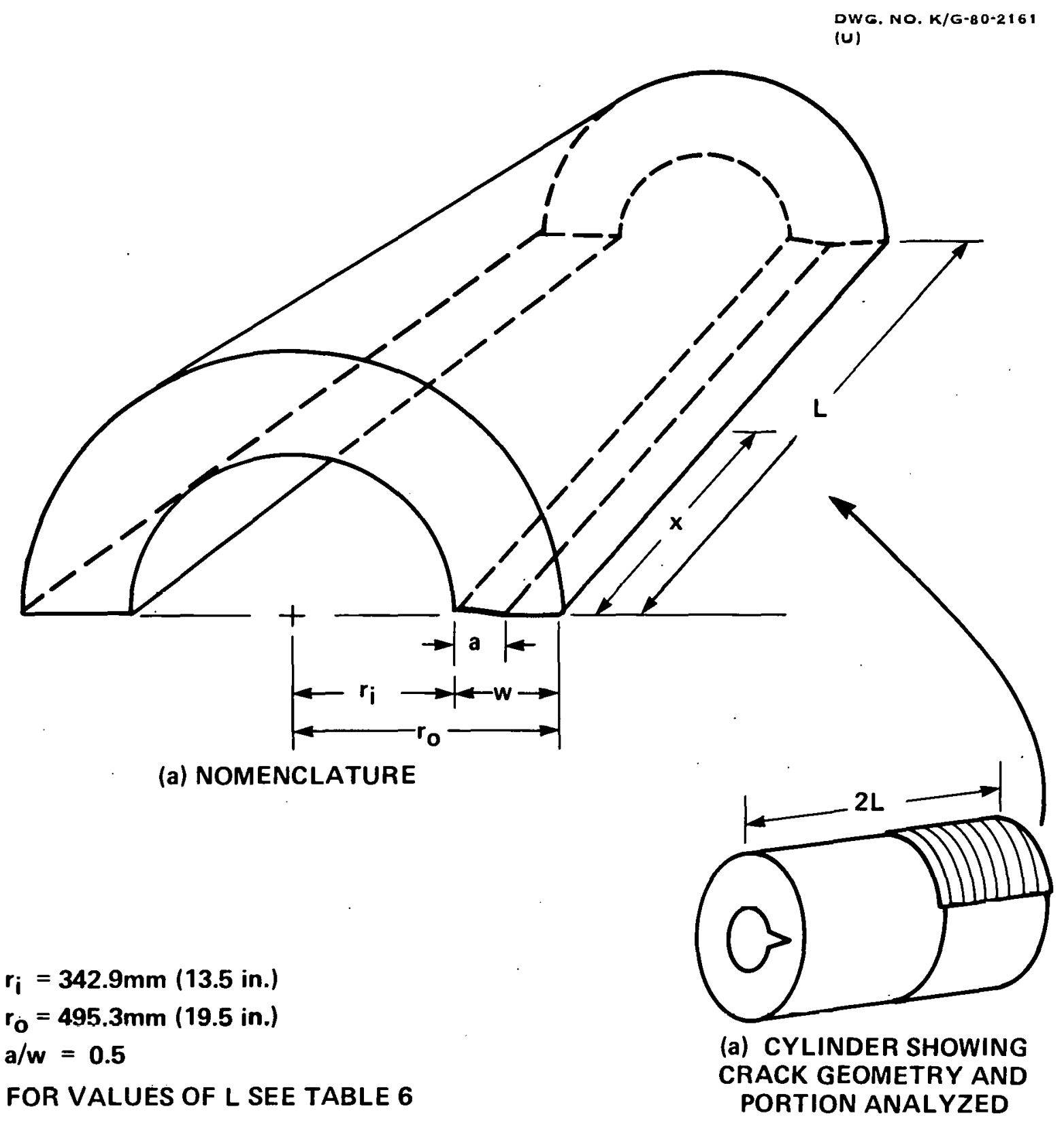

Figure 11. Notation used in the end effects study: (a) geometry of the problem, (b) nomenclature 
Table 4

Input data for HEATING5 analysis, case designation $13 \mathrm{C}$

(One-dimensional axisymmetric solution)

Cylinder Radii

Inside

Outside

Initial Temperature

Coolant Temperature

$\underline{\text { Density }}$

Conductivity

Specific Heat $^{a}$

$$
\begin{aligned}
& 343 \mathrm{~mm}(13.5 \mathrm{in} .) \\
& 495 \mathrm{~mm}(19.5 \mathrm{in} .) \\
& 129{ }^{\circ} \mathrm{C}\left(264^{\circ} \mathrm{F}\right) \\
& -196{ }^{\circ} \mathrm{C}\left(-320^{\circ} \mathrm{F}\right) \\
& 7 \cdot 83 \mathrm{~g} \cdot \mathrm{cm}\left(489 \mathrm{lb} \cdot \mathrm{ft} \cdot{ }^{-3}\right) \\
& 43 \cdot 3 \mathrm{~W} \cdot \mathrm{m}^{-1} \cdot \mathrm{K}^{-1}\left(25 \mathrm{Btu} \cdot \mathrm{hr}^{-1} \cdot \mathrm{ft}^{-1} \cdot{ }^{\circ} \mathrm{F}^{-1}\right)
\end{aligned}
$$

\begin{tabular}{|c|c|}
\hline${ }^{\circ} \mathrm{F}$ & $\mathrm{Btu} \cdot 1 \mathrm{~b}^{-1}{ }^{\circ} \mathrm{F}^{-1}$ \\
\hline-300 & 0.044 \\
\hline-250 & 0.060 \\
\hline-200 & 0.0745 \\
\hline-150 & 0.085 \\
\hline-100 & 0.092 \\
\hline-50 & 0.097 \\
\hline 0 & 0.101 \\
\hline 100 & 0.108 \\
\hline 200 & 0.1145 \\
\hline 300 & 0.1202 \\
\hline 400 & 0.1260 \\
\hline 500 & 0.1315 \\
\hline 600 & 0.1370 \\
\hline
\end{tabular}

\begin{tabular}{cc}
\multicolumn{2}{c}{$\mathrm{SI}$} \\
\hline $\begin{array}{c}{ }^{\circ} \mathrm{C} \\
-184\end{array}$ & $\mathrm{~J} \cdot \mathrm{Kg}^{-1} \mathrm{~K}^{-1}$ \\
-157 & 184 \\
-129 & 251 \\
-101 & 312 \\
-73 & 356 \\
-46 & 385 \\
-18 & 406 \\
38 & 423 \\
93 & 452 \\
149 & 479 \\
204 & 503 \\
260 & 528 \\
316 & 551 \\
& 574
\end{tabular}

US Units 
Table 4 (Contd.)

Surface Heat Transfer Coefficient ${ }^{a}$

\begin{tabular}{|c|c|c|c|}
\hline${ }^{\circ} \mathrm{C}^{\mathrm{b}}$ & $\mathrm{kW} \cdot \mathrm{m}^{-2} \mathrm{~K}^{-1}$ & ${ }^{\circ} \mathrm{F}$ & $\underline{B t u} \cdot \mathrm{hr}^{-1} \mathrm{ft}^{-2}{ }^{\circ} \mathrm{F}^{-1}$ \\
\hline-176 & 5.31 & -285 & 936 \\
\hline-162 & 4.05 & -260 & 714 \\
\hline-148 & 3.01 & -235 & 530 \\
\hline-134 & 2.22 & -210 & 391.2 \\
\hline-121 & 1.64 & -185 & 288 \\
\hline-107 & 1.21 & -160 & 213.6 \\
\hline-92.8 & 0.886 & -135 & 156 \\
\hline-78.9 & 0.668 & -110 & 117.6 \\
\hline-71.9 & 0.586 & -97.5 & 103.2 \\
\hline-65 & 0.531 & -85 & 93.6 \\
\hline-58.1 & 0.511 & -72.5 & 90 \\
\hline
\end{tabular}

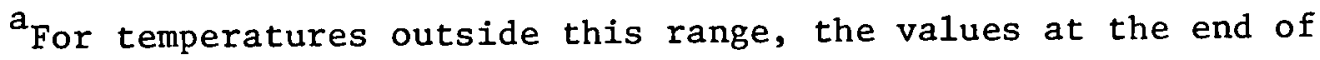
the table are used.

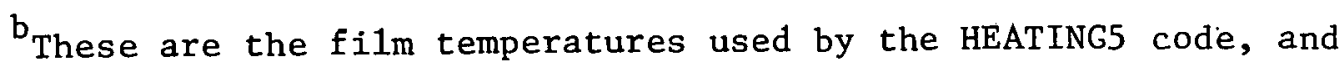
are the average of the surface temperature and the coolant temperature. 
DWG. NO. K/G-80-2165

(u)

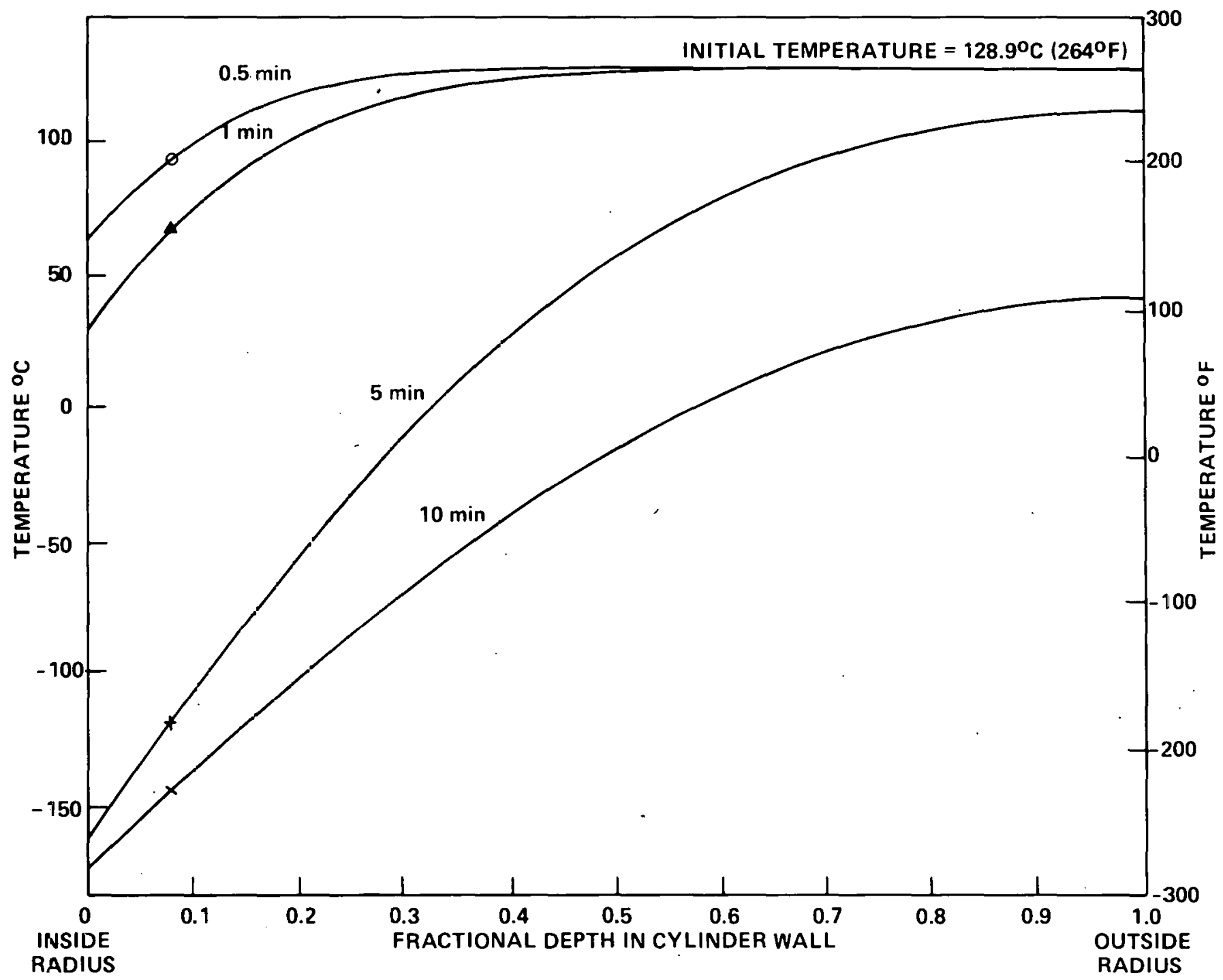

Figure 12. Temperature distributions calculated by HEATING 5 and used in the end effects.study 
Table 5

Data used in the free-end-effects study on cylinders

Temperature distribution designation

Nominal Axial Lengths 2L

$\begin{array}{rrr}\text { mm } & & \text { (in.) } \\ 406 & & (16) \\ 686 & & (27) \\ 914 & & (36) \\ 1219 & & (48)\end{array}$

Time in Transient

minutes

$$
\begin{aligned}
& 5 \\
& 5 \\
& 1,5,10
\end{aligned}
$$

$\underline{\text { Radii }}$

Inside

Outside
$343 \mathrm{~mm}$ (13.5 in.)

$495 \mathrm{~mm}$ (19.5 in.)

\section{Material Properties}

Young's modulus

$\begin{array}{lll}\text { Poisson's ratio } & \nu & 0.3 \\ \text { Coefficient of linear expansion } \alpha & 11.7 \times 10^{-6}{ }^{\circ} \mathrm{C}^{-1}\left(6.5 \times 10^{-6}{ }^{\circ} \mathrm{F}^{-1}\right)\end{array}$

Fractional crack depth a/w 0.5

Time in Transient (Minutes)

Displacement Method

Strain Energy Method

$\begin{array}{cccc}2-\mathrm{D} \mathrm{K} & \text { Values } & \mathrm{MPa} \cdot \mathrm{m}^{1 / 2}\left(\mathrm{ksi} \cdot \mathrm{in} .^{1 / 2}\right) \\ 0.5 & 1 & 5 & 10 \\ 21.6 & 37.4 & 180.2 & 149.4 \\ (19.7) & (34.0) & (164) & (136) \\ 19.56 & 38.3 & 181.2 & 150.4 \\ (17.8) & (34.9) & (164.9) & (136.9)\end{array}$


the material properties, and the 2-D plane strain $K_{I}$ values. These $K_{I}$ values were calculated using both the energy and the displacement methods. The results are very close to each other, an indication of the accuracy of either method.

The results of calculations for $914 \mathrm{~mm}$ (36 in.) length and three different times in the transient ( 1,5 , and 10 minutes) are shown in Figure 13. The 3-D $K_{I}$ values $\left(K_{I 3 D}\right)$ were normalized by dividing them by the $2-D K_{I}$ value $\left(K_{I 2 D}\right)$.

It appears that for this particular problem the end effects are largely independent of the time in the transient. Thus, calculations for other cylinder. lengths were made for a single time in the transient.

The results of analyzing different cylinder lengths are shown in Figure 14. The $K_{I}$ values near the mid-length are a11 greater than the corresponding 2-D value, except for the very short cylinder. In the shortest cylinders, the $\mathrm{K}_{\mathrm{I} 3 \mathrm{D}}$ values never attained the $\mathrm{K}_{\mathrm{I} 2 \mathrm{D}}$ values. For the longer cylinders, the $\mathrm{K}_{\mathrm{I} 3 \mathrm{D}}$ values exceeded $K_{I 2 D}$ for some portion of the cylinder length and then dropped rapidly to zero. The percentage of the cylinder. length with $\mathrm{K}_{I 3 \mathrm{D}}$ values within $\pm 15 \%$ of $\mathrm{K}_{\mathrm{I} 2 \mathrm{D}}$ was $23 \%, 47 \%, 67 \%$, and $73 \%$ for the $406,686,914$, and $1219 \mathrm{~mm}$ cylinders.

It may be worth noting that the free ends rotate inwards so that the ends appear to be concave, with the deepest point towards the inside radius (Figure 15). This is, of course, due to the inside being cooler than the outside, which tends to result in closing of the crack near the ends. In the 3-D 
DWG. NO. K/G-80-2162

(U)

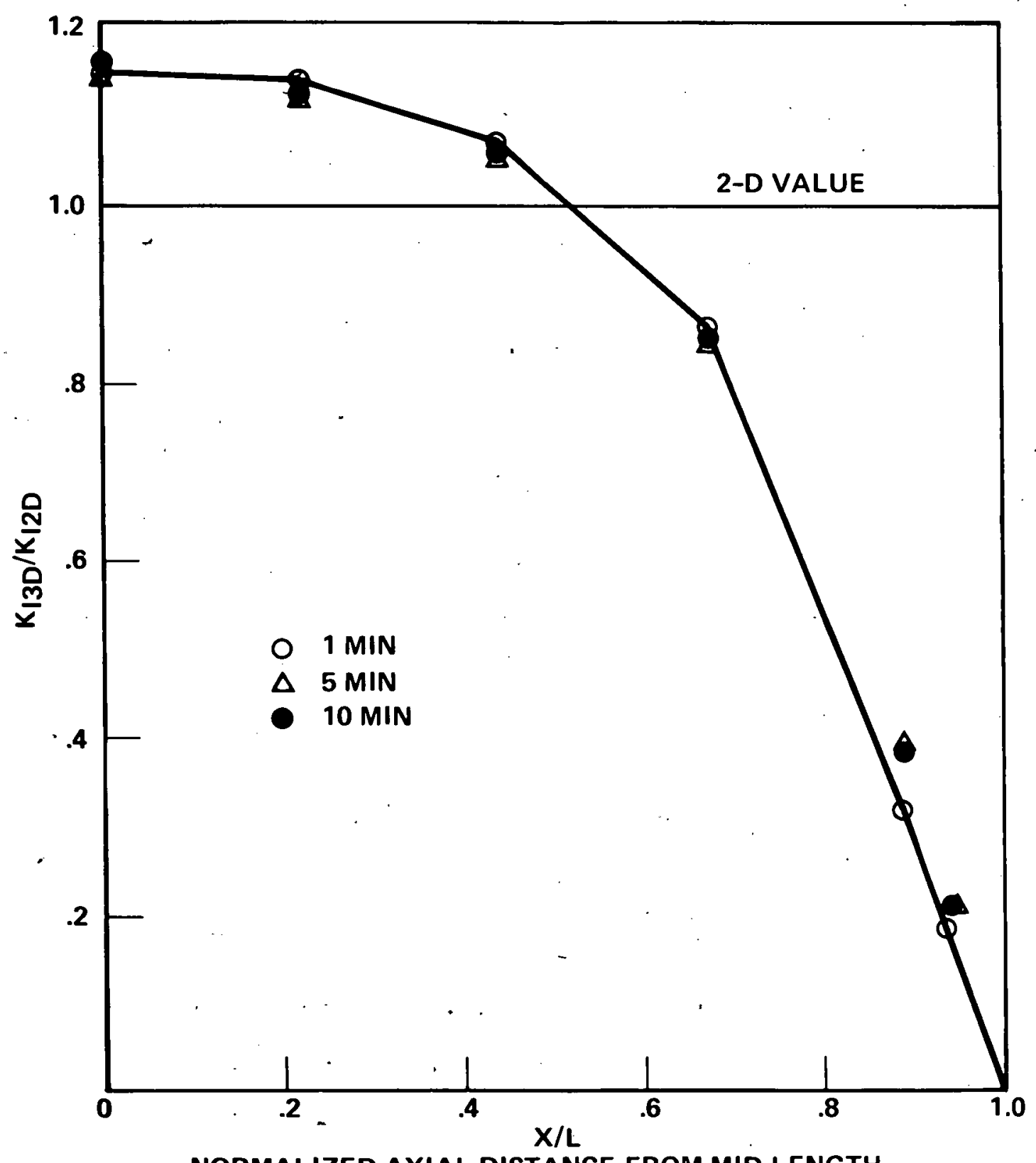

NORMALIZED AXIAL DISTANCE FROM MID-LENGTH

Figure 13. Variation of $K_{I}$ with distance from mid-length for different times in the transient for the $914 \mathrm{~mm}$ (36 in.) cylinder 


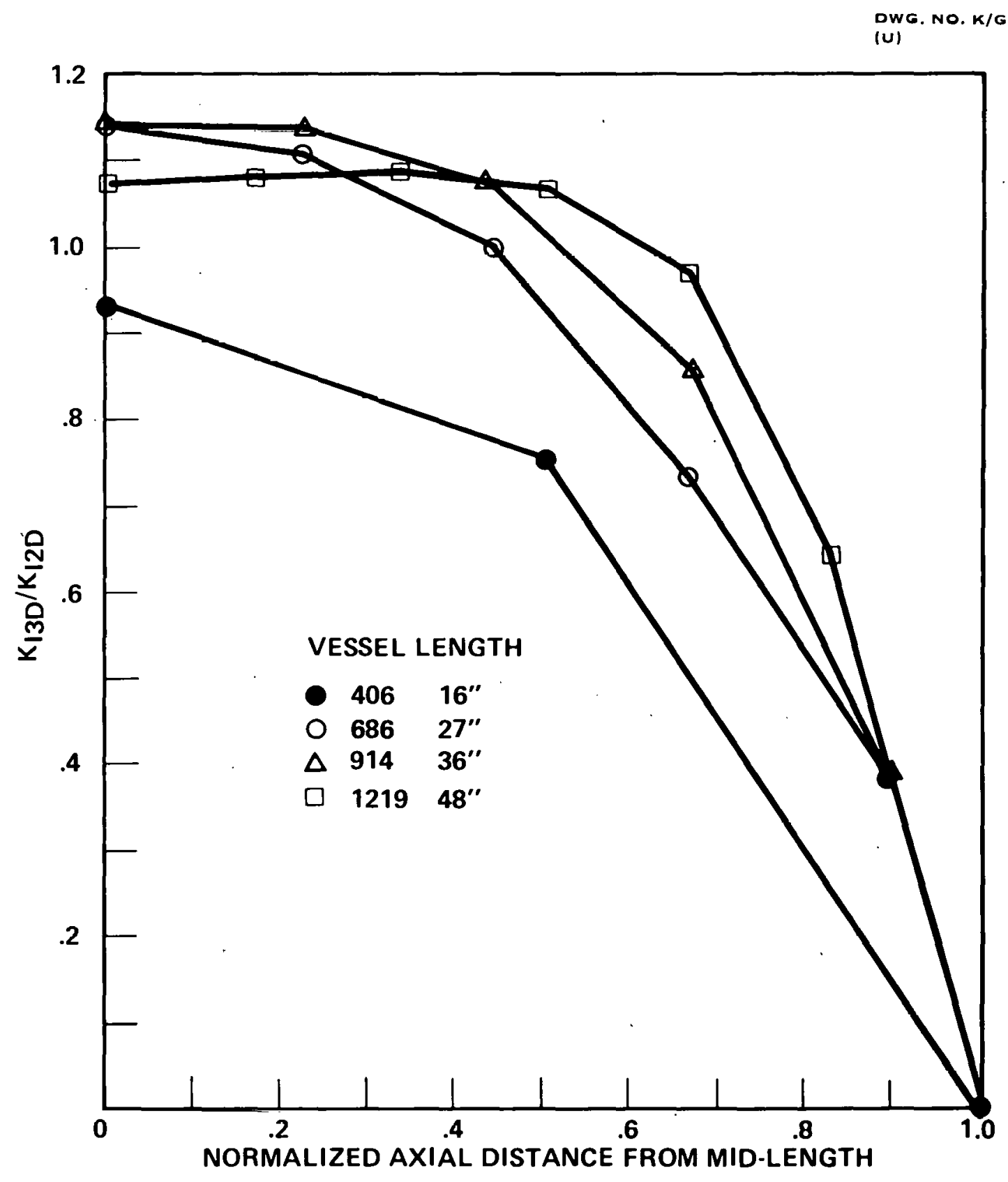

Figure 14. Variation of $\mathrm{K}_{\mathrm{I}}$ with axial distance from mid-length for different cylinder lengths 

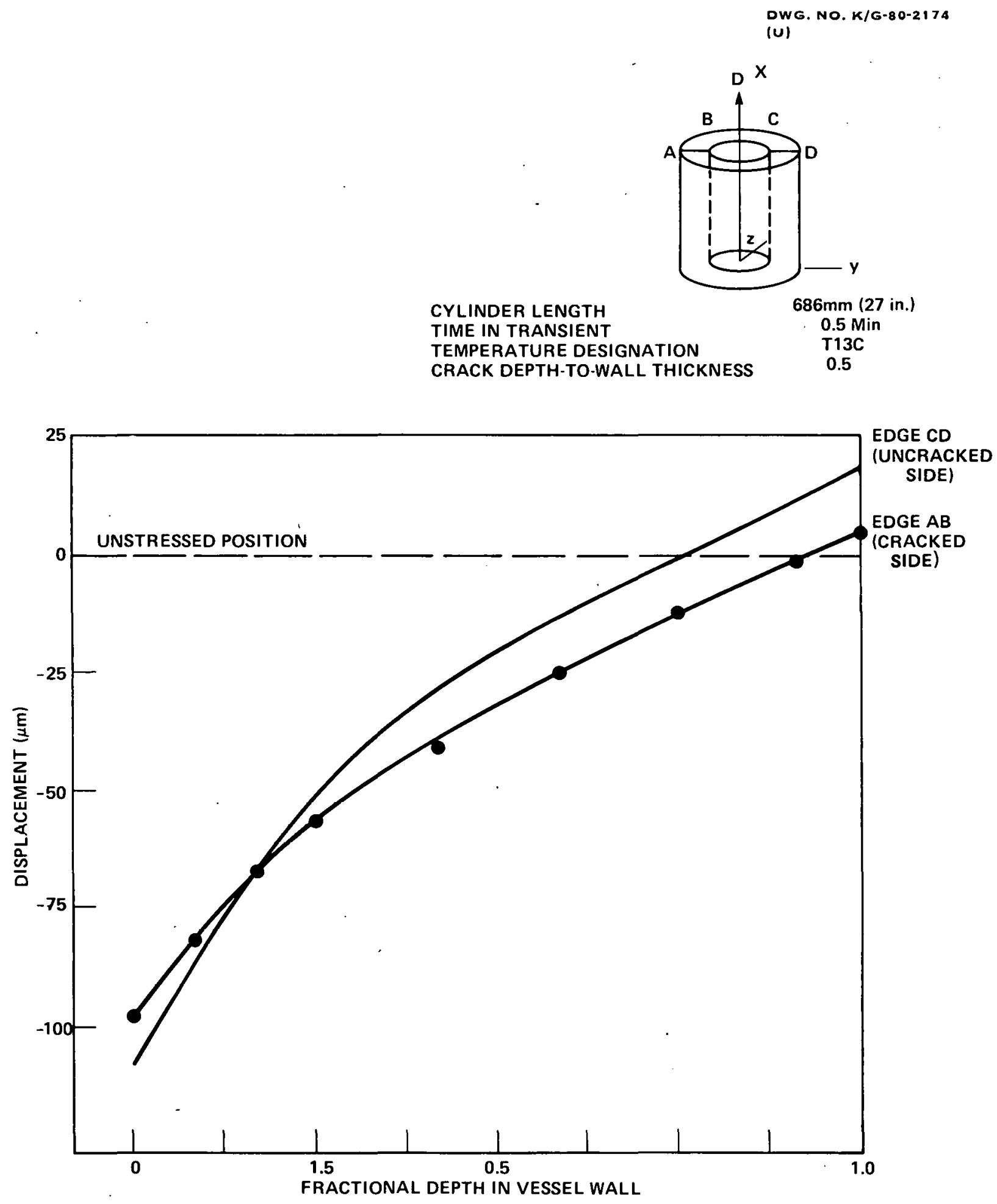

Figure 15. Axial displacements at the free end of radial lines on the plane of symmetry 
analysis, the nodes on the crack front were free to move and the two nodes at the end of the cylinder and closest to the crack root moved in such a way as to have "crossed" over the line of symmetry (see Figure 16). Such an anomalous behavior, of course, has no physical reality since the other face of the crack will prevent such an occurrence. This effect can be prevented by the use of crack elements, gap elements, etc. However, a simple stratagem was to fix a priori the nodes that had exhibited such a behavior in a previous analysis. This was tried out and had a negligible effect on the $\mathrm{K}_{\mathrm{I} 3 \mathrm{D}}$ values. The tendency of the nodes at the free ends and closest to the crack tip to close took place in all the cylinder lengths analyzed and, hence, the $\mathrm{K}_{\mathrm{I3D}}$ values at the free ends were assigned zero values.

\subsubsection{Analysis of the V-8 Cylinder}

Another example of the 3-D fracture mechanics analysis is that performed on a cylindrical vessel designated as $\mathrm{V}-8$. This vessel was tested in 1979 as a part of the ongoing HSST program, and full details may be found in Reference [24] with a summary in Reference [25]. It consists of an internally pressurized cylinder, closed at the ends, and with an external flaw.

Figure 17 gives the dimensions of the V-8 cylinder and the associated crack as modeled. Symmetry allowed the modeling of only one quarter of the cylinder. As explained in Appendix A, a 2-D mesh is produced from which the $3-D$ one is generated. Furthermore, the 2-D mesh itself is composed of two separate portions (coarse and fine) that are later merged together, as illustrated in Figure 18. 
DWG. NO. K/G-80-2172

(u)

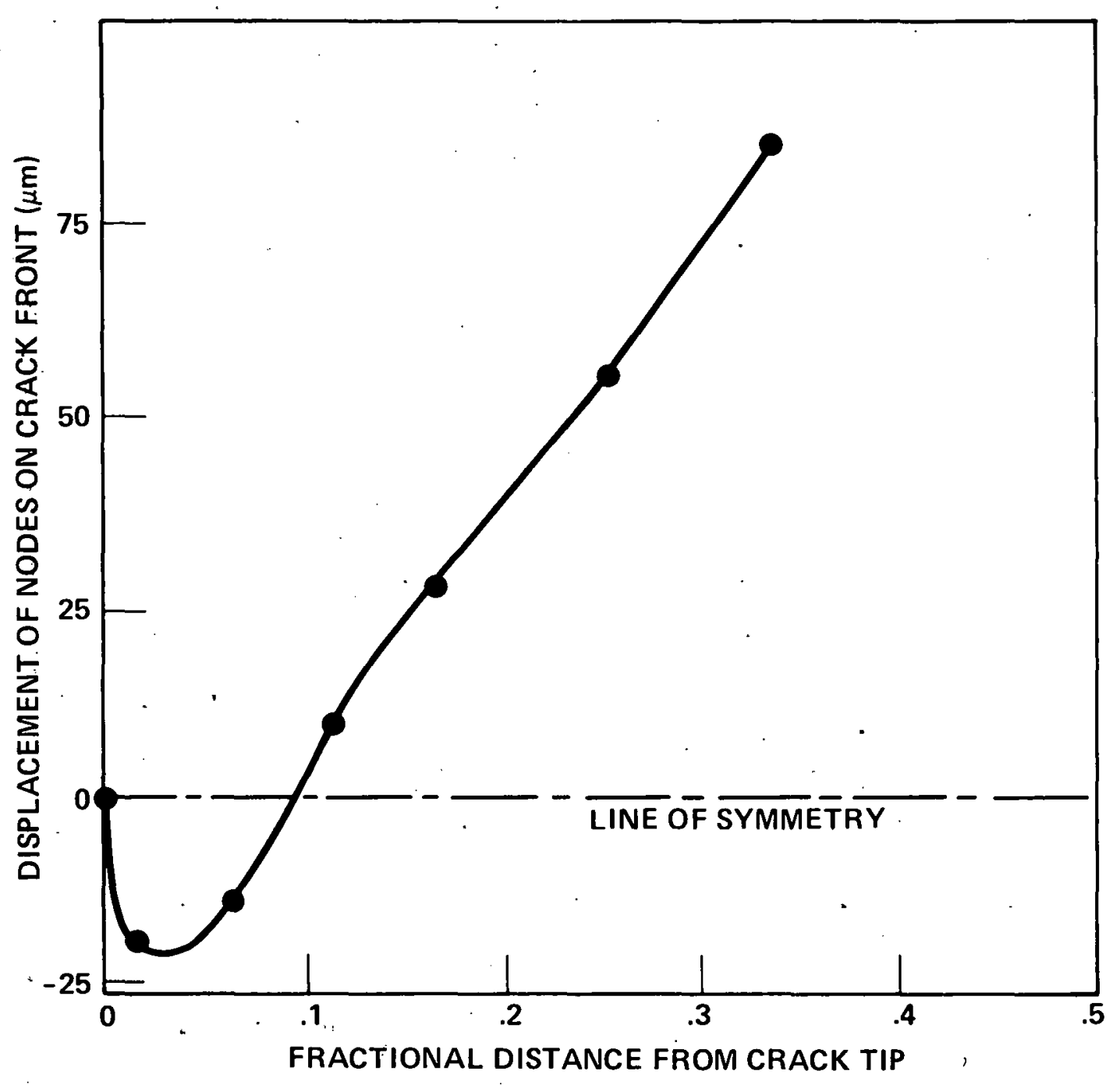

Figure 16. Anomaly in crack opening displacements near the free end 
DWG. NO. K/G-79-294 (U)
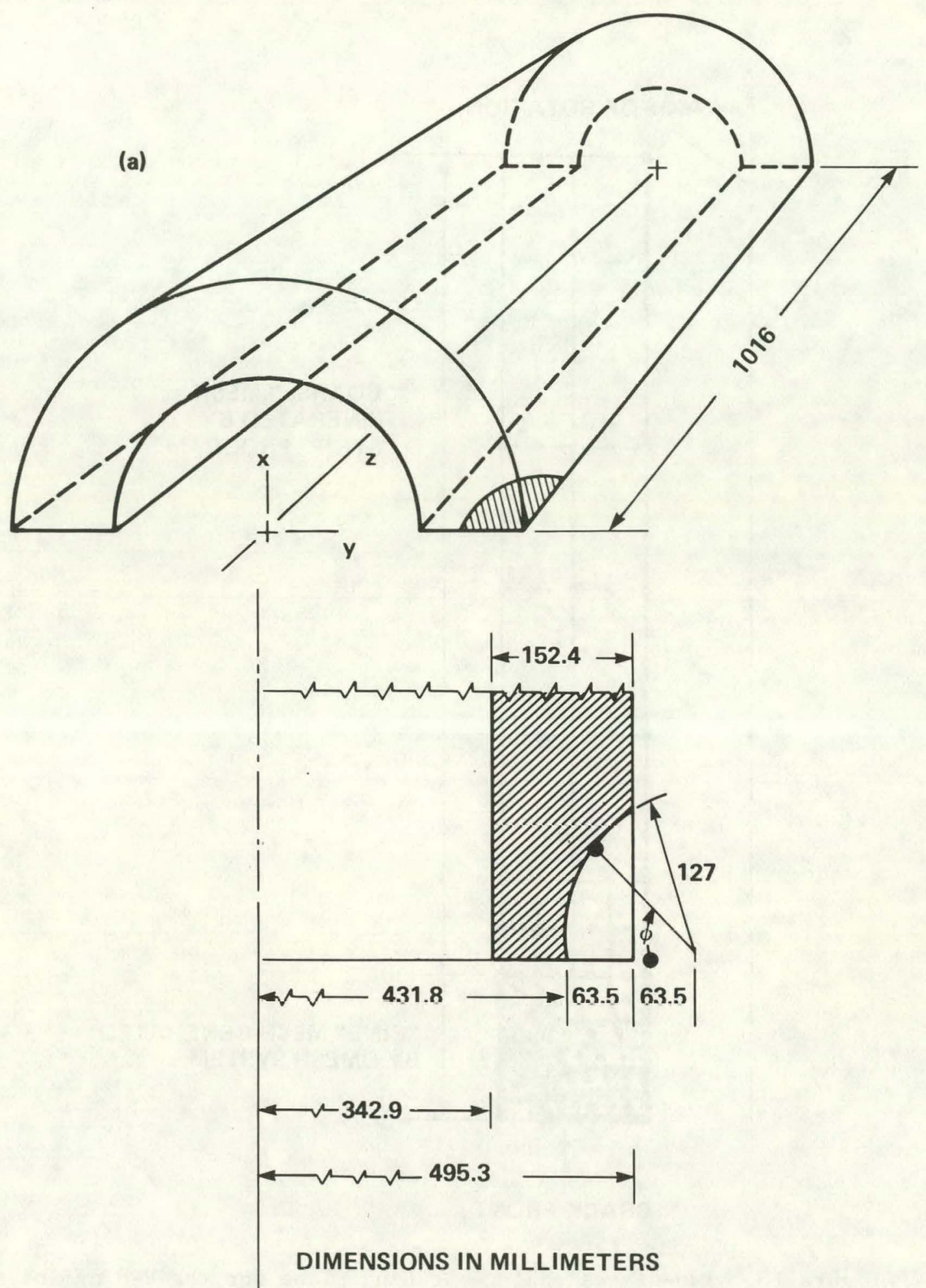

(b)

Figure 17. FE model used in the analysis of the V-8 cylinder: (a) quarter cylinder analyzed, (b) crack geometry 
DWG. NO. K/G-80-2175

(u)

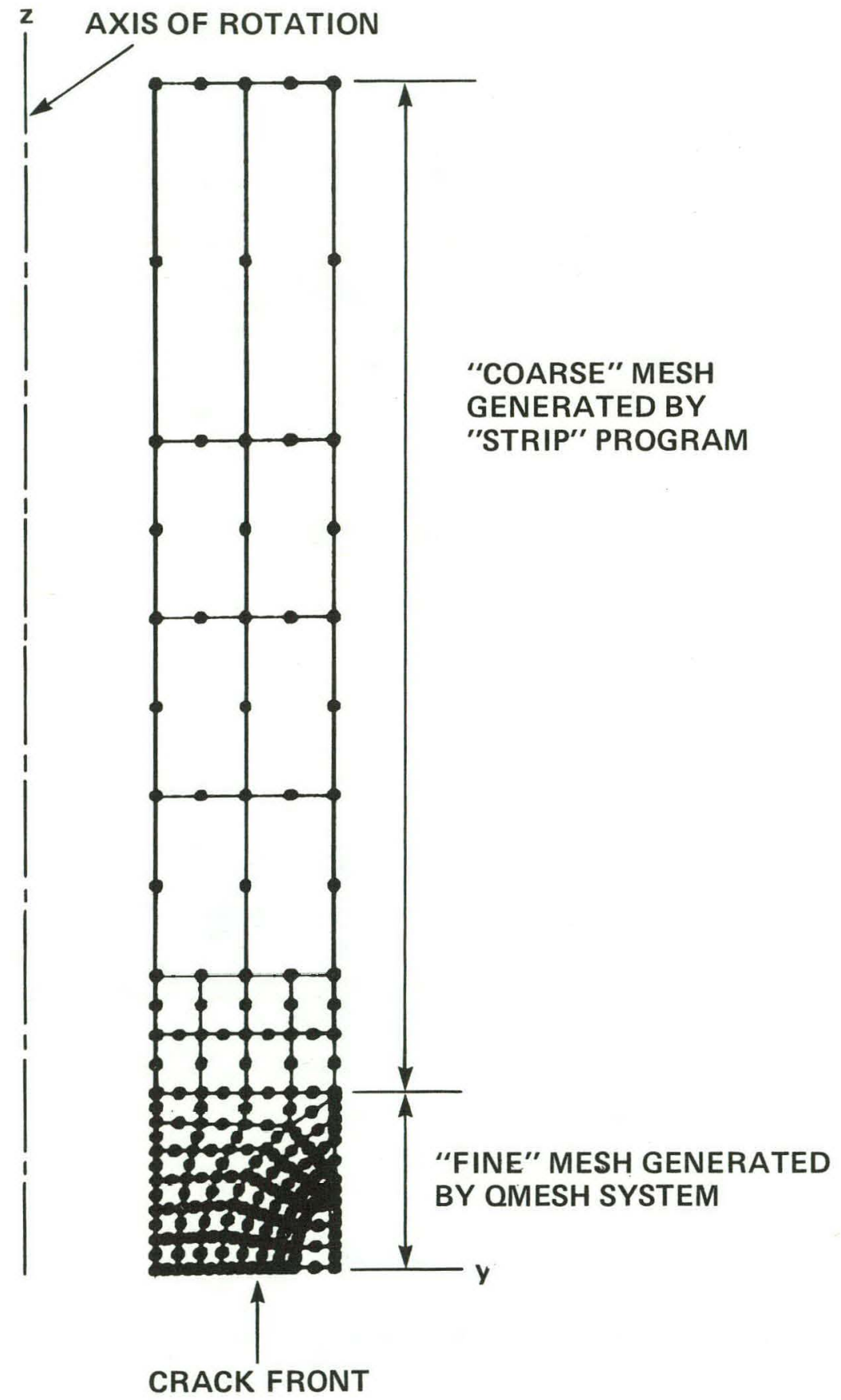

Figure 18. Two-dimensional generating plane for the V-8 cylinder analysis showing the "fine" and "coarse" mesh regions 
For the purpose of a convergence study, two FE models were analyzed in which the basic 2-D meshes of the cylinder wall differed in the "fine mesh" region (Figure 18) close to the flaw. The "coarse mesh" portion was the same for both meshes. The 2-D models of the fine mesh region are shown in Figures 19 and 20, and these are designated Mesh 1 and Mesh 2, respectively. Mesh 2 produced about 50\% more degrees of freedom (DOF) in the 3-D mesh. The 3-D meshes were generated from these 2-D meshes as described in the Appendix A. Figure 21 illustrates such a 3-D mesh generated from Mesh 1. The angles subtended by the elements in the circumferential direction and used to generate the 3-D meshes, the number of nodes, elements, DOF, etc., together with the computer resources required in the analyses are given in Appendix B. Under an internal pressure of $69 \mathrm{MPa}(10 \mathrm{ksi})$ the nodal displacement at the outside surface of the cylinder at the center of the crack for Mesh 1 and Mesh 2 were $99.5 \mu \mathrm{m}\left(3.92 \times 10^{-3}\right.$ in.) and $99.8 \mu \mathrm{m}$ (3.93 $\left.\times 10^{-3} \mathrm{in.}\right)$, respectively, a change of about $0.25 \%$. It was concluded that no significant benefit would be realized in analyzing the finer mesh.

The four analyses performed are summarlzed in Table 6; the resulting displacements normal to both the crack face and the crack front at various angles $\theta$ (Figure $17(\mathrm{~b})$ ) are given in Table 7. These displacements were used to calculate the $\mathrm{K}_{I}$ values given in Table 8 by means of the displacement method described in Chapter 2. These $K_{I}$ values were compared to those calculated by other methods [24, Table 4.6]. It appears that the $K I$ values calculated, by the methnd described above are accurate. 
DWG. NO. K/G-80-2167 (U)

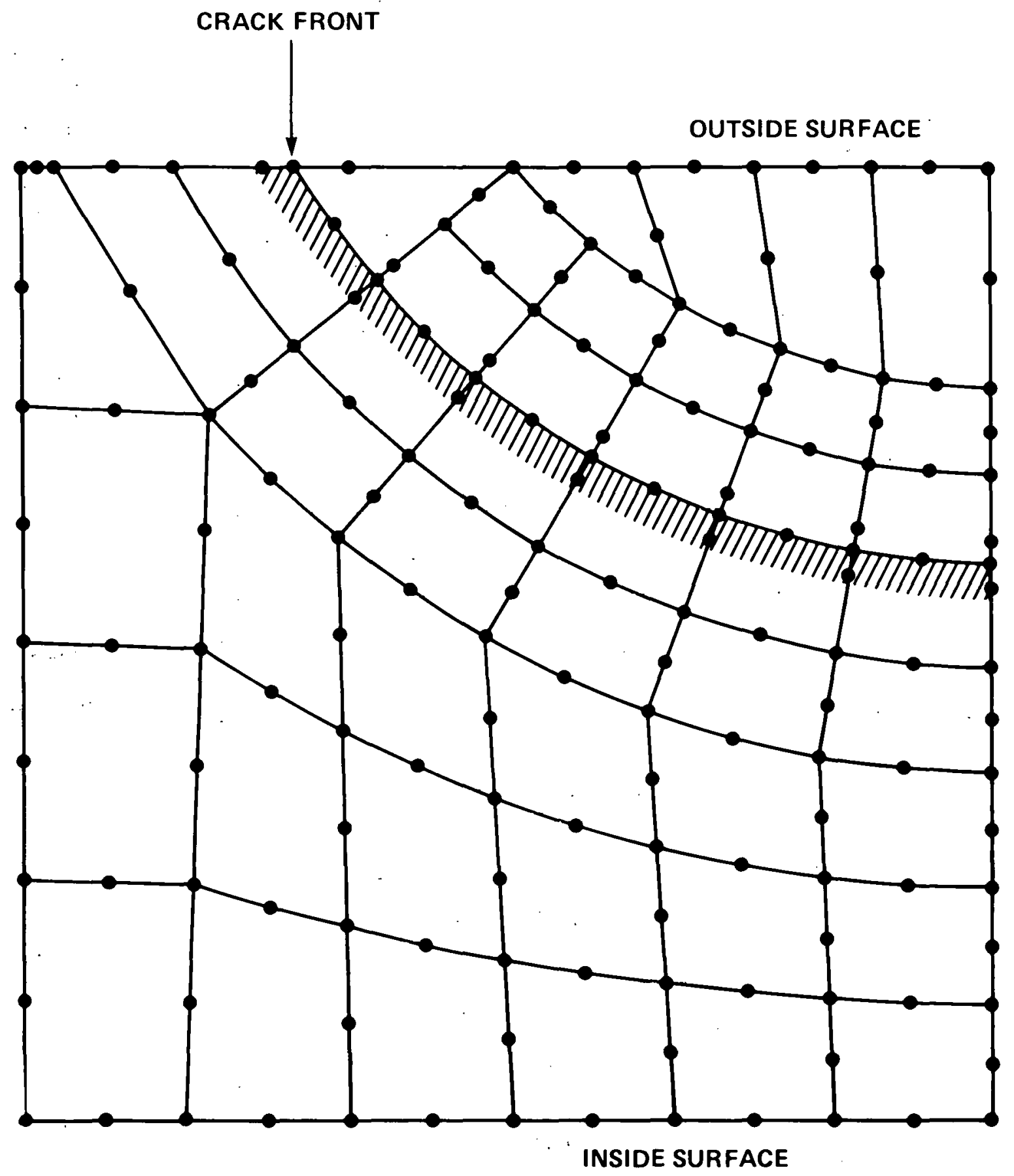

Figure 19. Two-dimensional "fine" mesh portion of the generating" plane (Mesh 1) for the V-8 cylinder 
DWG. NO. K/G-80-2169

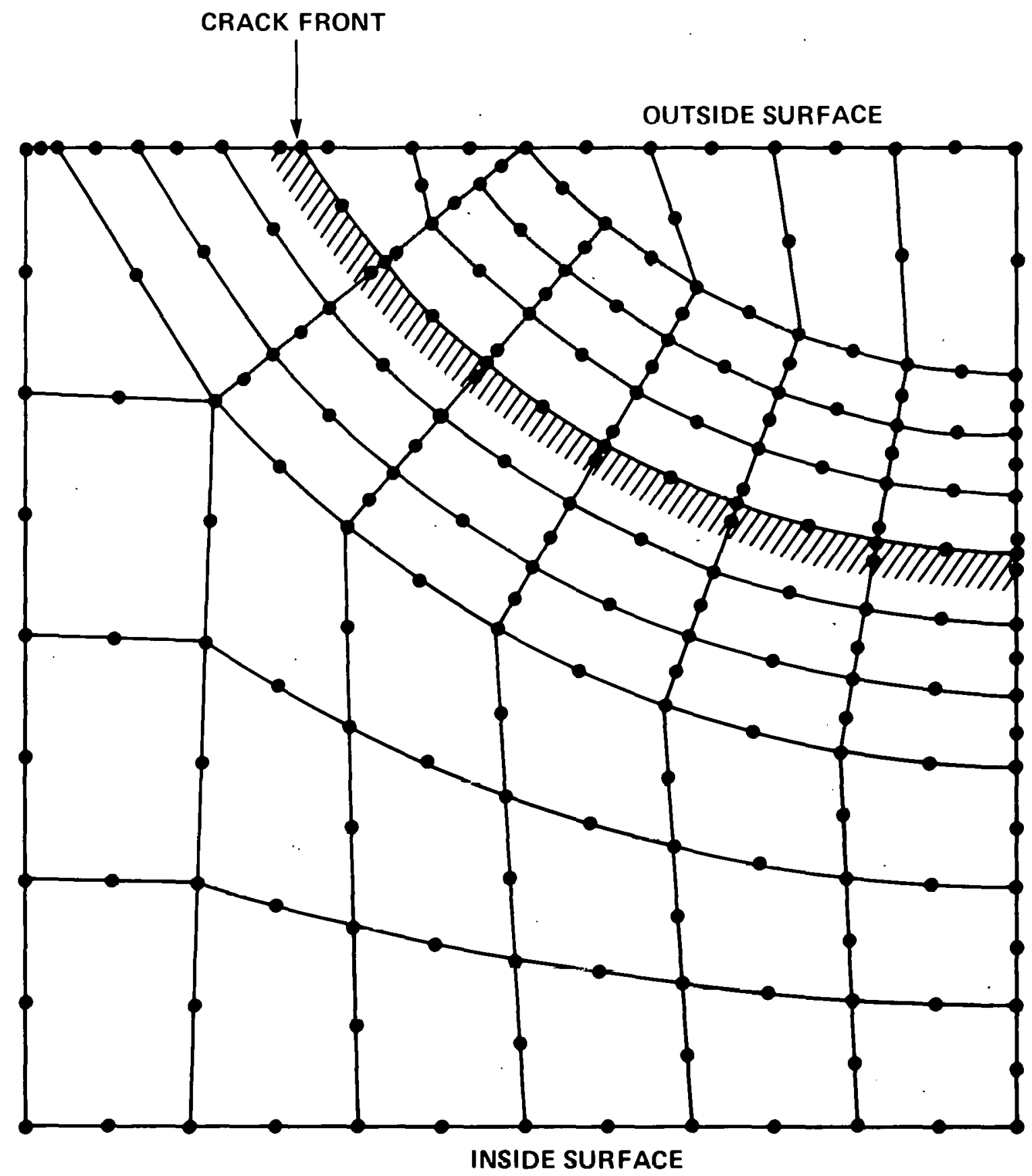

Figure 20. Two-dimensional "fine" mesh portion of the generating plane (Mesh 2) for the V-8 cylinder with more nodes than Mesh 1 


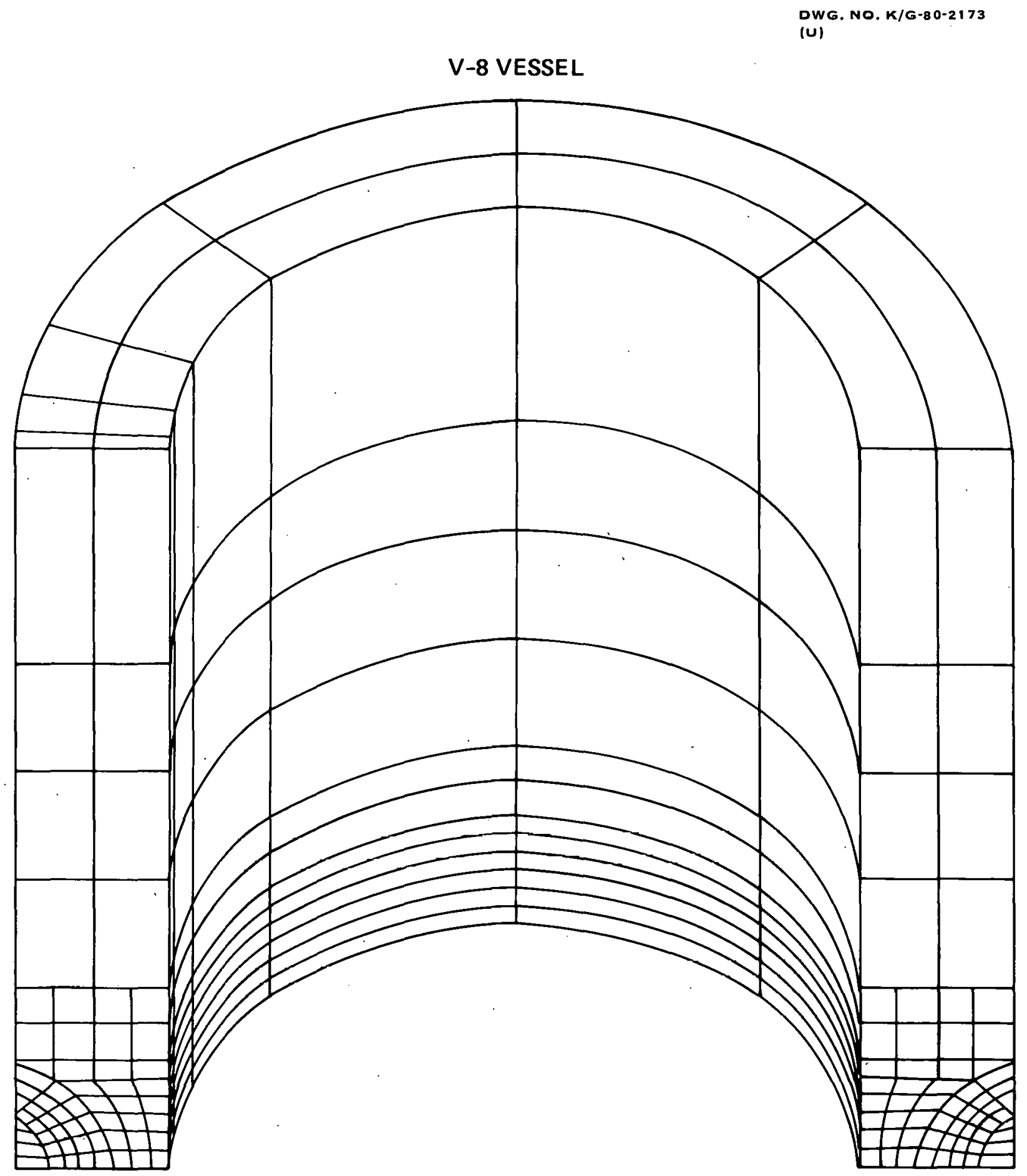

CRACK FRONT

Figure 21. Three-dimensional mesh generated from that shown in Figure 18 for the V-8 cylinder analysis. 
Table 6

Cases analyzed for V-8 test ${ }^{a}$

Young's Modulus

$\mathrm{E}=200 \mathrm{GPa}$

Poisson's Ratio

$v=0.29$

Case Number

1

2

3

4
Loading

Internal pressure $68.95 \mathrm{MPa}$

Ditto, using finer Mesh No. 2

Uniform Pressure on Crack Surface $68.95 \mathrm{MPa}$

Pressure on Crack surface varying linearly from $127.6 \mathrm{MPa}$ at the deepest point in the flaw corresponding to a radius of $431.8 \mathrm{~mm}$ to $255 \mathrm{MPa}$ at the outside radius of 495.3

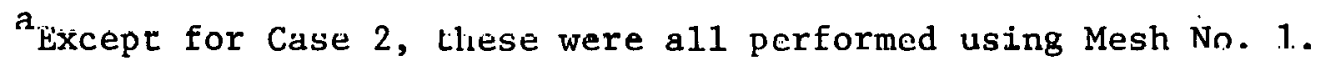


Table 7

Nodal displacements obtained from FE analysis of the V-8 cylinder for the four load cases

\begin{tabular}{|c|c|c|c|c|c|}
\hline \multicolumn{6}{|c|}{$\begin{array}{c}\text { Load Case } 1 \\
\text { Ințernal Pressure } 68.95 \mathrm{MPa} \text { with Mesh No. } 1\end{array}$} \\
\hline Node Designation & 2 & & 3 & & 4 \\
\hline $\mathrm{r} \mathrm{mm}$ & 14.10 & & 21.15 & & 28.19 \\
\hline Angle $\phi$ & \multicolumn{5}{|c|}{ Nodal Displacements $\mu \mathrm{m}$} \\
\hline 0 & 47.22 & & 57.58 & & 65.58 \\
\hline 10 & 47.09 & & 57.45 & & 65.46 \\
\hline 20 & 46.74 & & 57.05 & & 65.13 \\
\hline 30 & 46.08 & & 56.34 & & 64.59 \\
\hline 40 & 45.01 & & 55.22 & & 63.86 \\
\hline 50 & 42.47 & & 52.93 & & 62.89 \\
\hline \multicolumn{6}{|c|}{$\begin{array}{l}\text { Load Case } 2 \\
\text { Internal Pressure } 68.95 \mathrm{MPa} \text { and "Finer" Mesh (Mesh No. 2) }\end{array}$} \\
\hline$\underline{\text { Node Designation }}{ }^{a}$ & 2 & 3 & 4 & 5 & 6 \\
\hline $\mathrm{r} \mathrm{mm}$ & 9.53 & 14.10 & 18.80 & 23.50 & 28.19 \\
\hline Angle $\phi$ & \multicolumn{5}{|c|}{ Noda1 Displacements $\mu \mathrm{m}$} \\
\hline 0 & 38.40 & 47.63 & 54.58 & 60.50 & 65.86 \\
\hline 10 & 38.30 & 47.47 & 54.43 & 60.38 & 65.74 \\
\hline 20 & 37.95 & 47.09 & 54.03 & 59.99 & 65.41 \\
\hline 30 & 37.31 & 46.38 & 53.31 & 59.33 & 64.90 \\
\hline 40 & 36.32 & 45.24 & 52.22 & 58.42 & 64.24 \\
\hline 50 & 33.99 & 43.13 & 50.67 & 57.48 & 64.29 \\
\hline
\end{tabular}


Table 7 (Contd.)

\section{Load Case 3}

Crack Surface Pressurized with a Uniform Pressure of $68.95 \mathrm{MPa}$

\begin{tabular}{|c|c|c|c|}
\hline Node Designation $^{a}$ & 2 & 3 & 4 \\
\hline $\mathrm{r} \mathrm{mm}$ & 14.10 & 21.15 & 28.19 \\
\hline Angle $\phi$ & \multicolumn{3}{|c|}{ Nodal Displacements $\mu \mathrm{m}$} \\
\hline 0 & 23.61 & 28.96 & 33.20 \\
\hline 10 & 23.59 & 28.93 & 33.17 \\
\hline 20 & 23.54 & 28.88 & 33.15 \\
\hline 30 & 23.40 & 28.73 & 33.07 \\
\hline 40 & 23.11 & 28.42 & 32.94 \\
\hline 50 & 21.98 & 27.38 & 32.54 \\
\hline
\end{tabular}

Load Case 4

Crack Surface Pressurized with a Linearly Varying Pressure, 127.6 $\mathrm{MPa}$ at Crack Root and $255.1 \mathrm{MPa}$ at Outer Surface

Nude Designation $^{a}$

r $\mathrm{mm}$

Angle $\phi$

0

10

20

30

40

50

$\underline{2}$

14.10

Nodal Displacements $\mu \mathrm{m}$

65.13

65.66

67.23

69.55

72.06

71.96
82.19

97.08

82.78

84.51

87.02

89.79

90.09

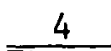

28.19

${ }^{a}$ These node designations are indicated in Figure 3. Displacements at node 1 are inaccurate as mentioned in text. 
Table 8

$\mathrm{K}_{\mathrm{I}}$ in $\mathrm{MNm}^{-3 / 2}$ as a function of $\phi^{\mathrm{a}}$

Angle $\phi$

\begin{tabular}{|c|c|c|c|c|c|c|}
\hline \multirow[b]{2}{*}{ Case Load } & \\
\hline & $0^{\circ}$ & $10^{\circ}$ & $20^{\circ}$ & $30^{\circ}$ & $40^{\circ}$ & $50^{\circ}$ \\
\hline 1 & 55.2 & 55.5 & 54.9 & 53.5 & 52.0 & 46.4 \\
\hline 2 & 55.7 & 55.9 & 55.7 & 53.7 & 52.2 & 47.4 \\
\hline 3 & 48.3 & 48.3 & 47.9 & 47.7 & 47.5 & 43.2 \\
\hline 4 & 71.4 & 71.9 & 73.8 & 76.7 & 80.1 & 78.2 \\
\hline
\end{tabular}

${ }^{a} 60^{\circ}$ is the point at the free surface. 


\section{DISCUSSIONS AND CONCLUSIONS}

The energy and stress/displacement methods used to calculate $\mathrm{K}_{\mathrm{I}}$ in 2- and 3-D problems have been documented in this report. These methods have been used for solving problems of interest to the HSST program. The stress/displacement methods are based upon the near field equations relating the stresses and displacements to the stress intensity factors. Some approximation is involved in the use of these equations, namely, the higher order terms are neglected since these terms are, in general, unknown. The term used is valid only in the "vicinity" of the crack. It was therefore important to validate the method through the solution of test problems with closed form solutions. The resulting methodology was used successfully for the solution of both 2- and 3-D problems, some of which have been presented in this report.

Energy methods described in this report do not involve such an approximation at the theoretical level. The approximations made are those associated with the numerical methods used and the resulting errors apply to both energy and stress/displacement methods. As such, energy methods are more reliable and accurate than stress/displacement methods. Their main limitation is the practicability of their application to 3-D problems.

This report also discussed the errors that may arise if the strain energy is used in place of the potential energy in problems where both mechanical and thermal loads occur.

Examples of 2- and 3-D problems solved have been presented. For 2-D problems, these have been solved by both energy and displacement methods, and the results of either method compare well with each other. 
This indicates that the methods as applied to the type of problems described in this report are accurate and reliable.

One of the errors that may arise in the FE method is that associated with a sufficiently fine mesh, especially in the vicinity of steep stress gradients such as those associated with cracks. Some assurance that an adequately fine mesh was used has been obtained by means of limited convergence studies in which the same problem was solved with two meshes, one of which had more degrees of freedom than the other. No significant change in the results was observed. The energy methods as implemented in the FMECH code use a fournoded quadrilateral, and the mesh in the crack region is fine enough to allow the depth of the crack to be changed by the small amount $\Delta A$ by means of releasing the node at the crack root. This method was preferred to altering the coordinates of crack root node by a small amount to achieve the same purpose because altering the coordinates will distort the two elements sharing that node with a possible loss in accuracy in that region. The stress/displacement method uses an eight-noded 1/4-point element. In terms of computer resources, the eight-noded element is more efficient than a four-noded element. However, the total effort required to compute $\mathrm{K}_{I}$ using the stress/displacement method is more than that required for the energy method since the former requires some manual effort. However, for the 3-D problems the stress/displacement method has proven useful since it is easily implemented if a suitable FE code is available and once the required input data is prepared.

In conclusion, each of the methods discussed in this report have their advantages and limitations, but within these limitations both methods are capable of yielding $K_{I}$ values within about $\pm 5 \%$ accuracy. 


\section{REFERENCES}

1. Tada, H., P. Paris and G. Irwin, Stress Analysis of Cracks Handbook, Del Research Corp., Providence, Rhode Island, 1973.

2. Besuner, P. M. and W. R. Caughey, "Comparison of Finite Element and Influence Function Methods for Three-Dimensional Elastic Analysis of Boiling Water Reactor Feedwater Nozzle Cracks," NP-261, Electric Power Research Institute, November 1976.

3. Cruse, T. A. and W. VanBuren, "Three-Dimensional Elastic Stress Analysis of a Fractured Specimen with an Edge Crack," Int. J. Fract. Mech., Vol. 7, No. 1, March 1971.

4. Zienkiewicz, 0. C., The Finite Element, 3 Ed., McGraw-Hill, 1977.

5. Griffith, A. A., "The Phenomena of Rupture and Flow in Solids," Phil. Trans. Royal Soc. of London, Vo1. 221, 1921, pp. 163-198.

6. Irwin, G. R. and J. Kies, "Fracturing and Fracture Dynamics," Welding Jour. Res. Supp1., Vol. 31, 1952, pp. 95s-100s.

7. Orowan, F., "Fundamentals of Brittle Behavior of Metals," Fatigue and Fracture of Metals, John Wiley \& Sons, 1952, pp. 139-167.

8. Irwin, G. R., "Analysis of Stress and Strains Near the End of a Crack Traversing a Plate," J. Appl. Mech., Vol. 24, 1957, pp. 361-364.

9. Iskander, S. K., "The Calculation of Stress Intensity Factors in Thick Cylinders sibjerted to Transient Temperature Gradients by the Finite Element Method," K/CSD/TM-2, Union Carbide Corporation, Nuclear Division, Oak Ridge, Tennessee, 1976.

10. Hellen, T. K, "On the Method of Virtual Crack Extensions," Int. J. Num. Meth. Eng., Vo1. 9, 1975, pp. 187-207.

11. Sokolnikoti, 1. S., Mathemar1cal Theory of Elasticity, 2nd Ed., McGraw-Hil1, 1956.

12. Kobayashi, A. S., Experimental Techniques in Fracture Mechanics, Society for Experimental Stress Analysis, 1973, Chapter 2, "Fracture Mechanics."

13. Wilkinson, J. H., The Algebraic Eigenvalue Problem, Oxford University Press, 1965.

14. Shah, R. C. and A. S. Kobayashi, "On the Parabolic Crack in an Elastic Solid," Eng. Fract. Mech., Vol. 1, 1968, pp. 309-325. 
15. Barsoum, R. S., "On the Use of Isoparametric Finite Elements in Linear Fracture Mechanics," Int. J. Num. Meth. Eng., Vo1. 10, 1976, pp. 25-37.

16. Henshell, R. D. and K. G. Shaw, "Crack Tip Finite Elements are Unnecessary," Int. J. Num. Meth. Eng., Vol. 9, 1975, pp. 495-507.

17. Isida, M., "Effect of Width and Length on Stress Intensity Factors of Internally Cracked Plates Under Various Boundary Conditions," Int. J. Fract. Mech., Vol. 7, 1971, pp. 301-316.

18. Bathe, Klaus-Jurgen, "ADINA - A Finite Element Program for Automatic Dynamic Incremental Nonlinear Analysis," Report 82448-1, Acoustics and Vibration Laboratory, Mechanical Engineering Department, MIT, Cambridge, Massachusetts.

19. Cheverton, R. D. and S. E. Bolt, "Pressure Vessel Fracture Studies Pertaining to a PWR LOCA-ECC Thermal Shock: Experiments TSE-3 and TSE-4 and Update of TSE-1 and TSE-2. Analysis," ORNL/NUREG-22, Oak Ridge National Laboratory, Oak Ridge, Tennessee, December 1977.

20. Sneddon, I. N. and J. T. Welch, "A Note on the Distribution of Stresses in a Cylinder Containing a Penny-Shaped Crack," Int. J. Eng. Sci., Vol. 1, 1963, pp. 411-419.

21. Rooke, D. P., Compendium of Stress Intensity Factors, H. M. Stationery off., London, 1976.

22. Boley, B. A. and J. H. Weiner, Theory of Thermal Stresses, John Wiley \& Sons, 1967.

23. Turner, W. D., et al. "HEATING5 - An IBM 360 Heat Conduction Program," ORNL/CSD/TM-15, Oak Ridge National Laboratory, Oak Ridge, Tennessee, 1977.

24. Bryan, R. H., et a1., "Test of 6-in. Thick Pressure Vessels, Series 3: Intermediate Test Vessel V-8," ORNL/NUREG-58, Oak Ridge National Laboratory, Oak Ridge, Tennessee, December 1979.

25. Bryan, R. H., et al., "Test of Thick Vessel with a Flaw in Residual Stress Field," 79-PVP-29, ASME PVP Conference, San Francisco, California, June 25-29, 1979.

26. Iskander, S. K., "A Two-Dimensional Plotting Code and Some Useful Two- and Three-Dimensional Mesh Generation Programs for Isoparametric Finite Elements," in preparation.

27. Jones, R. E., "QMESH: A Self-Organizing Mesh Generation Program," SLA-73-1088, Sandia Laboratories, Albuquerque, New Mexico, July 1974. 


\section{$63 / 64$}

28. Gibbs, N. E., W. G. Poole, Jr. and P. K. Stockmeyer, "An Algorithm for Reducing the Bandwidth and Profile of a Sparse Matrix," SIAM J. Numer. Anal., Vo1. 13, No. 2, April 1976.

29. Hellen, T. K., "Numerical Integration Considerations in Two and Three Dimensional Isoparametric Finite Elements," The Mathematics of Finite Elements and Applications II MAFELAP 1975, Academic Press, 1976.

30. Hellen, T. K., "On Special Isoparametric Elements for Linear Elastic Fracture Mechanics," Inst. J. for Num. Meth. in Eng., Vol. 11, No. 1 ,

31. Chan, S. K., I. S. Tuba and W. K. Wilson, "On the Finite Element Method in Linear Fracture Mechanics," Eng. Fract. Mech., Vol. 2, 1970, pp. 1-17. 
$65 / 66$

APPENDICES 
APPENDIX A

FINITE ELEMENT MESH GENERATION AND PROFILE REDUCTION

1. Mesh Generation

One important task (in fact, one of the most time-consuming ones in $\mathrm{FE}$ modeling) is that of mesh generation. A large number of codes were written, others acquired and implemented, to facilitate this task. For the cases described in this report, the geometry of the problem allows 3-D meshes to be generated from 2-D ones. By rotating the 2-D mesh, such as that shown in Figure 18 about an axis lying in its plane, a 3-D one may be obtained (Figure 21). Similarly, by propagating a 2-D one, such as that shown in Figure 8, in a direction normal to its plane, the 3-D mesh shown in Figure 9 is produced.

The mesh generating effort may be conveniently divided into two tasks. The first will be termed the "2-D level" and consists of generating the 2-D mesh. The second task, the "3-D level" one, comprises taking the 2-D mesh and producing from it the 3-D mesh.

At the 2-D level, the most important task was the coding of a mesh plotting program and implementing it on the time-sharing PDP-10 system [26]. All the 2-D plots shown in this report were produced by this package. It is capable of plotting the whole structure or, by means of user-defined coordinate limits, it can plot certain areas of the mesh thereby "zooming" on detailed areas. The node and element numbers may be displayed or suppressed.

This allows the analyst to generate and view the mesh. If it is deemed unsatisfactory, the whole process may be repeated. A satisfactory 
mesh may be produced in less than an hour. A similar process, when attempted in a batch mode, would take several days to complete.

Generation of the 2-D models of cylinders is accomplished by means of the GEN8 code [26], producing semicircular annuli similar to that shown in Figure A.1(a). The number of elements in the radial and circumferential directions, geometric progression factors for both these directions, and the inside and outside radii are the input parameters. Strips such as that shown in Figure A. 2 have been useful in the modeling process. The centrally cracked strip and the coarse mesh portion of the V-8 cylinder model (both mentioned earlier in this report) as well as many others have been generated by the "STRIP" code [26]. This allows the user to define the number of elements horizontally and vertically as well as their dimensions. The number of horizontal elements may be doubled in number as the mesh is generated vertically down, with a onetime transition from four to five elements possible. This allows a mesh to be produced that can be made finer in regions of high stress gradients. A third code "MERGE" [26] swaps any two elements designated by the user with a so-called singularity block (Figure A.1(b) and A.2(b)) to produce automatically the $1 / 4$-point singularity elements surrounding the crack tip (Figures A.1(c) and A.2(c)).

The "QMESH" system [27], a very useful tool that generates more complex 2-D meshes, was implemented and used to generate the meshes used, for example, in the centrally cracked circular bar and the V-8 cylinder. Being a general-purpose package, it is, however, too unwieldy to use for simple meshes such as those mentioned above and local mesh refinements are difficult to accomplish. 


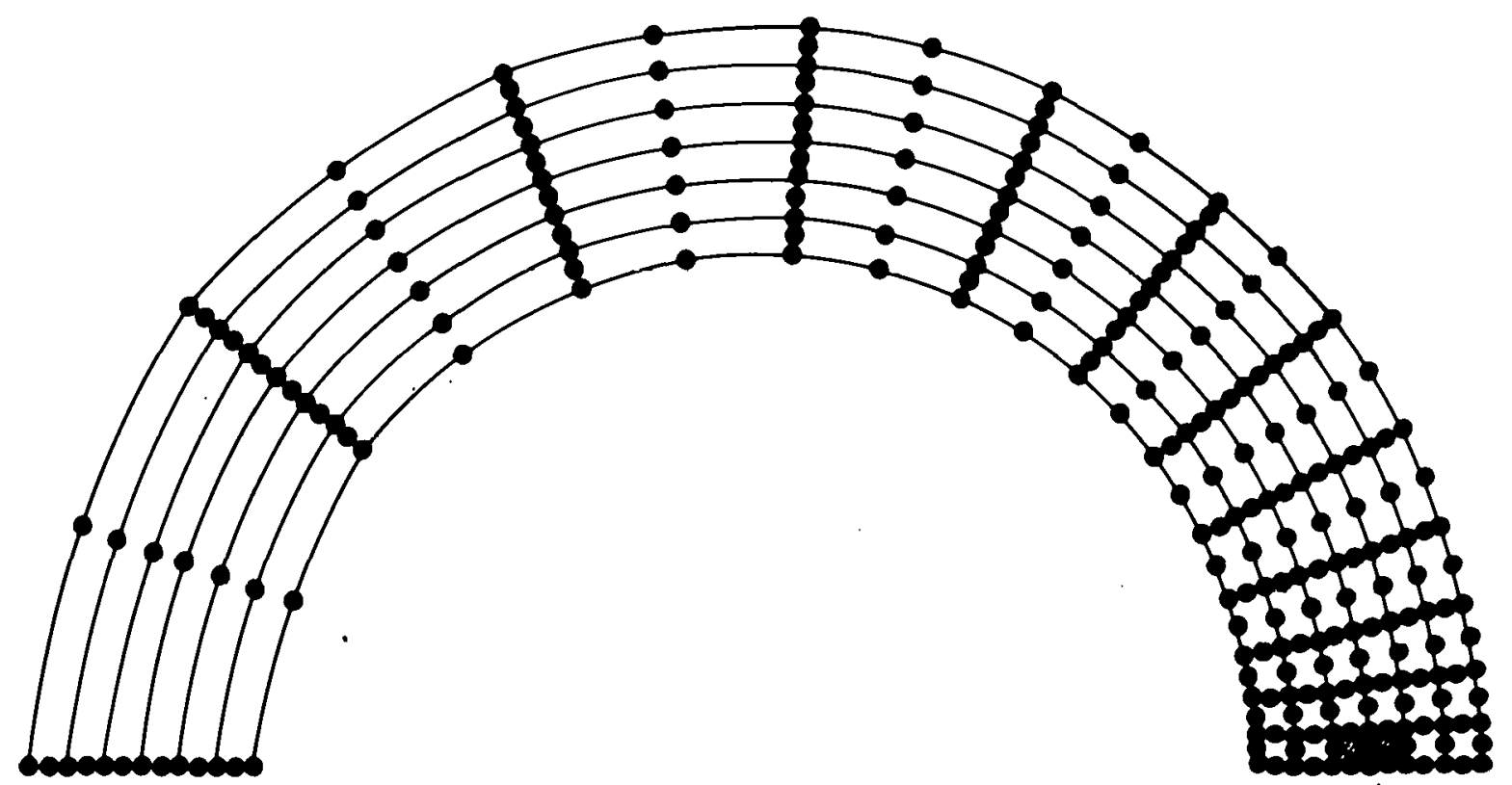

(a)
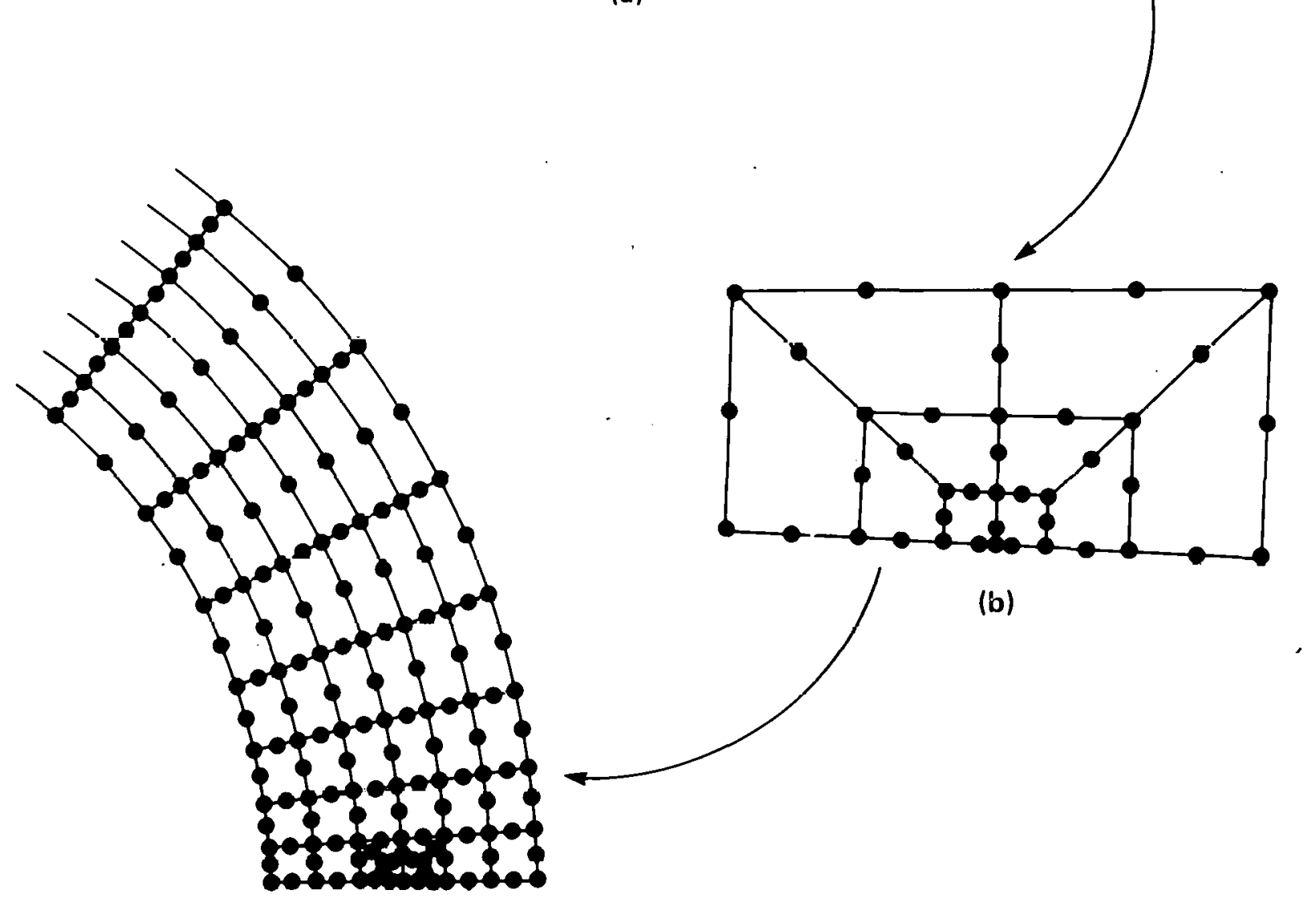

(c)

Figure A.1. (a) Typical finite element mesh generated by the "GEN8" code. The singularity block (b) is then "merged" into' a pair of elements, e.g., those shown shaded in (a) to produce a model with a "crack" located at $a / w=0.5$, a portion of which is shown in (c) 

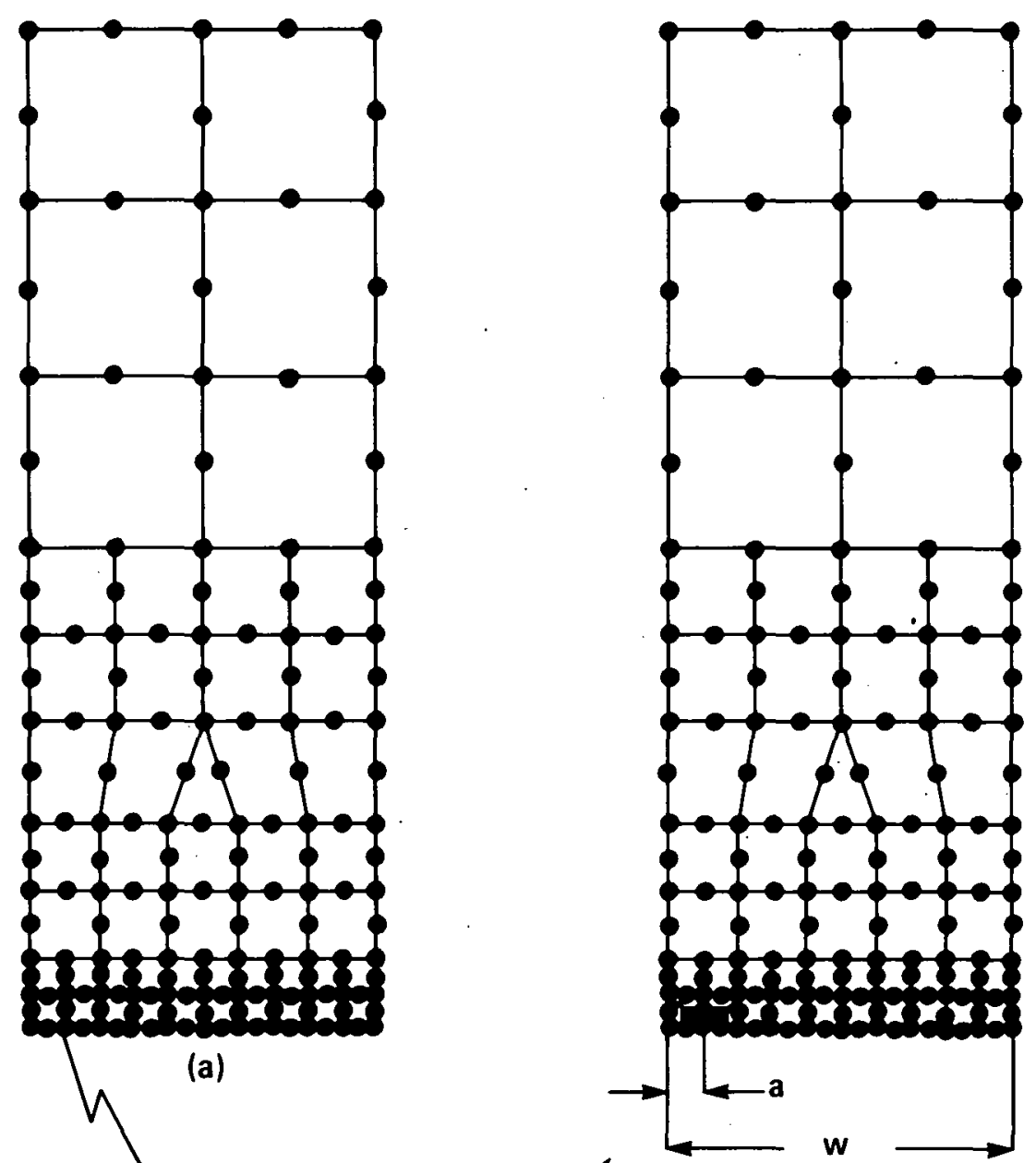

(c)

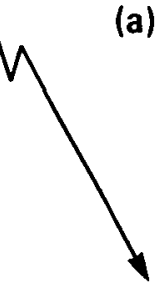

(a)

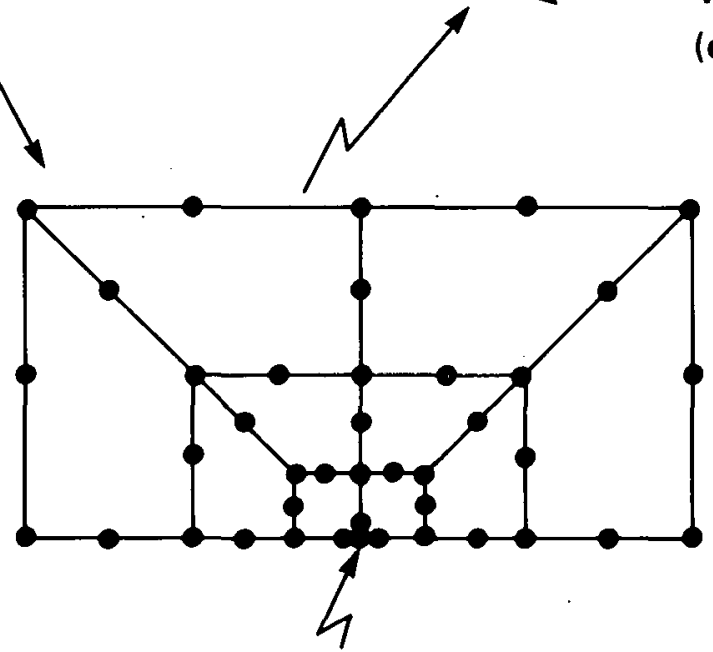

CRACK ROOT

(b)

Figure A.2. (a) Example of type of mesh produced by STRIP code, and the incorporation of the singularity block (b) by the MERGE code to produce the mesh (c) used in numerical experiments on the center cracked or edge notched bars. Note that the singularity block can be relocated at different positions giving in this case nine "specimens" with $a / w=0.1$ through $a / w=0.9$ 
The generation of 3-D meshes from any of the above 2-D.meshes is accomplished by means of the $3-D$ and $V-8$ codes [26]. These codes also produce output that allows the user to relate the $3-D$ models to the 2-D ones. It also produces output identifying element faces in a particular area, if desired. Such output would be useful in the FE analysis of pressure inaded structures, e.g., the V-8 cylinder analysis mentioned in Chapter 3.

The concept of the subdivision of a major task into smaller ones has allowed a considerable amount of modularity in coding the various programs. Furthermore, it permits the user to monitor the satisfactory completion of one task before proceeding to the next one. A major drawback of the 3-D mesh generation codes described above is that the whole mesh is penalized by the presence, at the 2-D level, of the fine mesh in the crack region which is then propagated into the third dimension. It is more efficient to implement a merging scheme at the 3-D level similar to that shown fin Figures A.1 and A.2 [OI 2-D meshes. For 3-D meshes, the process is accomplished in three steps. The first consists of generating a relatively coarse mesh for the 3-D structure to be analyzed. Then, a "block" containing the finer mesh required to adequately mode1 the rrack region is generated. The final stage would be tn merge this block into the mesh for the 3-D structure.

\section{Profile Reduction}

The bandwidth of automatically generated meshes is, generally speaking, larger than necessary. This condition not only leads to uneconomical FE analyses but, in some instances, to cases impossible 
to run on the computer. This is caused primarily by the very high number of input/output (I/O) operations necessary to store and solve out-of-core the large system of linear equations occurring in the $\mathrm{FE}$ method of analysis. This, in turn, causes large wall clock times (WCT) during which large segments of memory (1750K) are tied up for say, 10 hours, and unacceptable amounts of scratch disk space are required. Thus, it is imperative to optimize the node numbering scheme. This is accomplished by means of the computer code "REDUCE" [28]. As an illustration of some of the computer resources saved by optimizing the node numbering scheme of the FE models, some pertinent numbers from two separate analyses are given in Tables A.1 and A.2. The problem analyzed is the circular crack described earlier in this report. The "before" refers to values associated with the meshes as generated (i.e., with unoptimized meshes) while the "after" are values associated with the optimized meshes. The figures were compiled from the data generated by the ADINA and the REDUCE codes. These figures show a reduction of $20 \%$ to $47 \%$ in the computer resources required. The example problem selected was a small one. In cases like that of Mesh 2 of the V-8 analysis, the savings were significant enough to have made the difference between the feasibility or nonfeasibility of the FE analysis. 
Table A.1

Effect of node renumbering on the IBM $360 / 195$

computer resources required by

the ADINA computer code

(Approx. 1700K memory used) ${ }^{a}$

Number of Nodes 1286

Number of Elements 234

\begin{tabular}{|c|c|c|c|}
\hline . & Before & After & \% Reduction \\
\hline Number of Matrix Elements (approx.) & $1.897 \times 10^{6}$ & $1.498 \times 10^{6}$ & 21 \\
\hline Maximum Half-Bandwidth & 1415 & 962 & 32 \\
\hline Mean Half-Bandwidth & 552 & 436 & 21 . \\
\hline Number of Blocks & 29 & 23 & 21 \\
\hline CPU Minutes & 14 & 9 & 36 \\
\hline I/O in Thousands & 39 & 28 & 28 \\
\hline Wall Clock Time ${ }^{b}$ (Minutes) & 70 & 37 & 47 \\
\hline Approximate $\operatorname{Cost}^{\mathrm{c}}$ & $\$ 87$ & $\$ 58$ & 33 \\
\hline
\end{tabular}

aplane Circular Crack problem.

bon the IBM 360/195 MVT environment, this can vary widely.

crinted output to tape. 
Table A.2

REDUCE code data

\begin{tabular}{|c|c|c|c|c|c|c|c|c|}
\hline & \multicolumn{3}{|c|}{ Half-Bandwidth } & \multicolumn{3}{|c|}{ Profile (approx.) ${ }^{a}$} & \multirow{2}{*}{$\begin{array}{l}\text { CPU } \\
\text { Min } \\
\end{array}$} & \multirow{2}{*}{$\begin{array}{c}\operatorname{Cos} t^{b} \\
\$\end{array}$} \\
\hline & Before & After & $\%$ & Before & After & $\%$ & & \\
\hline Circular Crack & 506 & 331 & 35 & 256,000 & 193,000 & 25 & 6 & 28 \\
\hline Mesh No. $1^{c}$ & 1270 & 626 & 51 & 653,000 & 392,000 & 40 & 6 & 44 \\
\hline Mesh No. 2 & 1656 & 593 & 64 & $1,278,000$ & 777,000 & 39 & 24 & 115 \\
\hline
\end{tabular}

${ }^{a}$ Profile is the sum of the number of terms in the so-called "sky-line", based on the element connectivity, not upon the actual number of DOF.

${ }^{b}$ Includes print cost.

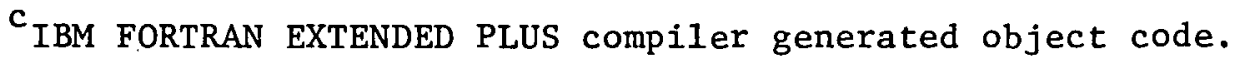




\section{APPENDIX B \\ DETAILS OF THE FE MODELING AND ANALYSIS}

In this appendix, details of the FE modeling and analysis are given. Apart from documenting the data used in the 3-D analyses described in Chapter 3, this information has proven useful as a basis for estimating the computer resources required for other similar 3-D computations. This information is important since an upper-limit estimate of the computer resources required in a particular run.must be declared before the run is made. 
Table B.1

Data used to propagate meshes from 2-D into 3-D

\begin{tabular}{|c|c|c|c|c|c|}
\hline Analysis & & Propagation & $\begin{array}{l}\text { No. of Elements } \\
\text { in } 3 \mathrm{rd} \text { Dimension }\end{array}$ & $\begin{array}{l}\text { Element Thickness } \\
\text { or Angular Dimension }\end{array}$ & Total \\
\hline Circular Crack & & Axial & 6 & $\begin{array}{l}25.4,25.4,50.8,101.6,203 \\
406 \mathrm{~mm}\end{array}$ & $813 \mathrm{~mm}$. \\
\hline & & & & $(1,1,2,4,8,16$ in. $)$ & (32 in.) \\
\hline End Effects Cylinders & & Axial & & & \\
\hline Nominal Lengths $2 \mathrm{~L} \mathrm{~mm}$ & (in.) & & & & \\
\hline 406 & (16) & & 2 & $\begin{array}{l}2 \times 101.6 \mathrm{~mm} \\
(2 \times 4 \text { in. })\end{array}$ & $\begin{array}{l}203 \mathrm{~mm} \\
(8 \mathrm{in.})\end{array}$ \\
\hline 686 & $(27)$ & & 6 & $\begin{array}{l}3 \times 76.2 \mathrm{~mm}+3 \times 38.1 \mathrm{~mm} \\
(3 \times 3 \text { in. }+3 \times 1.5 \text { in. })\end{array}$ & $\begin{array}{l}343 \mathrm{~mm} \\
(13.5 \mathrm{in} .)\end{array}$ \\
\hline 914 & $(36)$ & & 6 & $\begin{array}{l}4 \times 101.6 \mathrm{~mm} \times 2 \times 25.4 \mathrm{~mm} \\
(4 \times 4 \text { in. }+2 \times 1 \text { in. })\end{array}$ & $\begin{array}{l}457 \mathrm{~mm} \\
(18 \mathrm{in.})\end{array}$ \\
\hline 1219 & $(48)$ & & 6 & $\begin{array}{l}6 \times 101.6 \mathrm{~mm} \\
(6 \times 4 \mathrm{in.})\end{array}$ & $\begin{array}{l}610 \mathrm{~mm} \\
(24 \mathrm{in.})\end{array}$ \\
\hline V-8 Cylinder & & $\begin{array}{l}\text { Circumfer- } \\
\text { ential }\end{array}$ & & & \\
\hline Mesh No. 1 & & & 7 & $3^{\circ}, 6^{\circ}, 12^{\circ}, 24^{\circ}, 3 \times 45^{\circ}$ & $180^{\circ}$ \\
\hline Mesh No. 2 & & & 9 & $1^{\circ}, 2^{\circ}, 4^{\circ}, 6^{\circ}, 10^{\circ}, 22^{\circ}, 3 \times 45^{\circ}$ & $180^{\circ}$ \\
\hline
\end{tabular}




\section{$77 / 78$}

Table B. 2
Miscellaneous data of interest related to the
3-D FE analysis using the ADINA code ${ }^{a}$
(Fast Memory Used 1700K Bytes)

\begin{tabular}{|c|c|c|c|c|c|c|}
\hline & \multirow{2}{*}{$\begin{array}{c}\text { Circular } \\
\text { Crack } \\
\text { Problem }\end{array}$} & \multicolumn{3}{|c|}{$\begin{array}{l}\text { End Effects Study } \\
\text { Cylinder Lengths, mm }\end{array}$} & \multicolumn{2}{|c|}{ V-8 Cylinder } \\
\hline & & $406^{\mathrm{b}}$ & $686^{c}$ & $914^{\mathrm{d}}$ & $\begin{array}{l}\text { Mesh } \\
\text { No. } 1 \\
\end{array}$ & $\begin{array}{l}\text { Mesh } \\
\text { No. } 2 \\
\end{array}$ \\
\hline Nodes & 1286 & 1045 & 2573 & 2573 & 2328 & 3456 \\
\hline Elements & 234 & 160 & 480 & 480 & 434 & 666 \\
\hline $\begin{array}{l}\text { Equations (Degrees } \\
\text { of Freedom) }\end{array}$ & 3439 & 2726 & 7179 & 7179 & 6389 & 9603 \\
\hline $\begin{array}{l}\text { Matrix Elements } \\
\text { in millions (approx.) }\end{array}$ & 1.5 & 0.64 & 3.2 & 3.2 & 3.1 & 6.2 \\
\hline Max. Half Bandwidth & 962 & 509 & 900 & 900 & 1789 & 1543 \\
\hline Mean Half Bandwidth & 436 & 231 & 943 & 943 & 485 & 645 \\
\hline Max. Block Size & 67565 & 60127 & 39386 & 39386 & 44354 & 29226 \\
\hline Number of Blocks & 29 & 11 & 82 & 82 & 71 & 216 \\
\hline $\begin{array}{l}\text { CPU Time (Minutes) } \\
\text { IBM } 360 / 195\end{array}$ & 9 & 3.1 & 27 & 28 & 22 & 63 \\
\hline I/O (Thousands) $^{e}$ & 28 & 46 & 50 & 175 & 105 & 492 \\
\hline $\begin{array}{l}\text { Wa11 Clock Time } \\
\quad \text { (Minutes) }\end{array}$ & 37 & 90 & 175 & 250 & 125 & 585 \\
\hline Approximate Cost (\$) & 58 & 57 & 178 & $235^{g}$ & $165^{\mathrm{g}}$ & $600^{g}$ \\
\hline
\end{tabular}

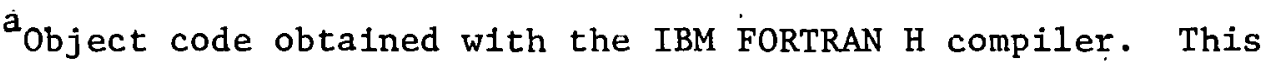
version still had the sequential I/O routines. profile.

$\mathrm{b}_{1500 \mathrm{~K}}$ region and $3 \mathrm{~K}$ blocking factor for scratch units, unoptimized

${ }^{c}$ One time step of the transient (also applies to $1219 \mathrm{~mm}$ cylinder).

$\mathrm{d}_{\text {Three }}$ time steps of the transient.

Depends upon blocking factor of the scratch units.

In an "Multiprogramming with a Variable Number of llasks" (MVT) environment, this can vary considerably for identical runs.

B Printed output to tape. 
Conversion Factors for Units Used in This Report

(Reference: Metric Practice ASTM E380-76)

\begin{tabular}{|c|c|c|c|}
\hline \multicolumn{2}{|c|}{ To Convert From } & \multirow[b]{2}{*}{$\mathrm{kPa}\left(\mathrm{kN} \cdot \mathrm{m}^{-2}\right)$} & Multiply By \\
\hline Stress/Pressure & $1 b f \cdot i n^{-2}(p s i)$ & & 6.894757 \\
\hline $\begin{array}{l}\text { Stress Intensity } \\
\text { Factor }\end{array}$ & $\mathrm{ksi} \cdot \mathrm{in}^{-1 / 2}$ & $\mathrm{MPa} \cdot \mathrm{m}^{1 / 2}\left(\mathrm{MN} \cdot \mathrm{m}^{-3 / 2}\right)$ & 1.098843 \\
\hline $\begin{array}{l}\text { Coefficient of } \\
\text { Heat Transfer }\end{array}$ & $\mathrm{Btu} \cdot \mathrm{h}^{-1} \cdot \mathrm{ft}^{-2} \cdot{ }^{\circ} \mathrm{F}^{-1}$ & $\mathrm{~W} \cdot \mathrm{m}^{-2} \cdot \mathrm{K}^{-1}$ & 5.678263 \\
\hline Heat Capacity & $\mathrm{Btu} \cdot 1 \mathrm{~b}^{-1} \cdot{ }^{\circ} \mathrm{F}^{-1}$ & $\mathrm{~kJ} \cdot \mathrm{kg}^{-1} \cdot \mathrm{K}^{-1}$ & 4.186800 \\
\hline $\begin{array}{l}\text { Thermal } \\
\text { Conductivity }\end{array}$ & $\mathrm{Btu} \cdot \mathrm{h}^{-1} \cdot \mathrm{ft} \mathrm{t}^{-2} \cdot{ }^{\circ} \mathrm{F}^{-1}$ & $\mathrm{~W} \cdot \mathrm{m}^{-1} \cdot \mathrm{K}^{-1}$ & 1.730735 \\
\hline Density & $1 b \cdot f t^{-3}$ & $\mathrm{~kg} \cdot \mathrm{m}^{-3}$ & 16.01846 \\
\hline
\end{tabular}


NUREG/CR-1499

ORNL/NUREG/CSD/TM-14

Distribution Category RF

INTERNAL DISTRIBUTION

1. B. R. Bass
2. B. R. Becker
3. S. E. Bolt
4. R. H. Bryan
5. J. W. Bryson
6. D. A. Canonico
7. H. P. Carter/A. A. Brooks/
8. CD Library
9. S. J. Chang
10. J. M. Cheverton
11. W. B. Cottre11
12. J. R. Dougan
13. G. J. Farris
14. P. P. Holz
15-19. S. K. Iskander
20. J. G. Merkle
21. C. A. Mills
22. S. E. Moore
23. F. R. Mynatt
24. D. S. Napolitan

25. D. J. Naus

26. H. A. Pohto

27. J. L. Rich

28. G. C. Robinson

29. G. M. Slaughter

30. J. E. Smith

31. W. J. Stelzman

32. R. E. Textor

33. D. G. Thomas

34. H. E. Trammell

35. D. B. Trauger

36. G. D. Whitman

37. Patent office

38. Central Research Library

39. Document Reference Section $-\mathrm{Y}-12$

40-42. Laboratory Records Department

43. Laboratory Records (RC)

44. ORGDP CSD Library.

45. ORGDP Library

46. ORGDP Plant Records

EXTERNAL DISTRIBUTION

47. Director, Division of Reactor Safety Research, Nuclear Regulatory Commission, Washington, DC 20555

48. Office of Assistant Manager for Energy Research and Development, Department of Energy, Oak Ridge Operations, Oak Ridge, TN 37830

49. C. Z. Serpan, Division of Reactor Safety Research, Ma11 Station 1130SS, U. S. Nuclear Regulatory Commission, Washington, DC 20555

50. M. Vagins, Division of Reactor Safety Research, Mail Station 1130SS, U. S. Nuclear Regulatory Commission, Washington, DC 20555

51-52. Technical Information Center, DOE

53-482. Given distribution as shown under category RF (10 copies - NTIS) 